\title{
A Self-Calibrating Remote Control Chemical Monitoring System
}

Jessica Croft

June 2007

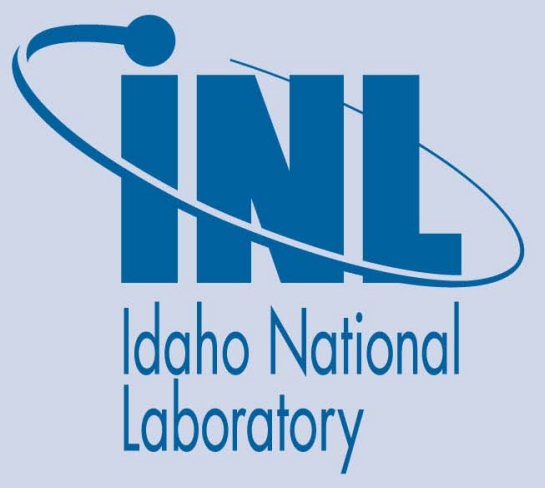

The INL is a U.S. Department of Energy National Laboratory operated by Battelle Energy Alliance 
INL/EXT-07-12890

\title{
A Self-Calibrating Remote Control Chemical Monitoring System
}

\author{
Jessica Croft
}

June 2007

\begin{abstract}
Idaho National Laboratory
Idaho Falls, Idaho 83415
\end{abstract}

Prepared for the

U.S. Department of Energy

Under DOE Idaho Operations Office

Contract DE-AC07-05ID14517 


\section{A Self-Calibrating Remote Control Chemical Monitoring System

\author{
by \\ Jessica Croft
}

A thesis submitted in partial fulfillment of the requirements for the degree of

Master of Science in Electrical Engineering

Montana Tech of The University of Montana

2007 


\begin{abstract}
The Susie Mine, part of the Upper Tenmile Mining Area, is located in Rimini, MT about 15 miles southwest of Helena, MT. The Upper Tenmile Creek Mining Area is an EPA Superfund site with 70 abandoned hard rock mines and several residential yards prioritized for clean up. Water from the Susie mine flows into Tenmile Creek from which the city of Helena draws part of its water supply. MSE Technology Applications in Butte, Montana was contracted by the EPA to build a treatment system for the Susie mine effluent and demonstrate a system capable of treating mine waste water in remote locations. The Idaho National Lab was contracted to design, build and demonstrate a low maintenance self-calibrating monitoring system that would monitor multiple sample points, allow remote twoway communications with the control software and allow access to the collected data through a web site. The Automated Chemical Analysis Monitoring (ACAM) system was installed in December 2006. This thesis documents the overall design of the hardware, control software and website, the data collected while MSE-TA's system was operational, the data collected after MSE-TA's system was shut down and suggested improvements to the existing system.
\end{abstract}

Keywords: remote monitoring, database backed website, LabVIEW, mine waste water 


\section{Acknowledgments}

I would like to acknowledge and gratefully thank the many people who provided help and support during this project. Thank you to John Morrison, my graduate advisor at Montana Tech, and Dan Trudnowski, professor at Montana Tech, for their help. Gail Heath from the Idaho National Lab (INL) for getting the project started, his help during the installation and subsequent trips up to Montana. Neal Yancey of INL for help with the initial design and installation and Clark Scott of INL for help with troubleshooting and ideas on data analysis. Thanks to Ken Moor, also of INL, for his support.

The funding for this project was provided through the EPA Technology Support Center for Monitoring and Site Characterization in Las Vegas, Nevada. Mike Bishop of EPA Region 8 in Helena, Montana also supported this project.

I wish to thank Jay McCloskey of MSE-TA in Butte, Montana for allowing us to use the water treatment facility as a test site and Roger James of Rimini, Montana for his time while I was up working on the monitoring system. 


\section{Contact Information:}

Gail Heath

Idaho National Lab

phone: 208 526-7009

email: gail.heath@inl.gov

Jessica Croft

phone: 406 491-3631

email: jesscroft@yahoo.com 


\section{Table of Contents}

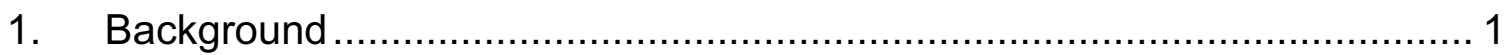

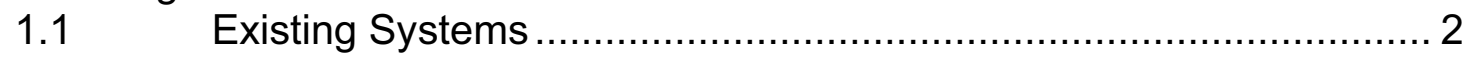

$1.2 \quad$ The Demonstration Site................................................... 4

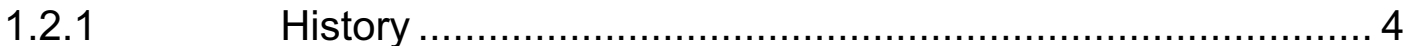

1.2.2 Mine Water Chemistry .................................................. 5

1.3 Demonstration Remediation System ……................................ 8

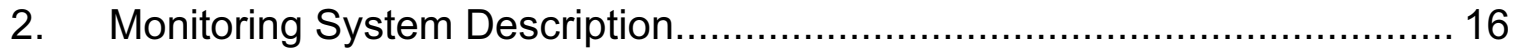

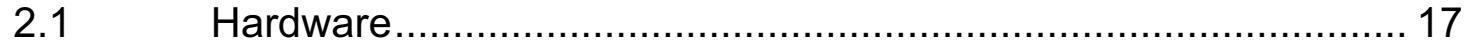

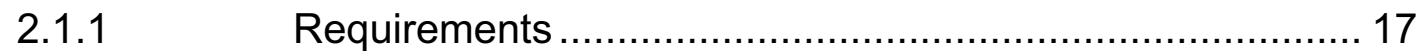

2.1.2 Description of hardware ............................................. 18

Pinch Valves.............................................................. 19

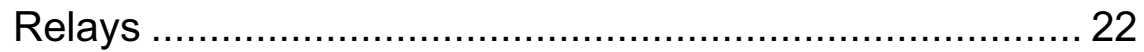

ADAMS Modules .................................................. 24

H-bridge motor controller ......................................... 27

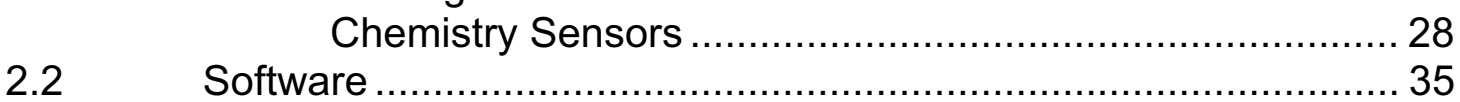

2.2.1 Requirements and Objectives ……............................ 35

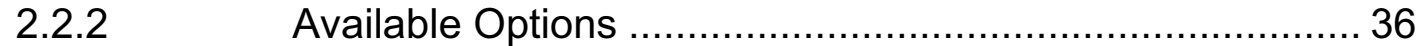

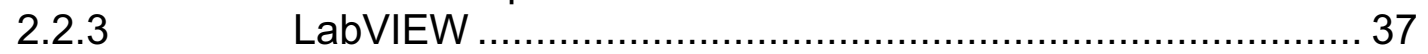

2.2.4 Control System Overview ............................................. 37

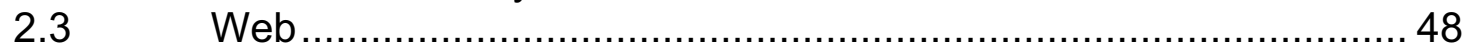

2.3.1 Data Access Requirements ...................................... 48

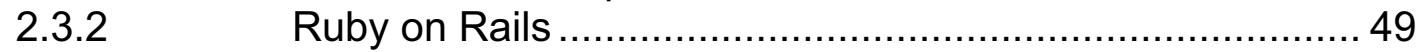

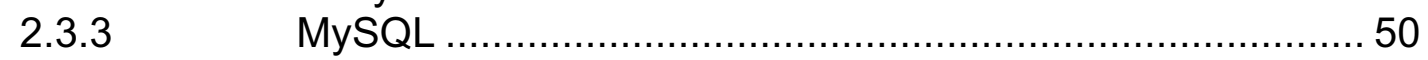

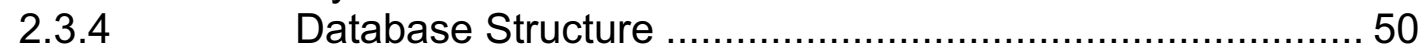

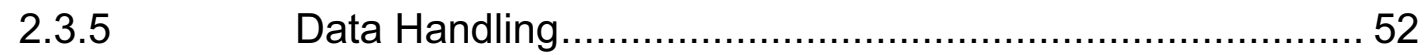

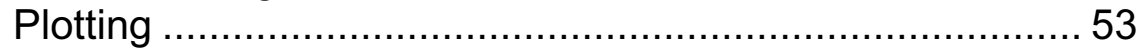

Missing data, bad data and outliers ............................... 57

User Permissions .......................................................... 58

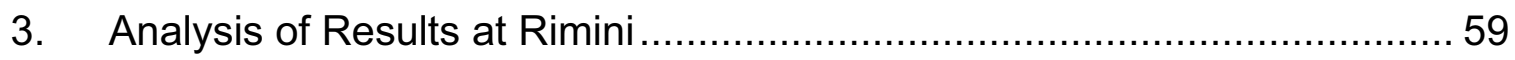

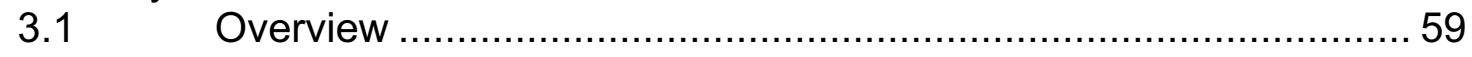

3.2 Performance During Treatment System Operation ...................... 59

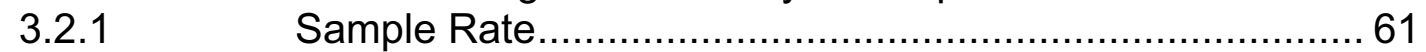

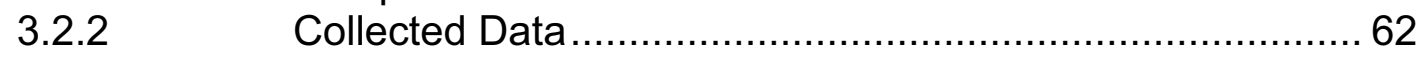

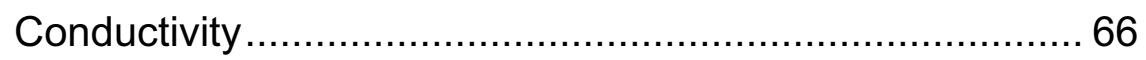

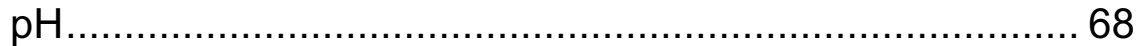

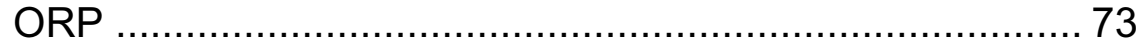

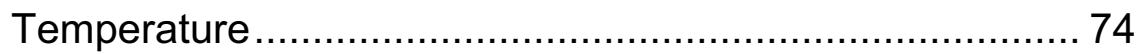

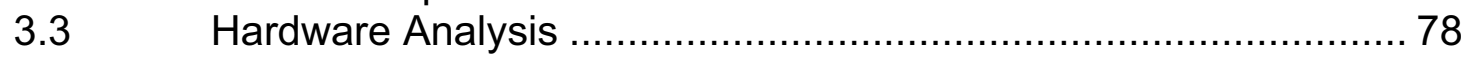

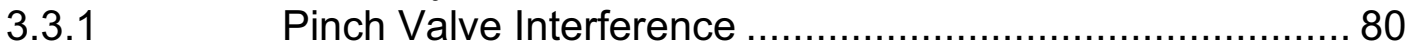

3.3.2 Snubbing on pinch valves............................................ 81

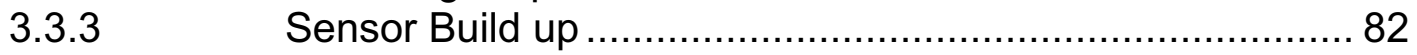

3.4 Control System Performance ...................................................... 84

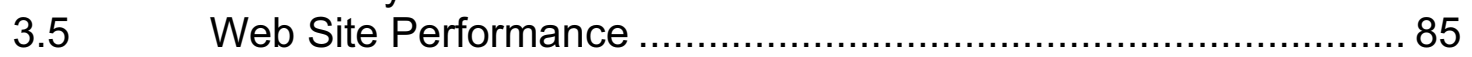


3.6 Performance After the Treatment System Shut Down................. 86

3.7 Calibration Data...................................................................... 92

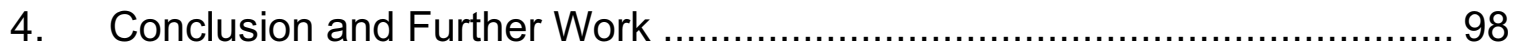




\section{Index of Figures}

Figure 1 Map of Upper Tenmile Mining Area and Superfund Site (shaded) ......... 5

Figure 2: Layout of Susie Mine Adit......................................................... 8

Figure 3. Looking towards the back of the mine. The dam is behind the black

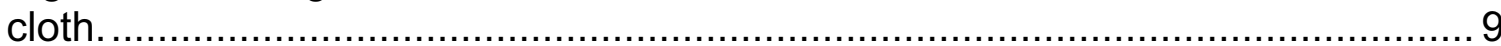

Figure 4. Looking towards the mine entrance........................................... 10

Figure 5. Susie mine adit - hardware and sample point locations for the ACAM

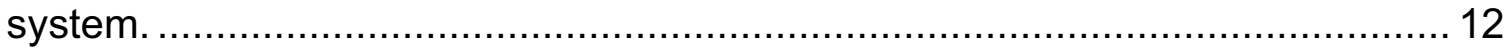

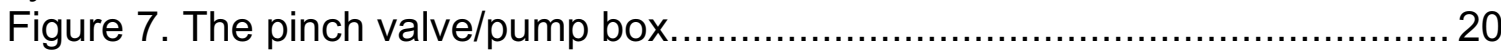

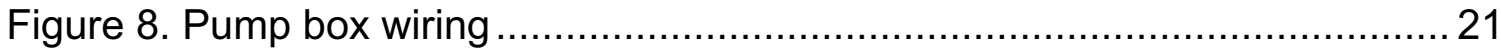

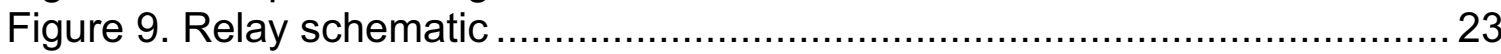

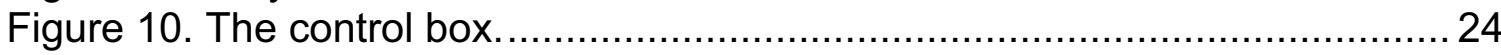

Figure 11. RS-485/ADAMs modules Network Topology ................................ 26

Figure 12. YSI chemistry sensor location. ……............................................. 29

Figure 13. Close of up chemistry sensors. ............................................... 30

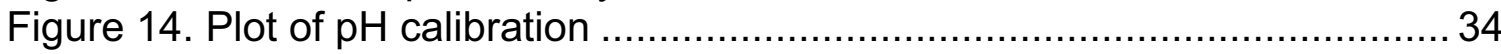

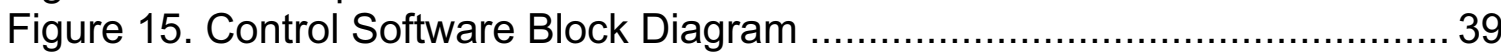

Figure 16. Digital Output Controller Front Panel....................................... 41

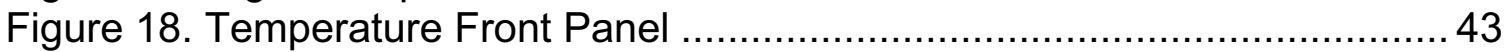

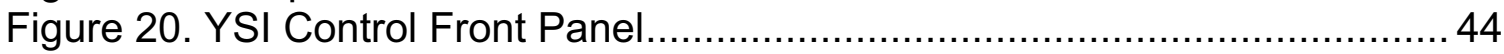

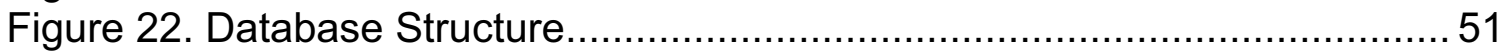

Figure 23. Web page for selecting data to plot. ......................................... 54

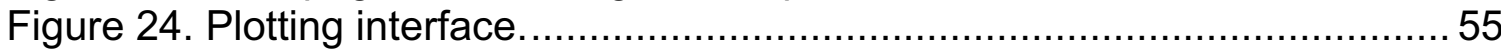

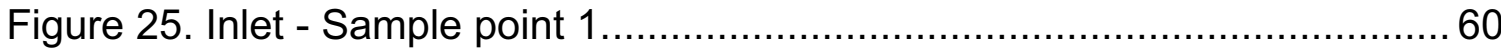

Figure 26. Treatment system flow rate ........................................................63

Figure 27. Susie mine adit - hardware and sample point locations....................65

Figure 28. Conductivity at all four sample points .........................................6 67

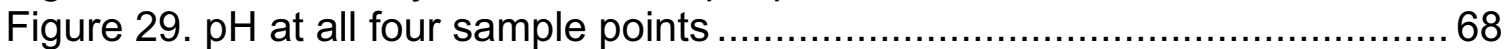

Figure 30. Effluent pH Figure courtesy of MSE-TA .................................... 71

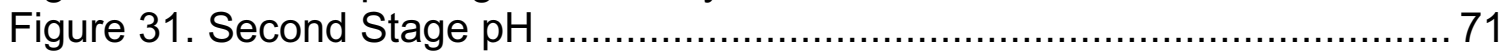

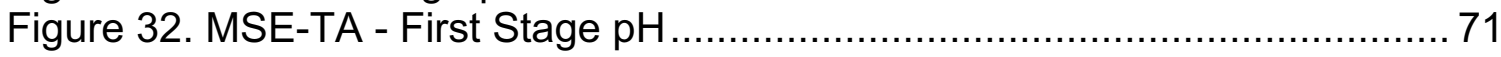

Figure 33. Oxidation Reduction Potential (ORP) at all four sample points .........73

Figure 34. Temperature at Inlet ........................................................ 75

Figure 35. Temperature after iron addition ............................................. 76

Figure 36. Temperature at outlet ............................................................... 77

Figure 37. Recorded conductivity at inlet during pump tubing failure ................ 79

Figure 38. Temperature data showing pinch valve interference ...................... 80

Figure 39. Temperature data after pinch valve interference was fixed .............. 81

Figure 40. Water from the third step, iron build up on the flow cell ................... 82

Figure 41. Dissolved Oxygen data showing evidence of sensor buildup ............ 83

Figure 42. Conductivity at first sample point from January 2007 through April

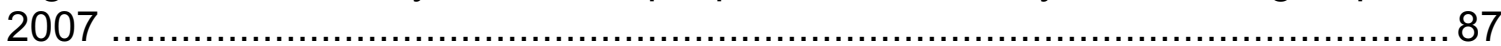

Figure 43. pH at the first sample point - February through April 2007 .............. 89

Figure 44. ORP at the first sample point - February through April 2007 ............ 90

Figure 45. Temperature data from first sample point .................................... 91

Figure 46. Temperature of water behind the dam...................................... 92 
Figure 47. ORP Offset Calibration Constants - December 2006 through March 2007

Figure 48. pH Offset Calibration Constants - December 2006 through March 2007

Figure 49. . pH Gain Calbration Constants - December 2006 through March 2007

Figure 50. Turbidity Gain Calibration Constants - December 2006 through March 2007 95

Figure 51. Dissolved Oxygen Gain Calibration Constants - December 2006 through March 2007 96 Figure 52. Calibration with respect to conductivity data. (Calibration constants not to scale) 


\section{Index of Tables}

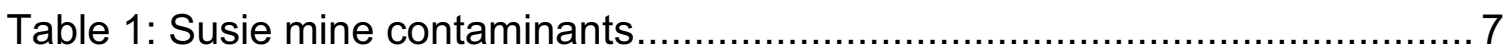

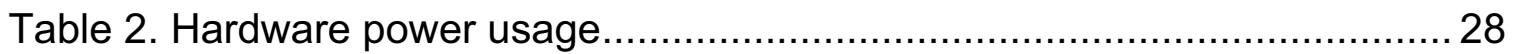

Table 3. Sensor information .............................................................. 33

Table 4. Control software failures - dates, causes and solutions ..................... 85

\section{Index of Abbreviations}

ACAM Automated Chemical Analysis Monitoring (system)

ADAM Advanced Data Acquisition Module

ASCII American Standard Code for Information Interchange

CRUD Create, Read, Update and Delete

DC Direct Current

DEQ Department of Environmental Quality

EDS Extended Deployment System

EIA Electronic Industries Alliance

EM Electro-Magnetic

EPA Environmental Protection Agency

FTP File Transfer Protocol

IC Integrated Circuit

INL Idaho National Lab

LCD Liquid Crystal Display

LED Light Emitting Diode

MSE-TA Mountain State Engineering Technology Applications

NTU Nepholometric turbidity unit

ORP Oxidation-Reduction Potential

$P V \quad$ polyvinyl

SQL Structured Query Lanquage

SSR Solid State Relay

VAC Volts Alternating Current

VI Virtual Instrument (LabVIEW)

YSI Company Name 


\section{Background}

Abandoned hard rock and coal mines pose a threat to the environment in the form of heavy metal contaminants leaking into rivers and streams. Mining activities expose rocks in underground tunnels and tailings piles which were previously in equilibrium with the surrounding environment to air and water. Exposure to air causes metals contained in the rocks to oxidize, while water dissolves the metals and washes them into rivers and lakes. Many of these metals, such as lead, arsenic and zinc are damaging to human health. The EPA estimates that there are 300,000 abandoned mines in the western United States [14].

As treatment systems (active or passive) are built to treat the waste water that result from abandoned mines, it will be necessary to frequently monitor the treatment systems to determine effectiveness. Currently, the EPA requires only quarterly monitoring for such treatment systems. This is not adequate when even seasonal variations in temperature and precipitation are considered, let alone monthly, weekly or daily variations. Also, the chemistry of a sample can change over time or with temperature; data from samples that are not analyzed shortly after being collected are not as accurate as data from samples analyzed immediately on-site. The cost associated with frequent sampling - both for the lab time and for the time associated with travel to the treatment site - is at least partially to blame for the slower sampling rates.

This project, the Automated Chemical Analysis Monitoring (ACAM) System, seeks to demonstrate the feasibility of a remote, autonomous, low cost per 
sample system to facilitate more frequent sampling and increase the effectiveness of treatment.

Requirements for the ACAM system include remote access to the control system, two way communications, self-calibration of the instruments, low on-site maintenance, low installation and construction costs and a method of accessing newly collected data without traveling to the site. The fulfillment of these requirements, especially remote access to the control system and remote access to the data, will drastically reduce cost and time associated with travel to the site. The chemistry of the water samples change with both temperature and time between the collection of the sample and chemical analysis. Since samples will be analyzed on-site the collected data will be more accurate. Most importantly, the low cost per sample and the ability to collect data in near real time will allow researchers to more fully understand the properties of the system being treated.

This project was funded through Idaho National Lab (INL) which itself received the funds from the EPA Technology Support Center for Monitoring and Site Characterization in Las Vegas, Nevada.

\subsection{Existing Systems}

The initial step in the project entailed a review of existing systems. Only those systems that could be accessed remotely, calibrated automatically, had more than one sample point, included a database in which to store the data and were accessible over the internet were considered. Three existing systems had one or more of these requirements. 
One system with many of the necessary features is the Automated Water Analyzer Computer Supported System (AWACSS) developed by researchers in Germany [16]. Their system was designed to monitor several organic pollutants at nanogram per liter levels in drinking water. AWACSS was developed in conjunction with a web site and database to allow remote access to the monitoring system and access to the collected data. Because AWACSS was developed to monitor mainly drinking water, it is many times more sensitive than needed for this project and consequently many times more expensive. AWACSS is not a system that is meant to be deployed in anything other than a controlled environment. It was designed to monitor more than one site, but only one sample point per site.

Another system with similar attributes was designed by T.N Burcham at Mississippi State University in 1998 to monitor runoff [3]. Although no method existed to access the data or the control system remotely, it was designed to monitor more than one sample point. It was programmed using $\mathrm{C}++$ and stored the data to ASCII text files. It used an RS-485 network to communicate with the instruments.

A more recent system, built in 2005 by Thomas Burge of Burge Environmental, was designed to sample water at different levels in a water well in order to determine the amount of Trichloroethane present in each sample [4]. Although the system did not have a web site for remote access to either the data or the control system, it was self-calibrating.

None of the reviewed systems had all of the required attributes and most were 
done on a much larger budget. Only the system built by Burge environmental could be remotely calibrated and the system built by T.N. Burcham though it could sample from more than one point did not have remote access to either the control system or the data.

\subsection{The Demonstration Site}

\subsubsection{History}

The Susie Mine, part of the Upper Tenmile Mining Area (Figure 1), is located in Rimini, Montana about 15 miles southwest of Helena, Montana. The Upper Tenmile Creek Mining Area is an EPA Superfund site with 70 abandoned hard rock mines and several residential yards prioritized for clean up. Mining in the area started before 1870 . The Susie mine was originally created as an adit to allow drainage of the Valley Forge Mine half a mile to the northeast of downtown Rimini. The Valley Forge Mine was most active around 1905-1906 and recorded production continued intermittently until 1948. Gold, silver, copper, zinc and lead were mined [10]. 


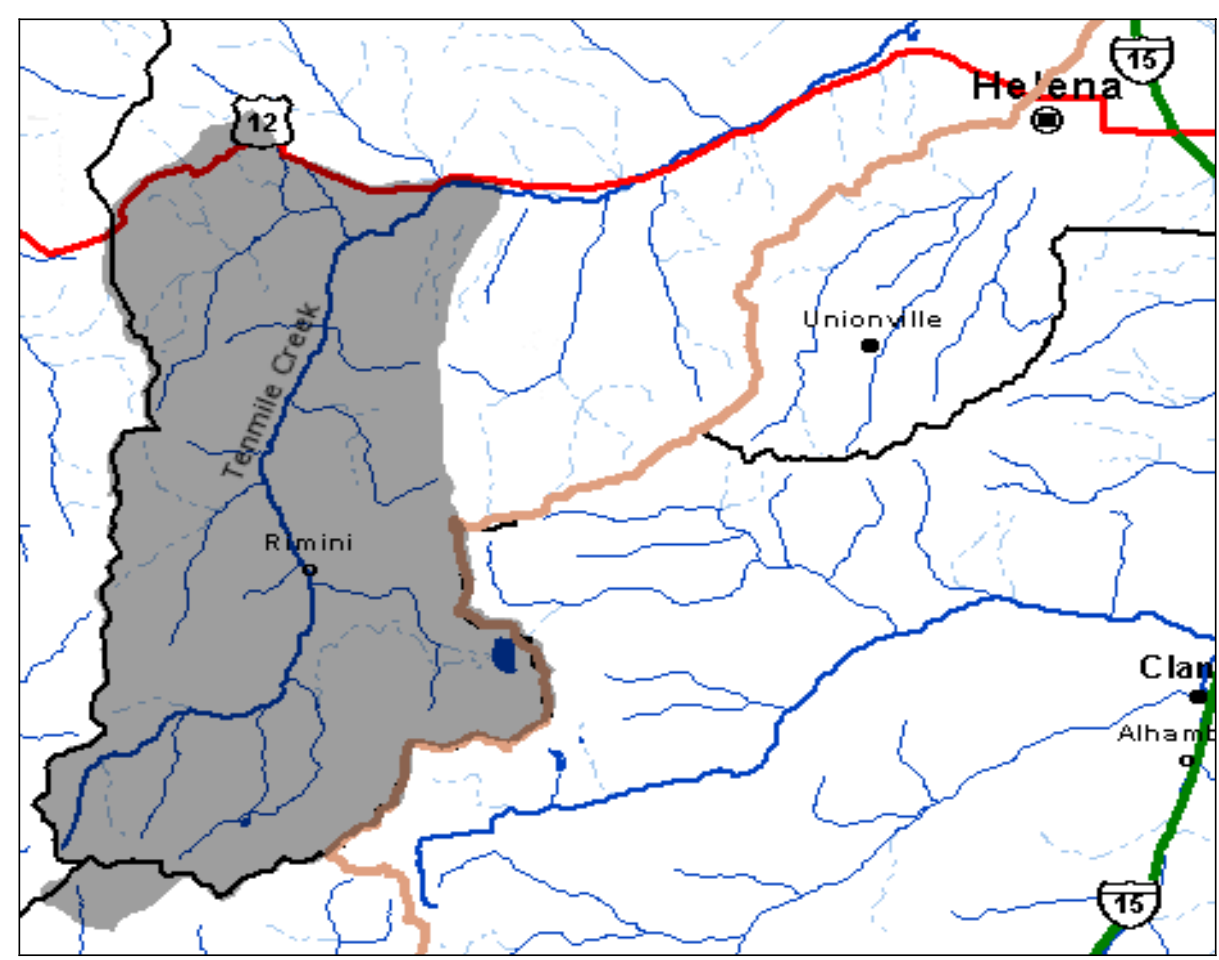

Figure 1 Map of Upper Tenmile Mining Area and Superfund Site (shaded)

The entrance to the Susie mine is in downtown Rimini. Looking out from the mine entrance, Tenmile Creek is across the main road through Rimini, about 75 yards away. Effluent from the Susie mine runs through a series of small settling ponds and then into the creek. Three residential homes are within 50 yards of the settling ponds.

\subsubsection{Mine Water Chemistry}

Mining allows oxygen and water access to rocks previously in equilibrium with the surrounding environment. Much of this rock contains iron disulfide also known as iron pyrite $\left(\mathrm{FeS}_{2}\right)$. When iron pyrite comes into contact with oxygen and water it is oxidized in a multistep process as described in the following equations [1]: 


$$
\begin{aligned}
& 2 \mathrm{FeS}_{2}+2 \mathrm{H}_{2} \mathrm{O}+7 \mathrm{O}_{2}=2 \mathrm{Fe}^{2+}+4 \mathrm{SO}_{4}{ }^{2-}+4 \mathrm{H}^{+}(\mathrm{aq}) \\
& \text { Pyrite + water + oxygen = ferrous iron + sulphate + acid } \\
& 4 \mathrm{Fe}^{2+}+4 \mathrm{H}^{+}{ }_{(\mathrm{aq})}+\mathrm{O}_{2}=4 \mathrm{Fe}^{3+}+2 \mathrm{H}_{2} \mathrm{O} \\
& \mathrm{FeS}_{2}+14 \mathrm{Fe}^{3+}+8 \mathrm{H}_{2} \mathrm{O}=15 \mathrm{Fe}^{2+}+2 \mathrm{SO}_{4}{ }^{2-}+16 \mathrm{H}^{+}(\mathrm{aq}) \\
& \mathrm{Fe}^{3+}+3 \mathrm{H}_{2} \mathrm{O}=\mathrm{Fe}(\mathrm{OH})_{3}+8 \mathrm{SO}_{4}{ }^{2-}+16 \mathrm{H}^{+}{ }_{(\mathrm{aq})} \\
& 4 \mathrm{FeS}_{2}+14 \mathrm{H}_{2} \mathrm{O}+150_{2}=4 \mathrm{Fe}(\mathrm{OH})_{3}+8 \mathrm{SO}_{4}{ }^{2-}+16 \mathrm{H}^{+}(\mathrm{aq})
\end{aligned}
$$

In (1) iron pyrite reacts with water and oxygen to produce ferrous iron, sulfate and free hydrogen ions which results in a lower $\mathrm{pH}$. In (2) the ferrous iron from the first step is further oxidized into ferric iron. The ferric iron created by steps (1) and (2) further oxidizes exposed pyrite. The fourth step is $\mathrm{pH}$ dependent and occurs at a pH less than about 3.5. During this step hydrolysis of ferric iron with water may form ferric hydroxide. If the $\mathrm{pH}$ is higher than around 3.5 a yellowish precipitate called "yellowboy" forms, otherwise the ferric hydroxide stays in solution. The overall result is shown in (5).

While mining activities are taking place this chemical process is moderated by the practice of mining, itself. Any water that comes into contact with exposed rock is pumped out before much oxidation takes place. However, once the pumps are turned off and/or the mine is abandoned, oxidation is unrestricted. Heavy metals, such as Zinc and Arsenic, exist in the form of sulfides in the same rocks that contain iron pyrite. As the oxidation of iron pyrite occurs, the surrounding water becomes acidic and these normally insoluble compounds become soluble. In this state, the water can present problems for human health. 
This is the situation at the Susie mine as indicated by its superfund status.

One of the treatment methods available for the remediation of acid mine drainage is the addition of a chemical, commonly some form of lime, to raise the $\mathrm{pH}(6)$ and precipitate out the heavy metals(7).

(6) $\mathrm{Ca}(\mathrm{OH})_{3}+3 \mathrm{H}^{+}=\mathrm{Ca}^{2+}+3 \mathrm{H}_{2} \mathrm{O}$

(7) $\mathrm{MX}+\mathrm{Ca}(\mathrm{OH})_{3}=\mathrm{M}(\mathrm{OH})_{3}+\mathrm{CaX}$

In (7) $M$ is a metal and $X$ represents any metal ligand such as sulphate [6][2].

Water leaving the Susie mine flows directly into Tenmile Creek from which, along with the surrounding streams, supplies $70 \%$ of Helena's water supply. The effluent from the Susie mine is high in Arsenic (As), Zinc (Zn) and Manganese (Mg). Concentration limits for these contaminants in drinking water are in Table 1.

Table 1. Susie mine contaminants

\begin{tabular}{|l|c|c|}
\hline & $\begin{array}{c}\text { Susie Mine Effluent } \\
(\mathbf{m g} / \mathbf{L})\end{array}$ & $\begin{array}{c}\text { EPA Drinking Water } \\
\text { Standards }(\mathbf{m g} / \mathbf{L})\end{array}$ \\
\hline Arsenic (As) & 18.9 & 0.01 \\
\hline Iron (Fe) & 150 & 0.3 \\
\hline Zinc (Zn) & 29.6 & 5 \\
\hline
\end{tabular}

Arsenic, as a primary standard, is legally enforceable while Iron and Zinc are secondary standards - meaning that while public water systems are not required to test for them, the standards provide some guidance as to what levels are detectable in drinking water. Iron dissolved in water can cause a rusty color while both Iron and Zinc result in a metallic taste. Arsenic has been linked to many types of cancer as well as blindness, nausea, and numbness in hands and 
feet.

\subsection{Demonstration Remediation System}

Mountain State Engineering Technology Applications (MSE-TA) of Butte, MT was contracted by the Montana Department of Environmental Quality (DEQ) and the Environmental Protection Agency (EPA) to build a treatment system for the water exiting the Susie mine in Rimini, MT. Like the ACAM system described herein, MSE-TA's system was for demonstration purposes. However, both projects were completely independent. The MSE-TA treatment system was designed to be a low maintenance system for remote areas. MSE-TA did not need or require

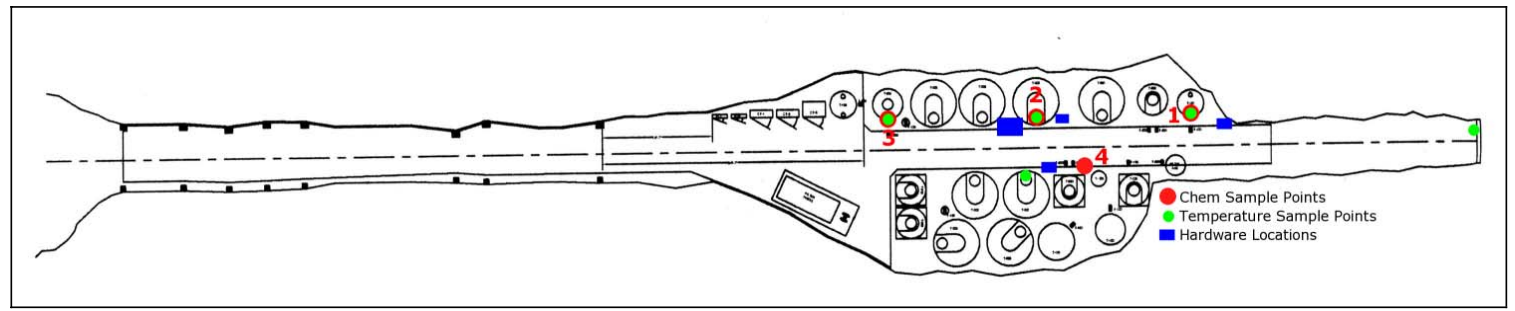

Figure 2: Layout of Susie Mine Adit

measurements taken by the monitoring system, but allowed the installation and testing of the monitoring equipment in their project site.

Originally, the Susie mine adit was just large enough for an ore cart. The entrance (on the left side of Figure 2) retains this original configuration, but MSETA blasted a room inside the adit about 50' long, 30' wide and 20' high to accommodate their new treatment system. Water exiting the mine was dammed up behind a concrete barrier (on the far right side of Figure 2). MSE-TA also installed a concrete walkway and a gravel floor in the adit. Figure 4 and Figure 3 show the inside of the Susie Mine while the MSE-TA treatment system was 
operating. The larger tanks on either side of the walk way are the settling tanks. Each holds up to 1000 gallons of water.

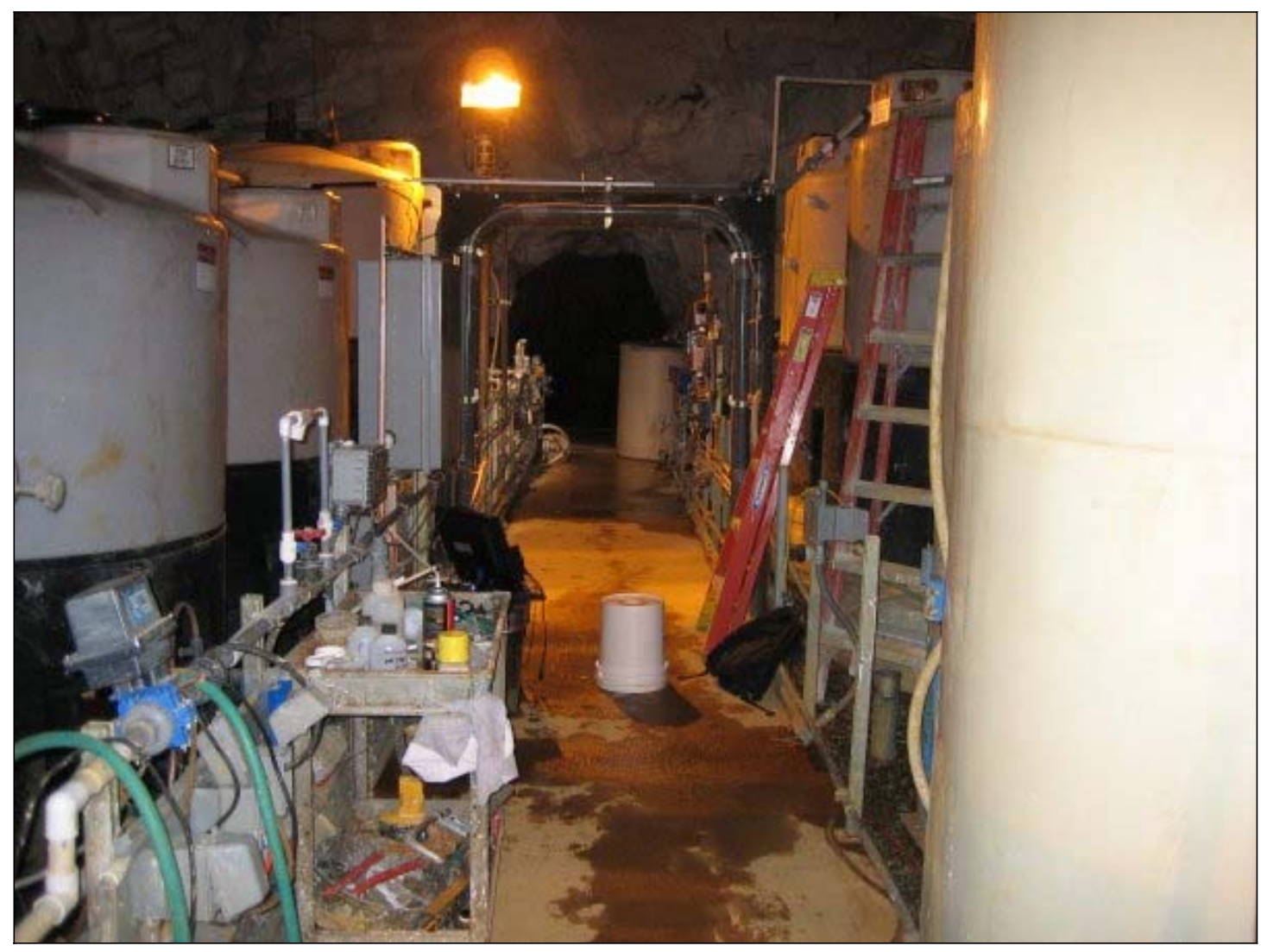

Figure 3. Looking towards the back of the mine. The dam is behind the black cloth. 


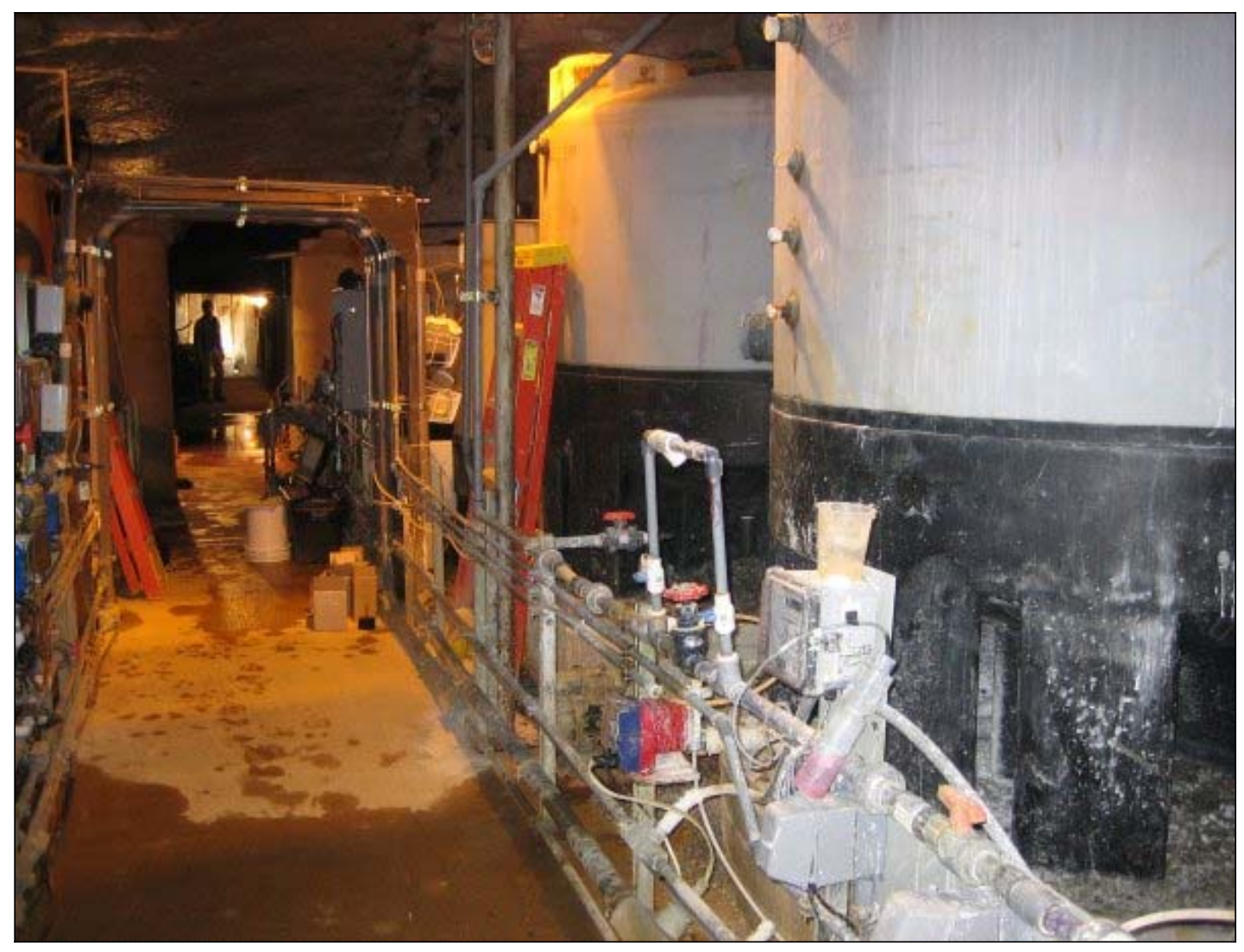

Figure 4. Looking towards the mine entrance.

In the MSE-TA treatment system, overflow from the dam first goes into the treatment system; any extra untreated overflow runs out into the old settling ponds and then into the creek. Figure 5 shows in detail both the locations of the sample points and the locations of the following steps. First in the treatment process, lime slurry is added to raise the $\mathrm{pH}$ of the inlet to around 9. Then the water is pumped to four settling tanks. The increase in $\mathrm{pH}$ causes the heavy metal contaminants to leave solution. Granular ferric hydroxide is then added to water from the first set of settling tanks, pumped into the second (and last) set of settling tanks and again allowed to precipitate. The resulting sludge is run through a compactor-filter and put into barrels for later transport to the Luttrell 
Waste Repository 15 miles south of Rimini. MSE-TA's treatment system ran for two weeks in January 2007. 


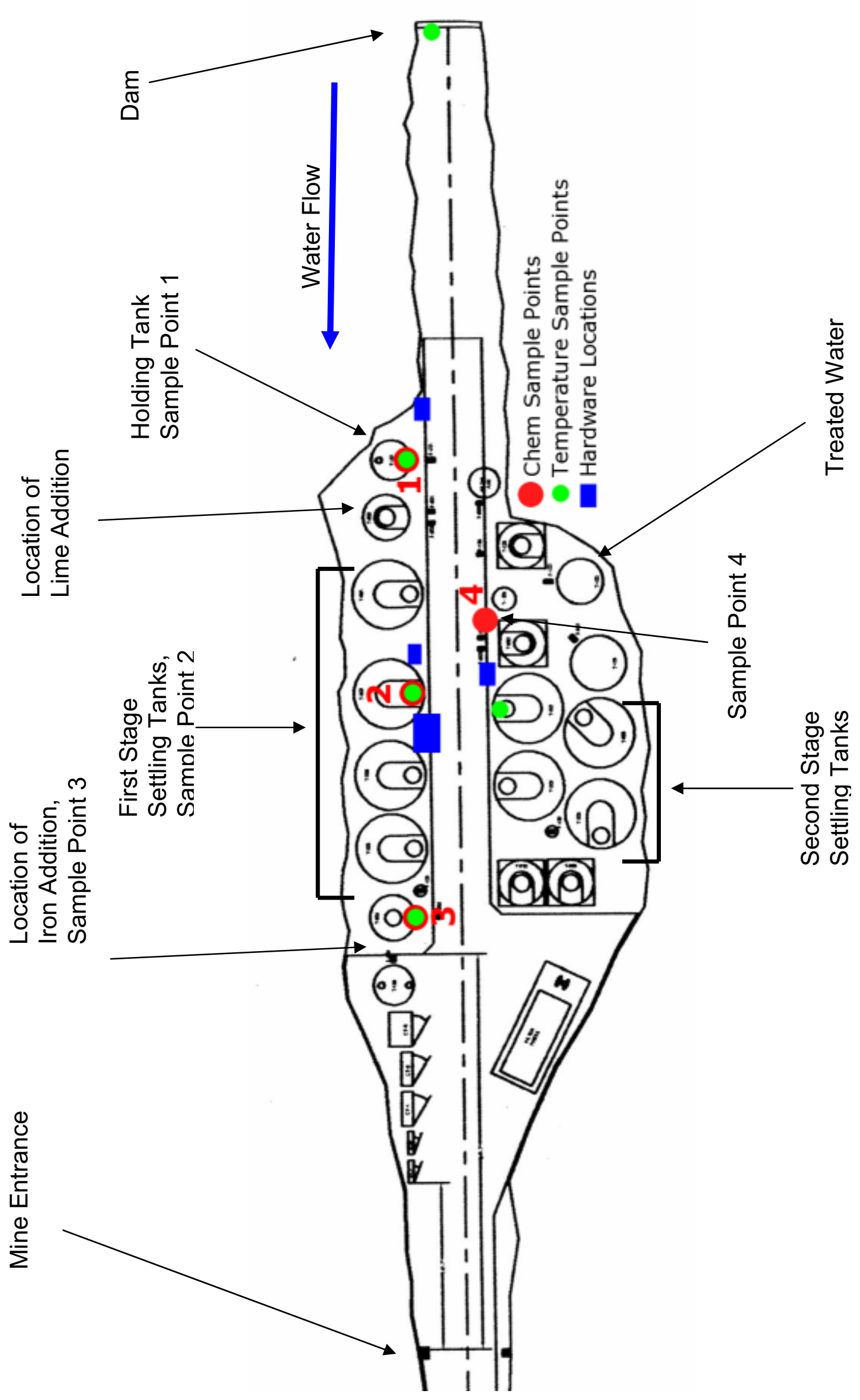

Figure 5. Susie mine adit - hardware and sample point locations for the ACAM system. 
MSE-TA's treatment facility was the ideal place to test the ACAM system because infrastructure was in place -120VAC power and a phone line to enable 2-way communications. It also had many possible sample points with differing chemical characteristics. The environment inside the adit forced the design to handle non-ideal conditions without being too inhospitable.

Two types of sensors were used in the ACAM system - chemistry and temperature. The chemistry measurements were taken using a multi-parameter sonde that held the sensors for $\mathrm{pH}$, dissolved oxygen, conductivity, temperature, turbidity and oxidation reduction potential. These two types, chemistry and temperature, were chosen because they are commonly used, relatively inexpensive and because they represent two possible methods to take readings. One of these methods, represented by the temperature sensors, takes the sensor to the sample. The other method, represented by the chemistry sensors, brings the sample to the sensor.

Chemistry measurements were taken at four points in MSE-TA's treatment system: the inlet, a settling tank after the addition of the lime slurry, the tank where iron is added and the outlet of the treatment system. These points are labeled in Figure 5. Rather than have four separate chemistry sensors, fluid from the four sample points was pumped to a central flow cell. Pinch valves, open and close as directed by the control software, control from which sample point the sample is taken. Temperature measurements were taken at 15 points in the adit - twelve of them in the water treatment/settling tanks, one for air temperature, one inside of the box containing the computer, and the last one in 
the water behind the dam.

Hardware for the ACAM system in the mine includes pinch valves, a pump, temperature modules, a power supply, relays, digital output modules, a computer to run the control software, and the chemistry sensor. Due to the humid environment of the adit, all electronic equipment is enclosed by airtight boxes. These are represented by the solid rectangles in Figure 5. The control software is on a computer inside the adit. A website built to allow remote access to the control system and previously collected data exists on a server at the Idaho National Lab (INL).

Figure 6 shows a simplified diagram of the overall design of the ACAM system. The pinch valves and pump direct the flow of water from either the sample points and to or from sample bottles to a central flow cell where the chemistry measurements are made. The pinch valves are controlled using relays and digital output modules to turn the relays on and off. The software on the computer gives instructions to the digital output modules; communicates with the 


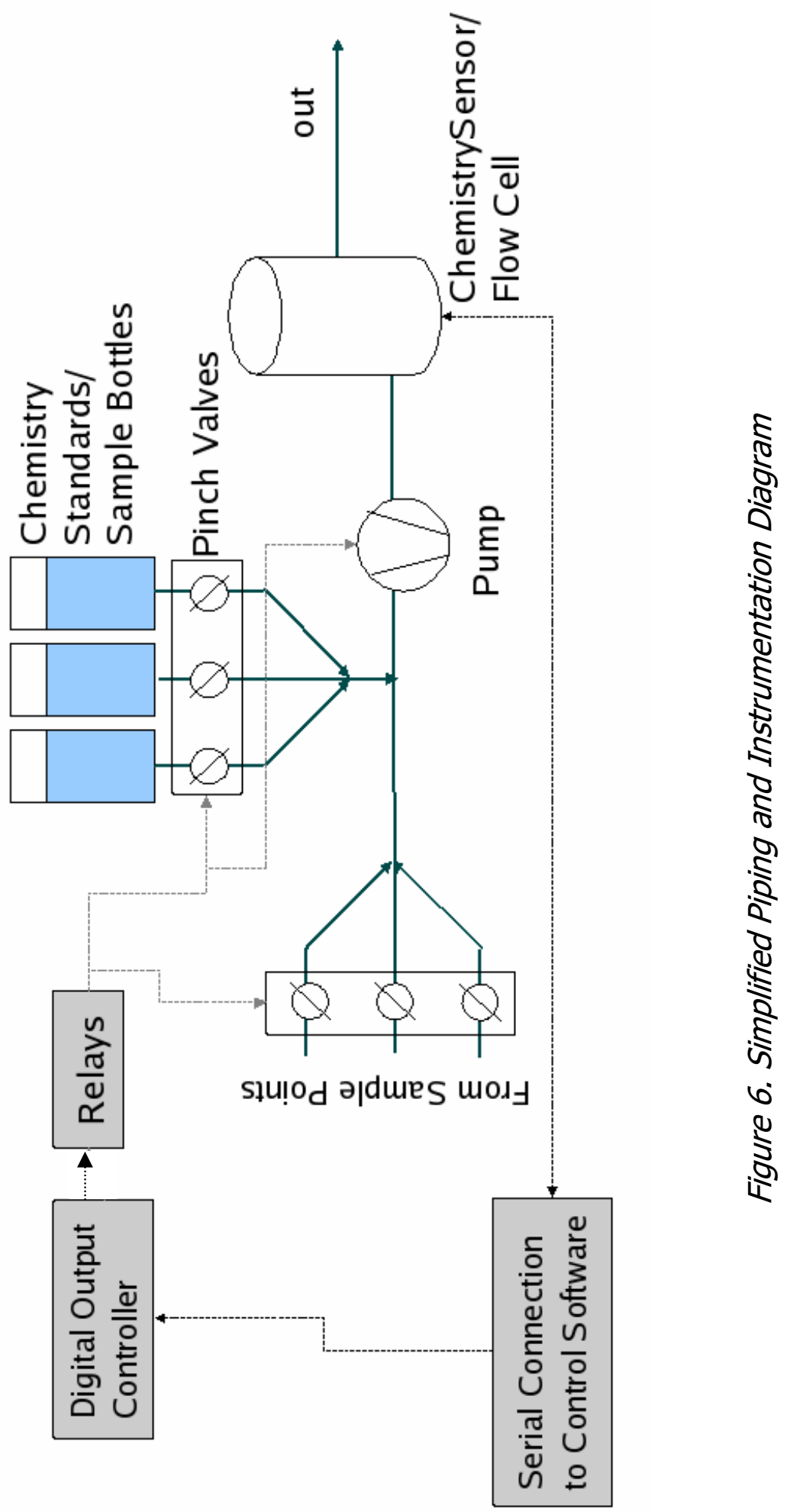


chemistry and temperature sensors; stores the collected data; and uploads and downloads data from an FTP (File Transfer Protocol) server.

This thesis will describe the hardware used in the system, the control software and the web site. Results from the Susie Mine are presented below along with problems encountered and devised solutions. A section on further work concludes the thesis.

\section{Monitoring System Description}

This project was a demonstration. The goal of this work was to create a framework that could be easily adapted to future locations and work the bugs out of the original design. As stated in the introduction, one of the overarching goals was to keep the cost per sample low - this limited the overall cost of the hardware. Also associated with cost per sample is the time and money necessary to fix or rebuild customized parts. In order to avoid this potential cost, most of the parts used in this project were off-the-shelf.

The time frame for design and testing was also limited. Since MSE-TA had a fixed budget, the operation time of their treatment system was not likely to be indefinite. In fact, the time period between design and installation was slightly less than six months. The time constraint tended to push the hardware decisions toward off-the-shelf solutions and software decisions were pushed toward software with an easy learning curve and fast development time.

The budget of this particular project also played a part in the hardware and 
software decisions. The first draft of the design included instruments to measure the concentrations of Arsenic, Zinc and Iron, but due to budgetary constraints they were left out of the final design. However, the final design of the project is such that it will be possible to add these instruments at a later date.

Software for the website tended to lean toward open source software. Although the website, once built, would not be subject to drastic change, the control software would vary depending upon the types of sensors used in future incarnations of the project. Because of this, the control system software needed to be something that is common to INL, relatively easy for a non-programmer to modify and with a good user interface.

\subsection{Hardware}

\subsubsection{Requirements}

Hardware used in this project needed to be durable in order to survive installation in hard to access spaces, easy to operate, interchangeable and easy to find offthe-shelf. The final system and any future adaptations will not be operated by an engineer and any custom designed parts, should they require replacing, would increase the operating costs. The hardware also needed to be suited to operation in a humid environment.

Fluid for the chemistry samples was pumped from one of four sample points to a central flow cell for chemical analysis. A simple, low cost and reliable pinch valve and pump system was activated by relays to move samples from the four sample points to the chemistry sensor. Calibration fluid was pumped from sample bottles to the chemistry sensor or, alternatively, fluid could be pumped to the sample 
bottles and stored for further analysis.

In order to fully evaluate the system, two types of sensors were used temperature and chemistry sensors. Thermocouples were used for the temperature sensors and chemistry measurements were taken by a multiparameter chemistry sensor from YSI Environmental. Temperature and chemistry measurements are likely to be required in future projects and the presence of both types of measurements demonstrated the ability of the control system to handle more than one sample rate. During operation of the ACAM system, temperature measurements were taken every three minutes while the chemistry measurements were taken every one or two hours.

\subsubsection{Description of hardware}

\section{Pump}

The pump is a $12 \mathrm{~V}$ DC peristaltic pump made by Watson-Marlow. See Figure 7. It pulls $0.8 \mathrm{~A}$. A peristaltic pump works by squeezing a length of tubing thereby pushing the fluid in one direction or another. One problem with this method is that the effectiveness of the pump depends upon how well the tubing recovers from being repeatedly squashed. As the tubing wears out, the pump becomes less effective. However, this problem is outweighed by the fact that the tubing can be replaced as opposed to dismantling a regular pump in order to clean it. Since for this project, samples are drawn from more than one point, it was necessary to thoroughly flush the fluid path between samples in order to prevent cross-sample contamination. 


\section{Pinch Valves}

The valves chosen were pinch valves made by Valcor (shown in Figure 7).

Similar to the pump, these particular pinch valves rely on tubing in order to work.

A metal pin attached to a spring and surrounded by a coil of wire normally presses down on flexible tubing to create a seal. When current runs through the surrounding coil of wire, it creates a magnetic field which lifts up on the pin and releases the seal on the tubing allowing fluid to flow. When open, each pinch valve used $0.6 \mathrm{~A}$ at $12 \mathrm{~V}$. Figure 7 shows the pinch valve/pump box. Figure 8 is a wiring diagram of the same. Pinch valves were labeled 1 to 12 , each with two leads connected to the relays. The letters on the pinch valves in the wiring diagram refer the color of wire used for the positive and ground connections. Four pinch valves were put on the same ground wire. In total there were 18 wires running from the pinch valve/pump box to the relays in the control box. 


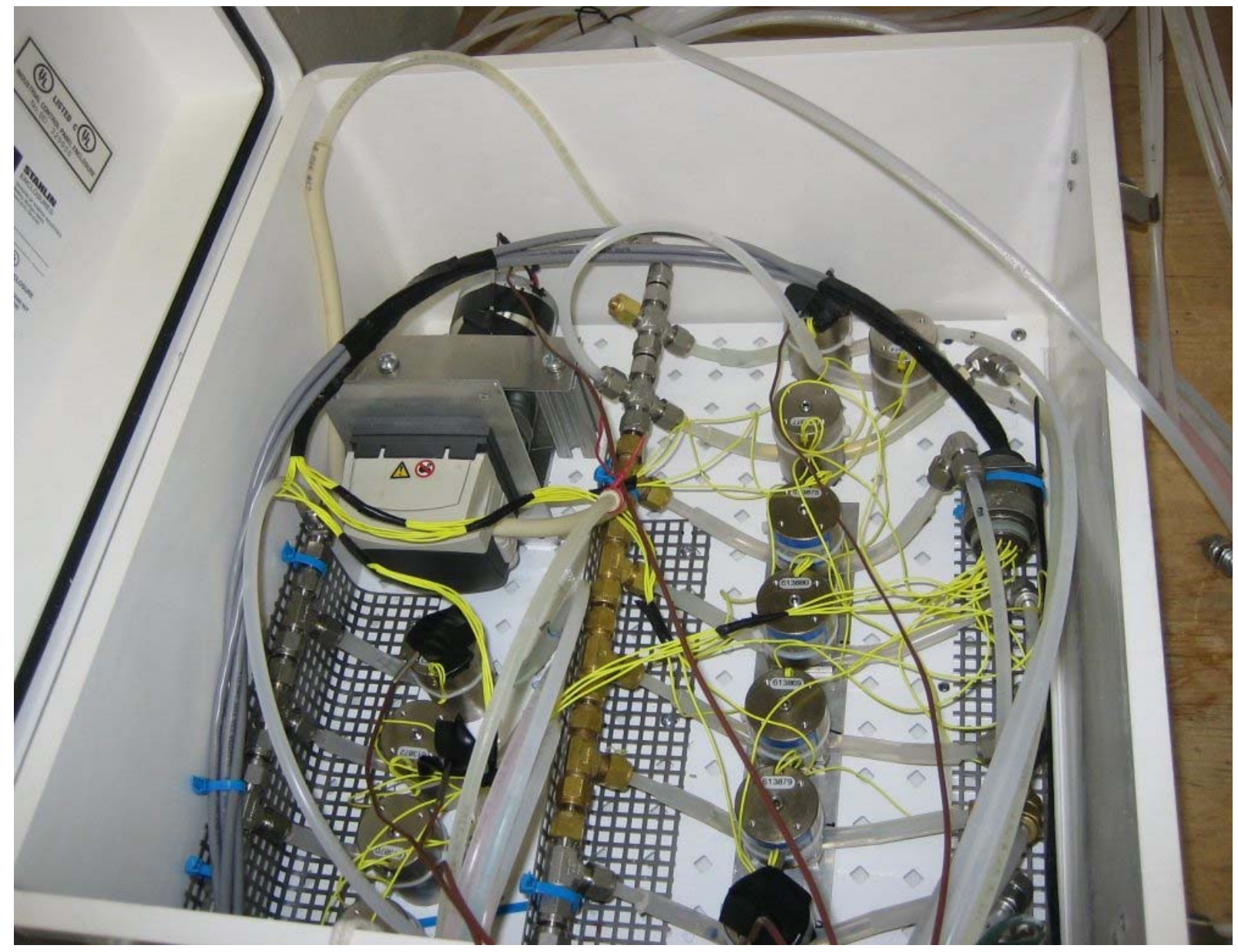

Figure 7. The pinch valve/pump box.

The pump is in the top left corner. The pinch valves are the cylinders in two columns beneath the pump and along the right side of the box. 


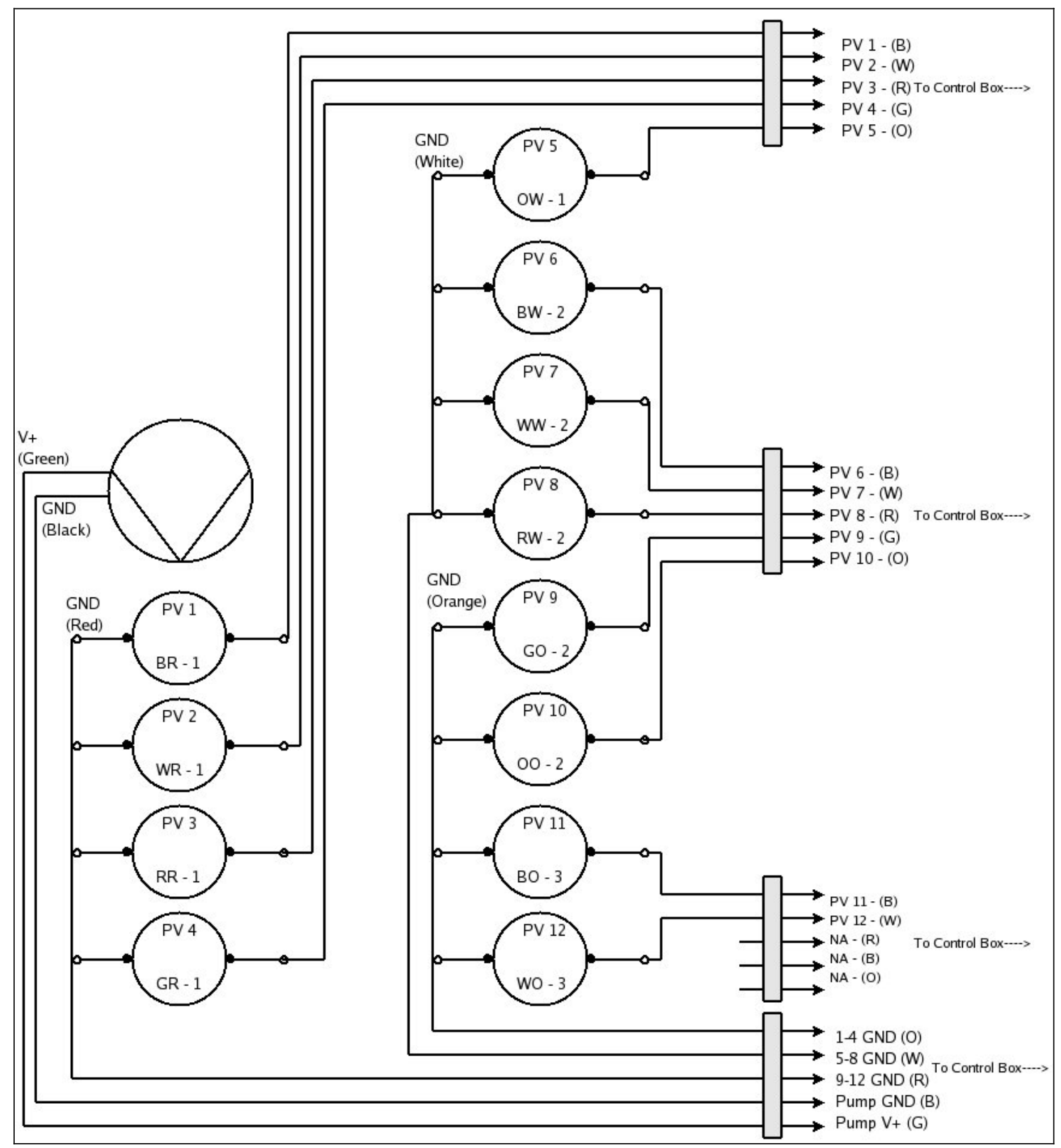

Figure 8. Pump box wiring

Pinch valves are labeled 1 to 12 . Numbers and letters below label refer to the color of the wire for the positive wire, the ground wire and the number of the wire bundle.

Connections between the pump, the pinch valves, the sample points and the chemistry sensor were made using $1 / 4$ inch inner diameter polyvinyl tubing. The 
polyvinyl tubing ran from the sample points to the box containing the pinch valves and the pump (Figure 7). The tubing from each sample point was slipped into one side of the flexible pinch valve tubing. Although not ideal, this formed an adequate seal between the PV tubing and the pinch valves. Stainless steel fittings then connected all twelve pinch valves together and more PV tubing connected the fittings to the pump. Depending on which pinch valve is open, fluid could be pulled through any one of the twelve pinch valves.

\section{Relays}

Four solid state relay modules manufactured by Opto-22 control the pinch valves and the pump. Each module contains two pairs of relays, each pair working off of a common voltage source for a total of 16 relays. The four modules were installed on a controller board also by Opto-22. The controller board, allowed easy interfacing with the digital output modules through a ribbon cable. Five strands of shielded wire were used between equipment boxes both for communication wire and to connect the pinch valves to the relays. Figure 10 shows the control box which holds the relays and the ADAMs modules from the next section. 
Although the Opto-22 solid state relays (SSRs) are significantly more expensive than electro-mechanical relays, they are more durable. Unlike the electromechanical relays, SSRs contain no moving parts and in the humid environment of the mine adit there are no exposed contacts to maintain. SSRs are also somewhat smaller and the LEDs built into the relay modules provided an easy way to see which relays were on and which were off. The pinch valves and the pump were inductive loads so diodes were used to protect the relays. Figure 9 is a diagram of the relay wiring. The wires on the top left are the wires coming in from the pinch valves and pump. The wires on the bottom left are the power and

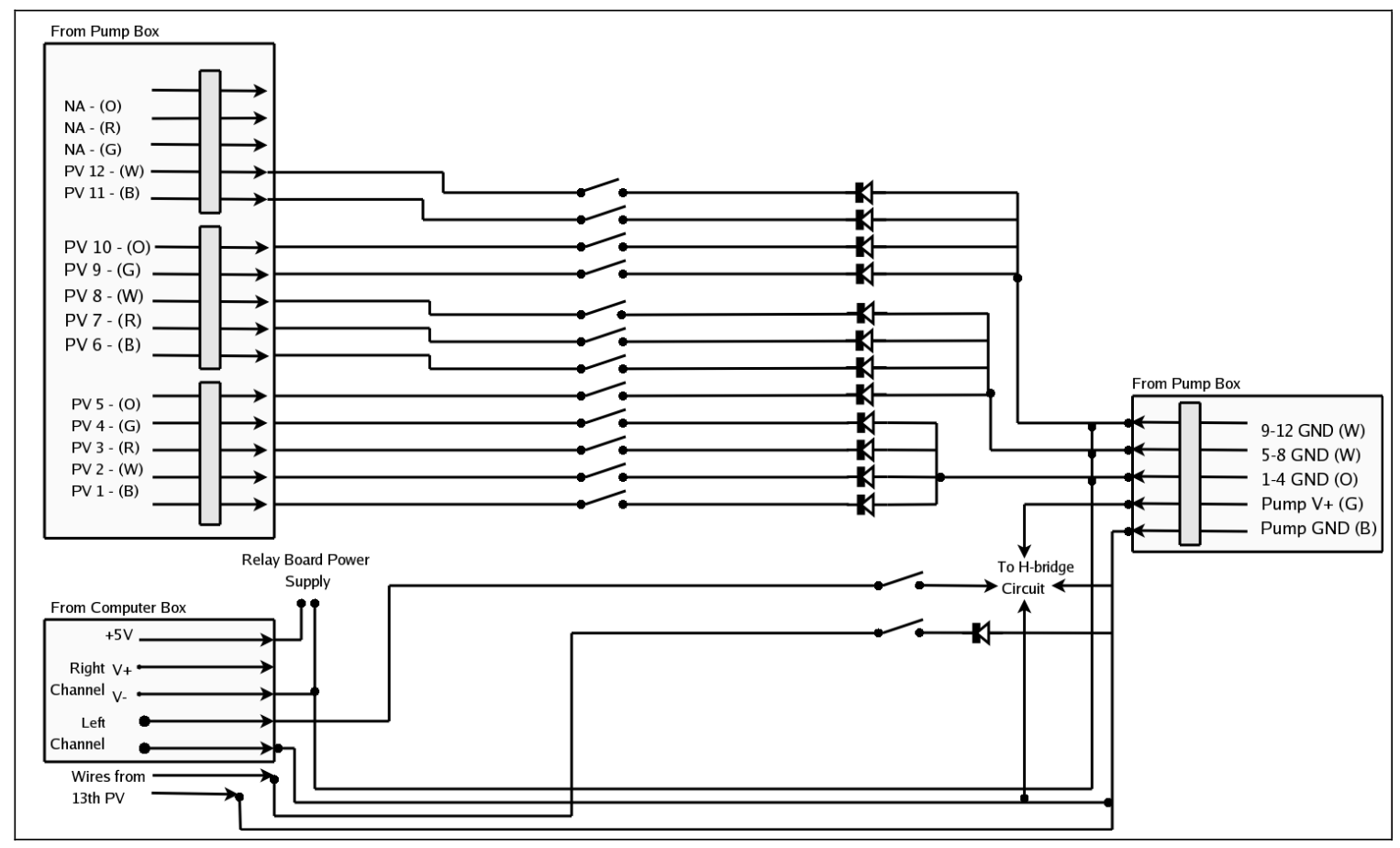

Figure 9. Relay schematic

Shows where each pinch valve or motor connection is made on the Opto-22 relay board. Diodes were placed across each connection to prevent voltage spikes caused when current is abruptly cut to the inductive pinch valve loads. communications wires from the computer. 


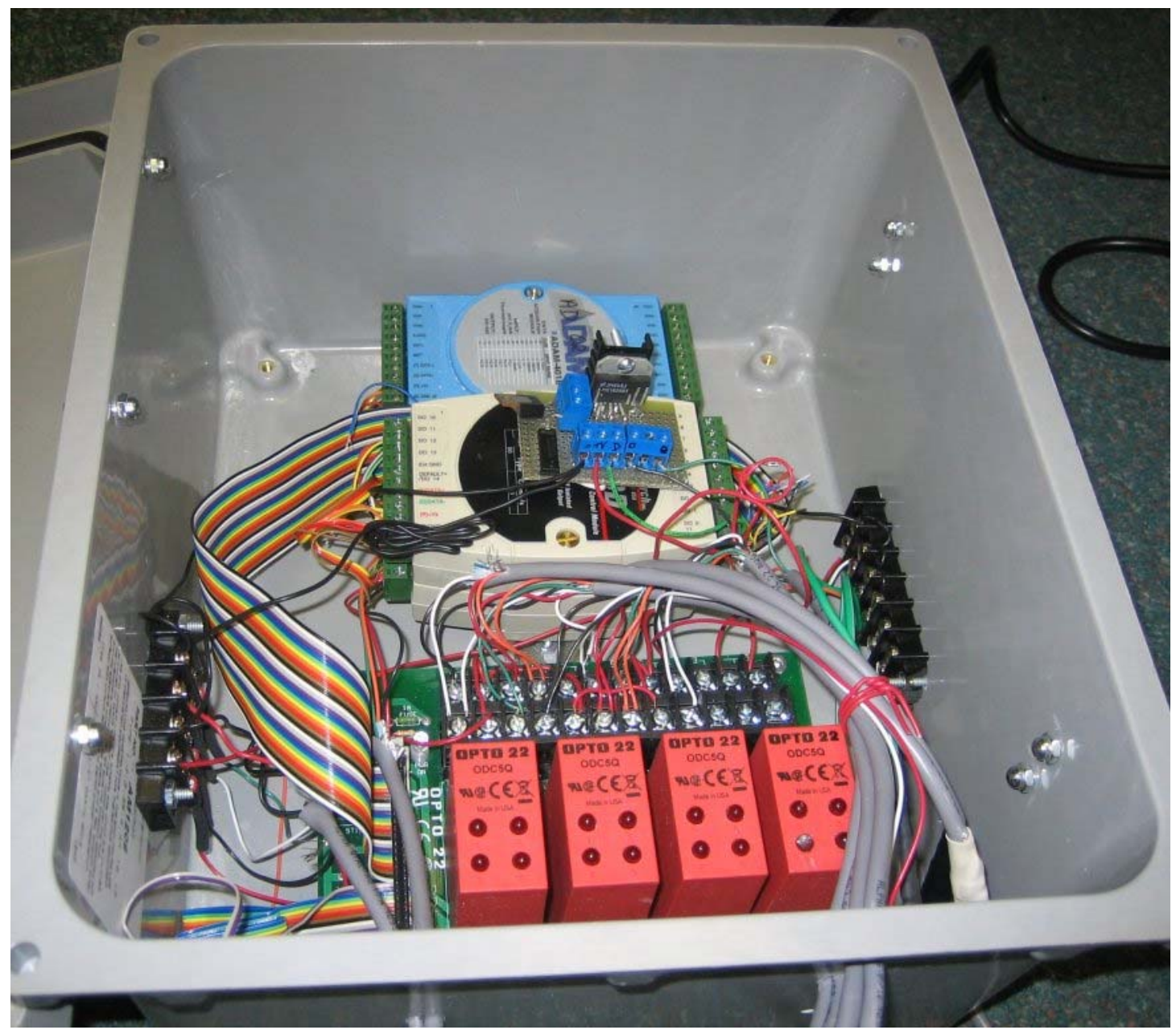

Figure 10. The control box.

The gray wires coming in are from the pinch valve/pump box and communication wires from the computer box. The red boxes at the bottom are the SSRs, the blue and cream boxes are the ADAMs modules. The circuit board with the blue terminal blocks in the center is the H-Bridge circuit for control of the pump.

\section{ADAMS Modules}

ADAMs modules (pictured in Figure 10) were used to control the relays and to take temperature readings. Adams modules are a series of off-the-shelf analog and digital input/output devices. Three types were used in this project: four analog temperature input (4018), two digital output (4056S), and one RS-232 to 485 converter (4520). All of the modules are controlled through a simple serial connection on an RS-485 network. Each module requires an unregulated 10- 
$30 \mathrm{~V}$ with less than a $200 \mathrm{mV} \mathrm{p}-\mathrm{p}$ ripple to operate. The power consumption for all seven of the ADAMs modules totaled $3.25 \mathrm{~W}$ at $12 \mathrm{~V}$. Special software is not required to communicate with the modules - HyperTerminal worked to test functionality. Each ADAM module has its own address on the RS-485 network. An RS-485 network, more formally known as EIA-485, is an OSI Model physical electrical specification of a two-wire, half duplex, multi-point serial connection [12]. It is akin to RS-232 (serial port). Up to 256 devices can be used on one RS-485 network with signal amplification. Because the voltage difference between the two communication wires conveys the data, rather than absolute voltage, communication over an RS-485 network remains reliable in the presence of common-mode electromagnetic interference. The recommended topology of an RS-485 network is point-to-point in order to reduce reflections on the communications wires, although the ADAMs modules do have built in noise suppression. An RS-232/485 converter module allowed communication to the RS-485 network using the serial port on the computer. The topology for the ADAMs modules used in this project is seen in Figure 11. 


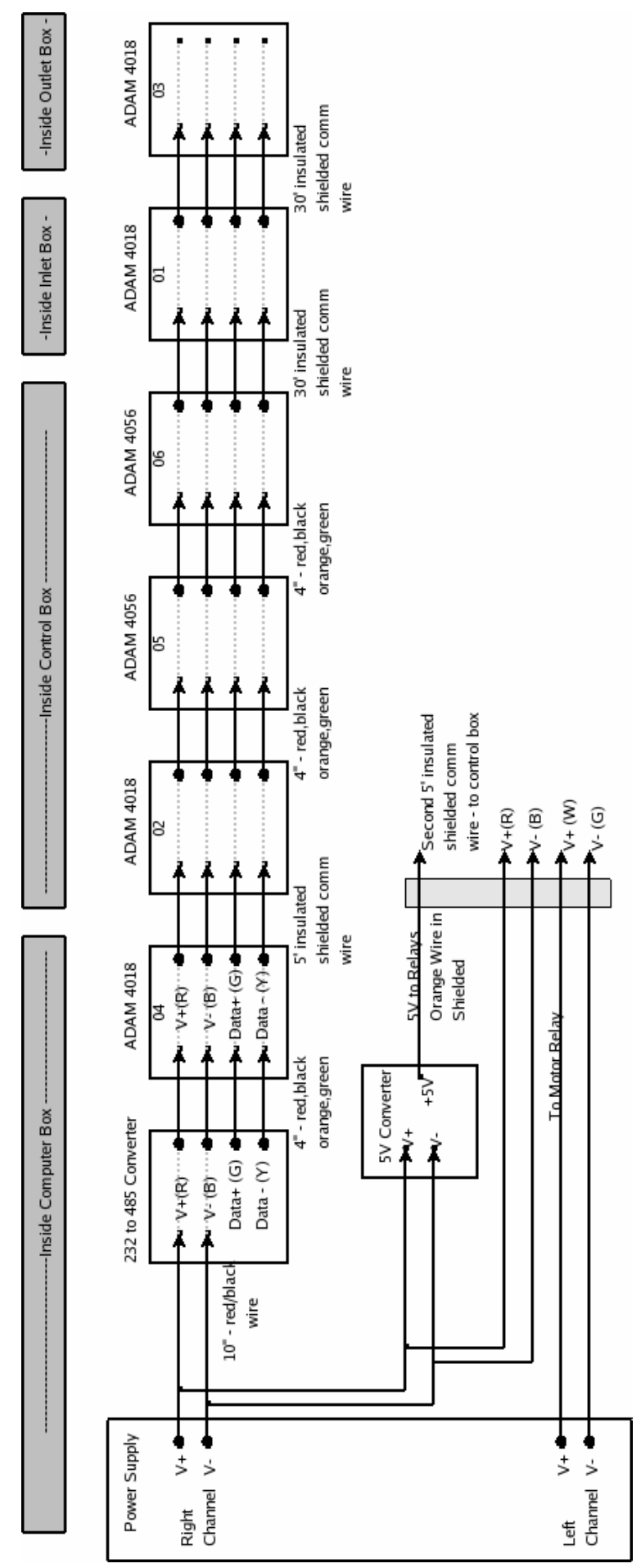

Figure 11. RS-485/ADAMs modules Network Topology

Four ADAM-4018 analog temperature modules were used in the project. The 
4018 is a versatile six channel analog to digital converter that returns data in a serial digital format. It can be configured to read various data ranges such as $\pm 15 \mathrm{mV}, 4-20 \mathrm{~mA}$ and various thermocouple types. The 4018 has six differential 16 bit channels and two single ended 8 bit channels, although only the differential channels were used. Each channel can be addressed individually or the module can return the data from all of the channels at once. Type $T$ thermocouples, which have a range of -100 to $400 \mathrm{C}$, were used for this project. The ADAM-4018 has some signal conditioning built in and an accuracy of $\pm 0.3 \mathrm{C}$.

Two ADAM-4056S digital output modules were used to control the pinch valves and the pump. Each module contains fourteen outputs - each output controlled one relay on the Opto-22 relay board. Instructions to the ADAM-4056 consist of the address of the ADAMs module and a 4 one digit hexadecimal numbers. For instance, the string "\#05T0001" sent out on the RS-485 network will instruct the ADAMs 4056 module with address 5 to put its first output channel low. The string "\#06T0020" would instruct the ADAMs 4056 module with address 6 to put it's sixth channel low.

\section{H-bridge motor controller}

A LMD18200T H-bridge IC controlled the direction of the motor. See Figure 10. Normally the motor was run forward to pump fluid from the sample points to the flow cell, but by setting an output on one of the digital output modules low, the polarity on the motor was reversed to pump fluid from the flow cell to a separate sample bottle. This was used to conserve calibration fluid or to save samples for further analysis. 


\section{Power Supply}

The power supply was a TopWard 6036. It had two channels that each supplied a variable voltage $0-30 \mathrm{~V}$ and sourced $3 \mathrm{~A}$. Since the pump consumed the most power it was placed by itself on channel two. The ADAMs modules, the pinch valves and the relays were powered on the first channel. The total number of pinch valves open at one time was always two or less. The power consumed by the Opto-22 relay board was negligible. Table 2 lists the power consumption on each channel of the power supply.

Table 2. Hardware power usage

\begin{tabular}{|l|c|c|c|}
\hline & Voltage (V) & Current (A) & Power (W) \\
\hline (2) Pinch Valves & 12 & 1.2 & 13.2 \\
\hline Adams Modules & 12 & 0.27 & 3.24 \\
\hline \multicolumn{2}{|c|}{ Channel 1 Totals: } & 1.47 & 16.44 \\
\hline Pump & 12 & 0.8 & 9.6 \\
\hline \multicolumn{2}{r|}{ Channel 2 Totals: } & 0.8 & 9.6 \\
\hline
\end{tabular}

\section{Chemistry Sensors}

The 6600 Extended Deployment System (EDS) built by YSI Environmental was used to house the various chemistry sensors. See Figure 12 and Figure 13. There are two parts to the 6600EDS: the individual chemistry sensors and the sonde into which the sensors fit. Although it was designed for extended deployment in a lake or ocean, it also worked for the ACAM system. The 6600EDS can be deployed either as a stand alone system with data stored internally or attached to a data collection system/computer. Power is supplied by four $\mathrm{C}$ batteries or by a transformer plugged into an electrical outlet. This sensor was chosen in part because, like the ADAMs modules, communication with the 
6600 is over a serial port. A system of menus is built into the 6600 allowing for calibration, automated data collection, and report generation.

The flow cell of the 6600EDS is the "central point" to which fluid is pumped. It was placed about 5 feet from the computer and control boxes in the middle of the adit. In Figure 12, the chemistry sensor is the long cylinder hanging from the cross beam in the left third of the image.

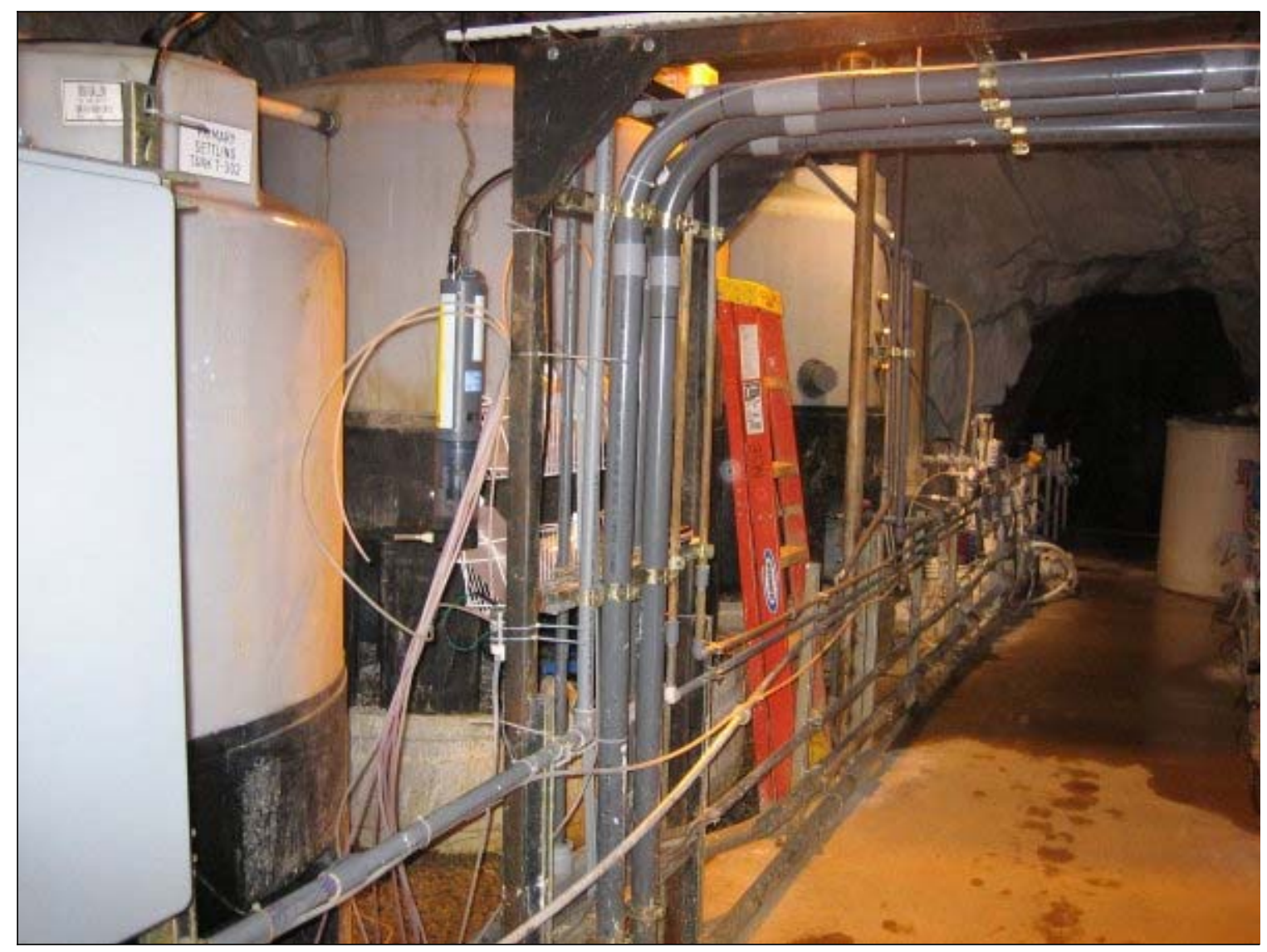

Figure 12. YSI chemistry sensor location.

The flow cell is a cylindrical cup that threads onto the bottom of the sonde. At the bottom of the flow cell is the inlet point. In the center of the cell is an overflow tube. Once the fluid reaches the height of the overflow tube, water runs out of the cell. A "T" fitting was placed on the inlet point of the flow cell. At one side of 
the "T" is the output of the pump, at the other side of the "T" is a pinch valve. After each sample the pinch valve is opened to allow the flow cell to drain fully. In the absence of a pinch valve, the sample would have needed to be diluted in order to analyze a new sample thereby increasing the time required for each sample.

As seen in Figure 13, the 6600 is simply a holder for individual chemistry sensors. The possible sensors include normal chemistry measurements such as of $\mathrm{pH}$ and conductivity as well as more biologically useful measurements like ammonia and chlorophyll concentrations. We used four sensors to measure six different parameters. Starting at the top of Figure 13 and going clockwise the sensors are: $\mathrm{pH} / \mathrm{Oxidation}$ Reduction Potential (ORP), Conductivity/Temperature, Dissolved Oxygen and Turbidity.

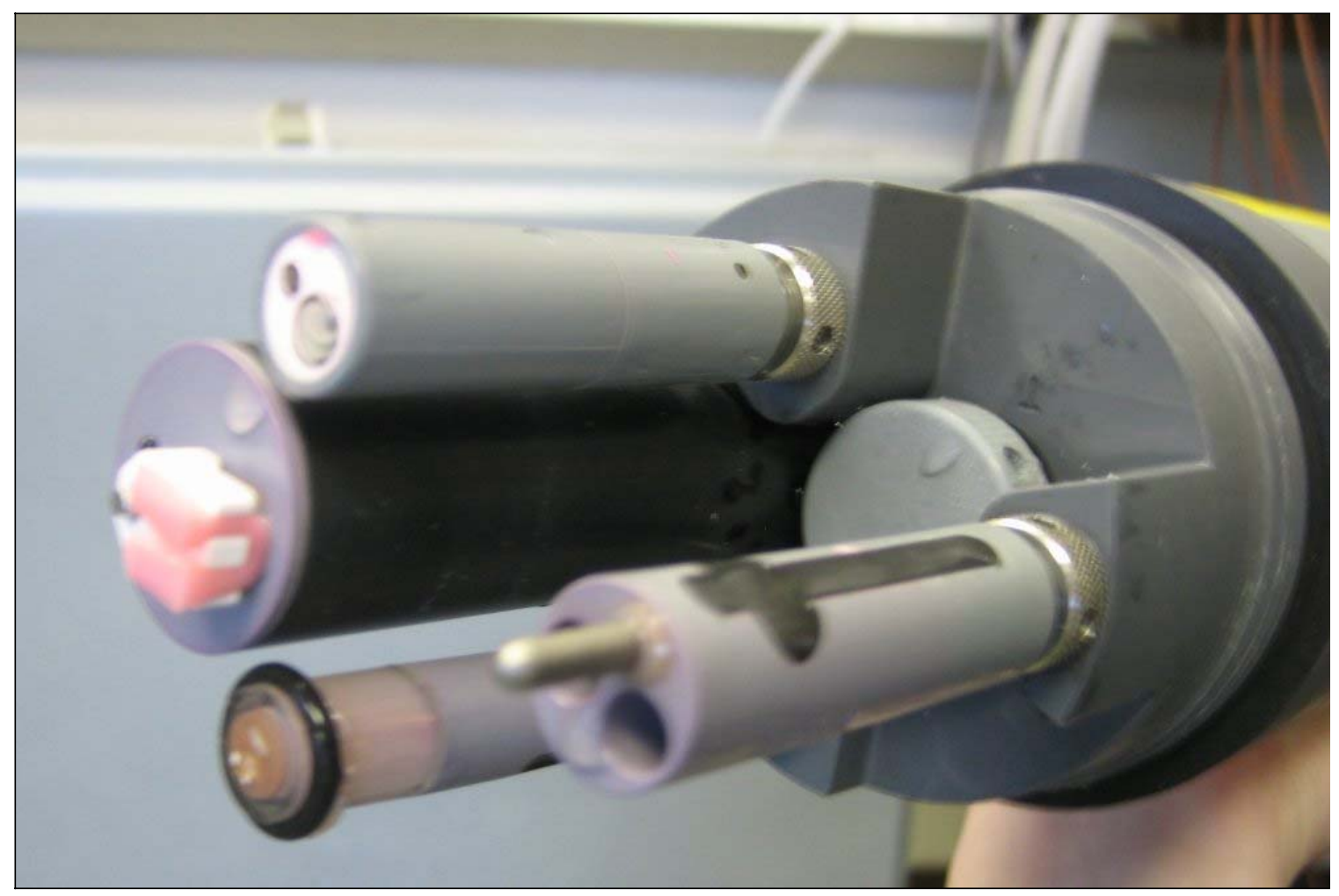

Figure 13. Close of up chemistry sensors. 


\section{pH/ORP}

$\mathrm{pH}$ and ORP are measured using the same sensor housed in the 6600 EDS. pH is a measure of the concentration of hydrogen ions $(\mathrm{H}+)$ in a solution. Fewer $\mathrm{H}+$ ions mean a higher $\mathrm{pH}$ or and more basic solution. More $\mathrm{H}+$ ions mean a lower $\mathrm{pH}$ or a more acidic solution. ORP is a measure of the tendency of an ion to reduce, or gain an electron. In a solution, a higher ORP indicates the presence of an oxidizer and a lower ORP indicates the presence of a reducer. ORP is measured in millivolts $(\mathrm{mV})$. The $\mathrm{pH} / \mathrm{ORP}$ sensor consists of a small disk of platinum, a proton selective glass reservoir filled with a buffer with a $\mathrm{pH}$ of 7 , and an $\mathrm{Ag} / \mathrm{AgCl}$ reference electrode. Since MSE-TA used $\mathrm{pH}$ adjustments in their treatment process, $\mathrm{pH}$ is of particular interest.

$\mathrm{pH}$ is measured using the proton selective glass reservoir and the $\mathrm{Ag} / \mathrm{AgCl}$ reference electrode. On one side of the glass is the $\mathrm{pH} 7$ buffer and on the other side is the unknown solution to be measured. This sets up a potential gradient across the glass. This difference, measured relative to the $\mathrm{Ag} / \mathrm{AgCl}$ electrode is proportional to the $\mathrm{pH}$ of the unknown solution. This $\mathrm{mV}$ difference is translated to $\mathrm{pH}$ by the software on the 6600 sonde using a linear $(y=m x+b)$ relationship. Calibration of $\mathrm{pH}$ consists of at least two known $\mathrm{pH}$ buffer solution to determine the slope and the offset of the equation. ORP is the voltage difference between the $\mathrm{Ag} / \mathrm{AgCl}$ reference electrode and the small platinum disk. The range of the ORP sensor is -999 to $999 \mathrm{mV}$ with an accuracy of $20 \mathrm{mV}$. ORP is temperature dependent and can vary up to $100 \mathrm{mV}$. When calibrating the sensor, temperature 
of the environment is taken into account.

\section{Dissolved Oxygen}

Dissolved oxygen is a measure of the amount of oxygen dissolved in a fluid. The dissolved oxygen sensor of the 6600EDS works by measuring the current associated with the reduction of oxygen that is diffused through a Teflon membrane. A thin layer of $\mathrm{KCl}$ electrolyte sits between the Teflon membrane and the electrodes to measure current.

\section{Conductivity and Temperature}

Conductivity and temperature were measured by the same sensor in the 6600EDS. Conductivity is a measure of how well a solution conducts current. Copper has a conductivity of $59.6 \times 10^{6} \mathrm{~S} / \mathrm{m}$ while seawater has a conductivity of about $50 \mathrm{mS} / \mathrm{cm}$. Conductivity can be tied to the over all ion concentration of a solution so perfectly distilled water would have a conductivity of zero. The sensor used consisted of four nickel electrodes. Two were current driven and two measured the voltage drop. The temperature portion of the probe uses a thermistor. Although the collected temperature data did not prove useful in determining the temperature of the various sample points due to the distance the water must travel from the sample point to the chemistry sensor, conductivity readings are dependent upon the temperature of the solution so it was important to document for other measurements.

\section{Turbidity}

Turbidity is a measure of the amount of solid suspended in a fluid. It is 
determined by shining light into the sample solution and measuring the amount of light that is scattered. Usually the light source is an LED. The output of the turbidity sensor is processed by the sonde software and reported in nephelometric turbidity units (NTUs).

Table 3 lists information about each sensor in YSI's 6600EDS as reported in the sensor operations manual [15].

Table 3. Sensor information

\begin{tabular}{|c|c|c|c|c|c|c|}
\hline Sensor & Parameter & Units & $\begin{array}{c}\text { Min } \\
\text { Range }\end{array}$ & $\begin{array}{c}\text { Max } \\
\text { Range }\end{array}$ & Resolution & Accuracy \\
\hline \multirow[t]{2}{*}{ YSI 3036} & $\mathrm{pH}$ & -- & 0 & 14 & 0.01 & \pm 0.2 \\
\hline & ORP & $\mathrm{mV}$ & -999 & 999 & 0.1 & \pm 20 \\
\hline YSI 6562 & $\begin{array}{l}\text { Dissolved } \\
\text { Oxygen }\end{array}$ & $\%$ Sat & $0 \%$ & $500 \%$ & $0.1 \%$ & $\begin{array}{l} \pm 2 \% \text { of } \\
\text { reading }\end{array}$ \\
\hline \multirow[t]{2}{*}{ YSI 6560} & Conductivity & uS/cm & 0 & 100,000 & 0.1 & $\begin{array}{l}0.5 \% \text { of } \\
\text { reading plus } \\
1 \mathrm{uS} / \mathrm{cm}\end{array}$ \\
\hline & Temperature & ${ }^{\circ} \mathrm{C}$ & -5 & 60 & 0.01 & \pm 0.15 \\
\hline YSI 6136 & Turbidity & NTU & 0 & 1000 & 0.1 & \begin{tabular}{|l} 
$\pm 2 \%$ of \\
reading
\end{tabular} \\
\hline $\begin{array}{l}\text { ADAM } \\
4018\end{array}$ & Temperature & ${ }^{\circ} \mathrm{C}$ & -100 & 400 & 0.01 & \pm 0.3 \\
\hline
\end{tabular}

\section{Calibration}

Almost all of these sensors create a voltage signal proportional to the parameter of interest ( $\mathrm{pH}, \mathrm{ORP}$, turbidity etc) that the software on the sonde translates into engineering units. Calibration of the sensors involves placing the sensor package in a solution of known value. This solution is called a standard. Most of the sensors have more than one possible calibration sequence. For instance, the $\mathrm{pH}$ sensor can be calibrated using one, two or three standards. After the 
calibration sequence is selected, the value of the standard is entered and the software on the sonde sends back readings from the sensors. When the value of the sensor being calibrated levels off, the user presses a key to tell the sonde the calibration is done. A plot of the readings from a pH calibration using $\mathrm{pH} 10$ standard is shown in Figure 14. Starting from a previous calibration using $\mathrm{pH} 7$ standard the $\mathrm{pH}$ approaches 10.2 before starting to level off.

pH Calibration - pH 10 Standard

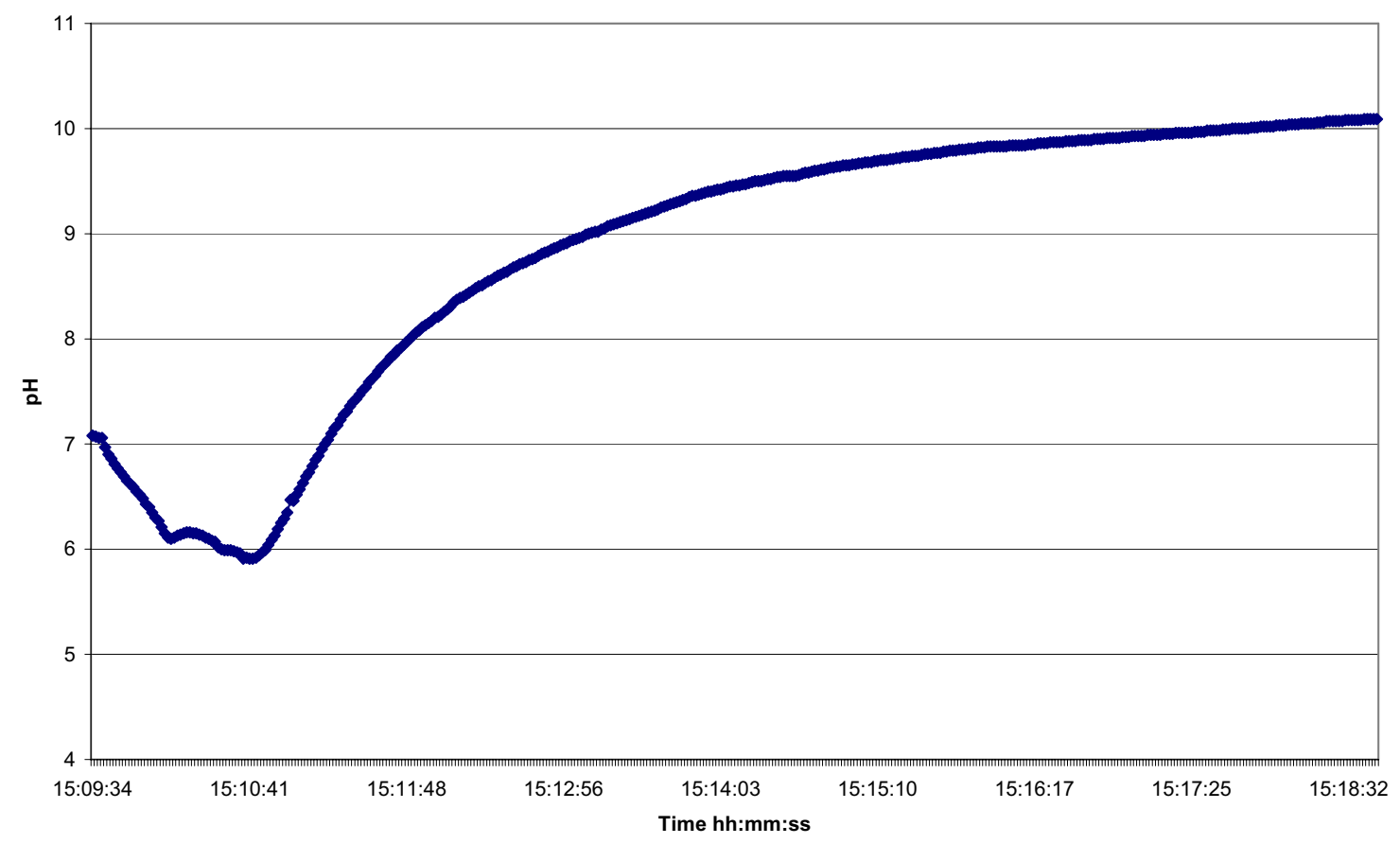

Figure 14. Plot of $\mathrm{pH}$ calibration

Each type of sensor has an accuracy that doesn't change. For example, the $\mathrm{pH}$ sensor has an accuracy of \pm 0.2 , but the simple use of the sensor can cause errors in the readings. According to $\mathrm{YSI}$, the $\mathrm{pH} / \mathrm{ORP}$ sensor is prone to drift while the turbidity, dissolved oxygen and conductivity sensors are prone to fouling. Since the 6600EDS is more commonly used in a lake environment, fouling is most likely due to algae build up on the sensor, it was thought that 
fouling would not be such a large problem in this project because there is no sunlight in the mine to nourish plant life. The problem of drift would be addressed by more frequent calibrations. While data collected by the system would be of most interest, we were also trying to obtain an idea of how often calibrations of each sensor should be conducted. Since the calibration standards are somewhat expensive, the fewer times the sensors had to be calibrated the lower the cost per sample.

\subsection{Software}

\subsubsection{Requirements and Objectives}

The function of the control software is to operate the system. System operation includes performing calibrations, performing samples, acquisition and archive of data, and to interface to local and remote human operators for the purpose of displaying results, configuration and receiving command updates. The control software needed to be easy for a non-programmer to modify and have a user interface. Ideally the control software would be a stand alone program easily transferable from a development computer to the actual system computer. The user interface had to show which pinch valves were on, have a way to plot the data and show what the last measurement was for both the temperature and chemistry sensors. The data output from the system was to be in the form of a text file containing the data and time stamps as well as a log file to record any errors encountered during operation. Inputs to the system included when samples were to be taken, how often to upload data to the web server and various locations of the control files. 


\subsubsection{Available Options}

The options available to program the control software included LabVIEW, Ruby and the use of a microprocessor. Each system had advantages as well as as disadvantages for the ACAM system.

LabVIEW, a visual programming language, is commonly used at INL, but it is expensive and requires a computer on which to run. On the positive side, LabVIEW did have most of the needed functionality built in and the design of a control system in LabVIEW includes the user interface. It also has pre-made bits of code to do plotting, serial communications, and it can be compiled into a freestanding program.

Another option was Ruby, an open source object oriented programming language. It is not common to INL and as a textual (typed code) language would have been difficult for a non-programmer to modify. A control system written in Ruby would have required a computer and probably another software package to design the user interface. However, on the positive side since Ruby is open source it is free.

The complexity of the tasks to be accomplished by the control software did not require a complete desktop computer. Another option was a microprocessor. This would have had some of the same detrimental implications as Ruby, but it would not have needed a full computer. A user interface would have been much harder to create and would have required implementation of an LCD screen to view the status of the control system. However, using a microprocessor would have made it possible to design a system that could run on just a battery charged 
with solar panels. Had the time been available, a microprocessor or some type of embedded system would have been the ideal choice. However, LabVIEW was chosen in the end because it is the standard at the INL and because it's ease of implementation justified the higher cost.

\subsubsection{LabVIEW}

The basis of design in LabVIEW is the use of a front and back panel. Various indicators and/or controllers such as LEDs, buttons, text boxes or indicators are placed on the front panel, this is the user interface. At the same time, representations of these parts appear on the back panel. The back panel holds the actual code which is comprised of wires to connect pieces together, control structures such as "for" or "while" loops which appear as gray boxes on the screen and various functions in the form of graphical symbols with terminals for input and output. LabVIEW has all of the data structures and variable types as a typed programming language such as $\mathrm{C}$, but the graphical nature of LabVIEW allows it to be much more accessible to a non-programmer than a textual language.

\subsubsection{Control System Overview}

A simplified block diagram of the control system software is in Figure 15. The basis of the control software is a timer (located at the bottom of the next page). Once every minute, the program checks a text (script) file to see if an action is scheduled to run at that particular time. If an action is scheduled, the program puts the command into a queue. Because the instructions for taking chemistry measurements are time intensive as opposed to the other types of actions, the 
two types are split up into separate queues. The first queue contains actions relating to chemistry measurements. Typically, instructions that go in the first queue involve turning on the pump, opening a pinch valve and waiting a specified number of minutes for the flow cell to fill, flush or empty. The second queue contains everything else - temperature readings, data file archiving, upload and download from the web server. These actions can be accomplished while the instructions from the first queue are being carried out. 


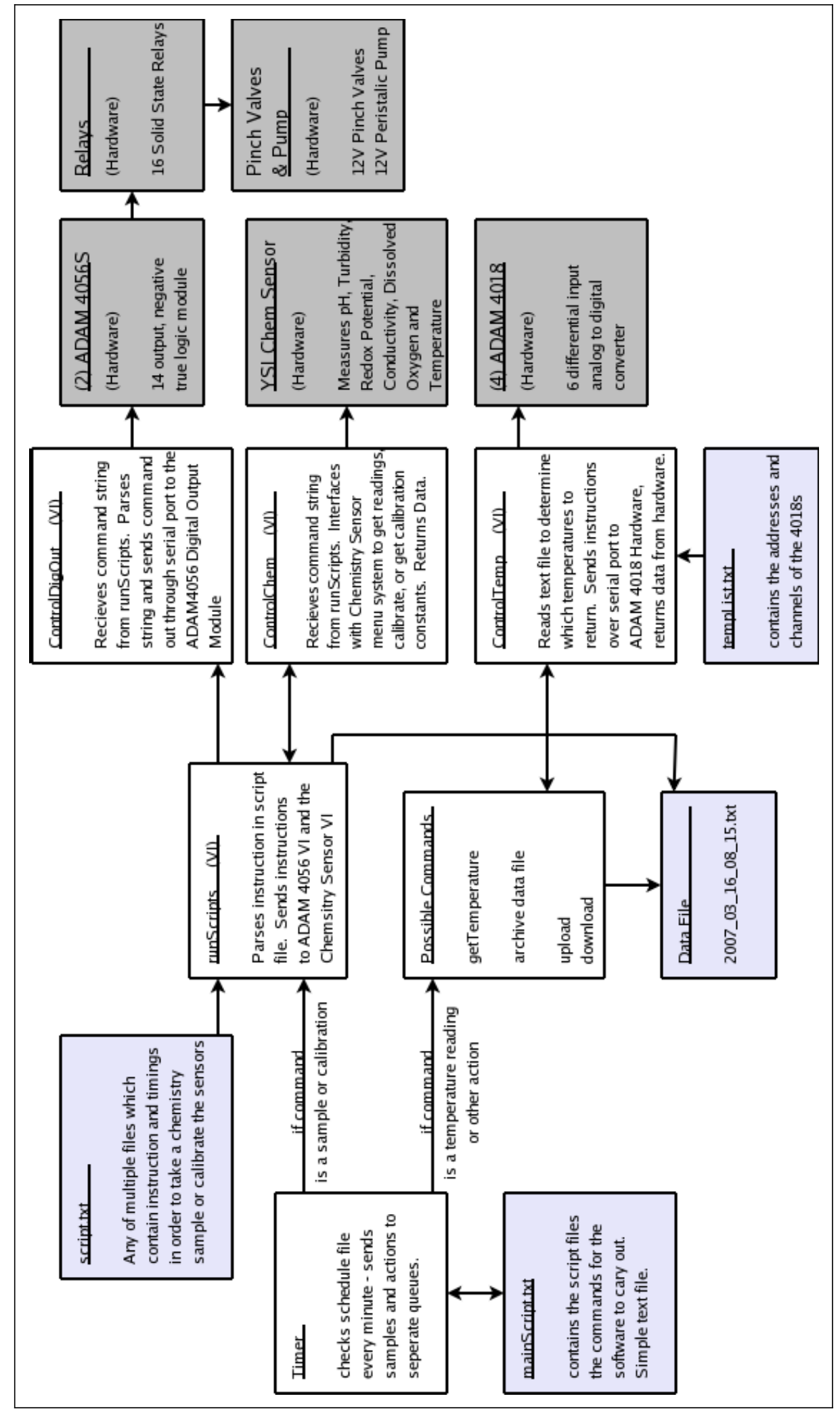

Figure 15. Control Software Block Diagram

Light gray boxes are text files used by the software, dark gray boxes are hardware. White boxes are LabVIEW code. 
In addition to important sampling controls, the LabVIEW control software also provides manual control for the pinch valves and pump, a way to plot data already stored in the data files as well as modification of the control system variables such as file locations and information about the FTP site. Various indicators on the front panel show which pinch valves are on and whether there is currently activity with the ADAMs modules on the RS-485 network.

For the ACAM system, three types of hardware had to be controlled by the LabVIEW software: the ADAMs temperature modules, the ADAMs digital output modules and the YSI chemistry sensor. Each of these three pieces of hardware had its own LabVIEW virtual instrument $(\mathrm{VI})$. A VI is a small LabVIEW program with inputs and outputs that can placed in a larger LabVIEW program. The temperature module VI included inputs to indicate the address of the module and which channel selected to return the temperature. The digital output VI had inputs to indicate the address of the module, which port to turn on or off and an input for timed operation. The chemistry sensor VI was more complicated because it had to interface with a menu system built into the chemistry sensor. The temperature $\mathrm{VI}$ and chemistry sensor $\mathrm{VI}$ return data in the form of a string that includes the measurements, a time stamp and a string that identifies the location and type of sample. Figure 16 through Error! Reference source not found. show the front and back panels of the digital output, temperature and YSI controller VIs. 


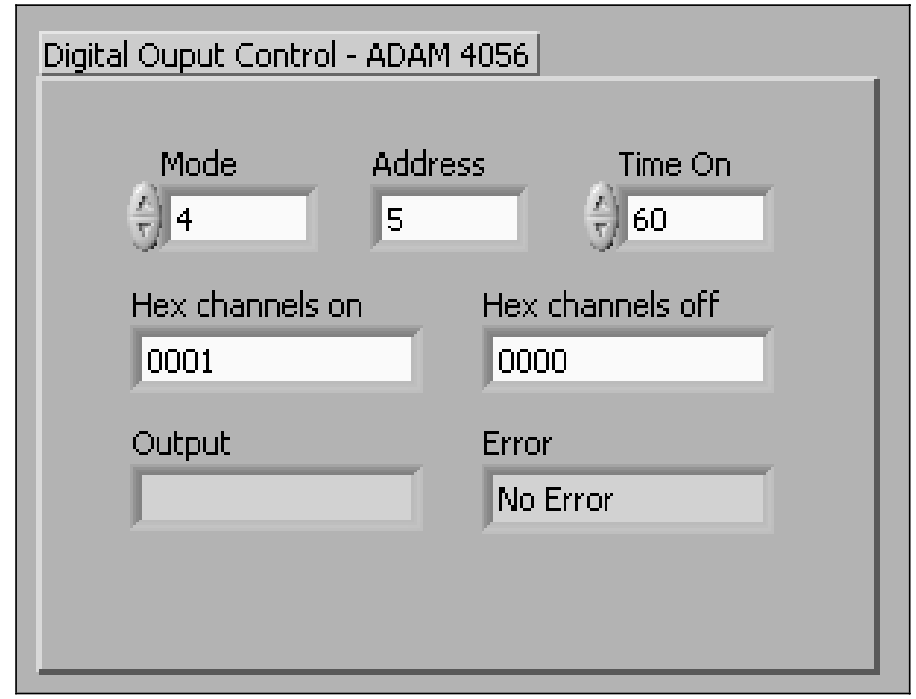

Figure 16. Digital Output Controller Front Panel 


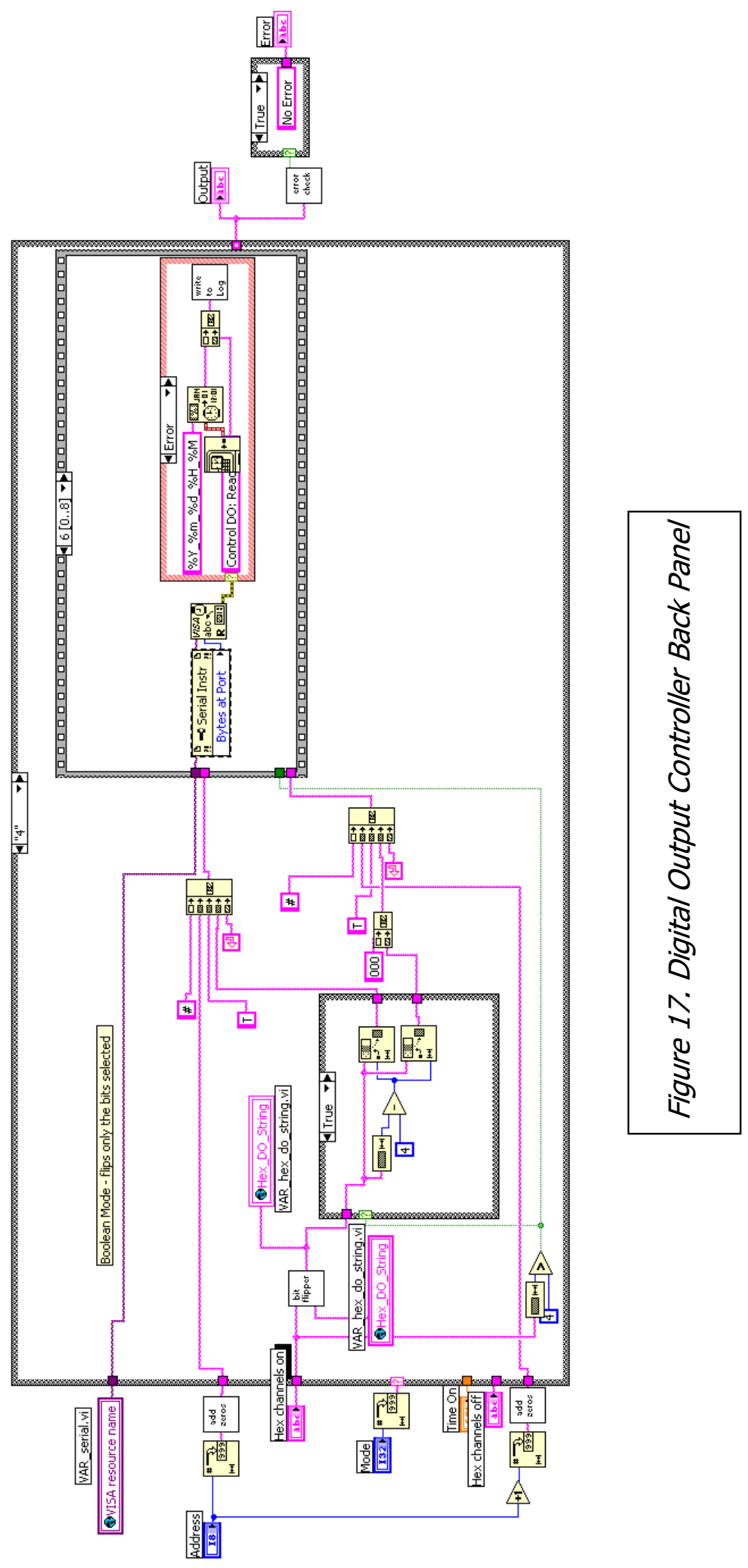




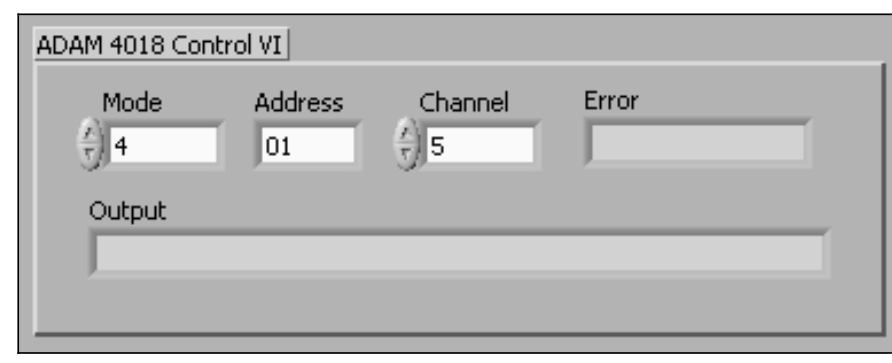

Figure 18. Temperature Front Panel

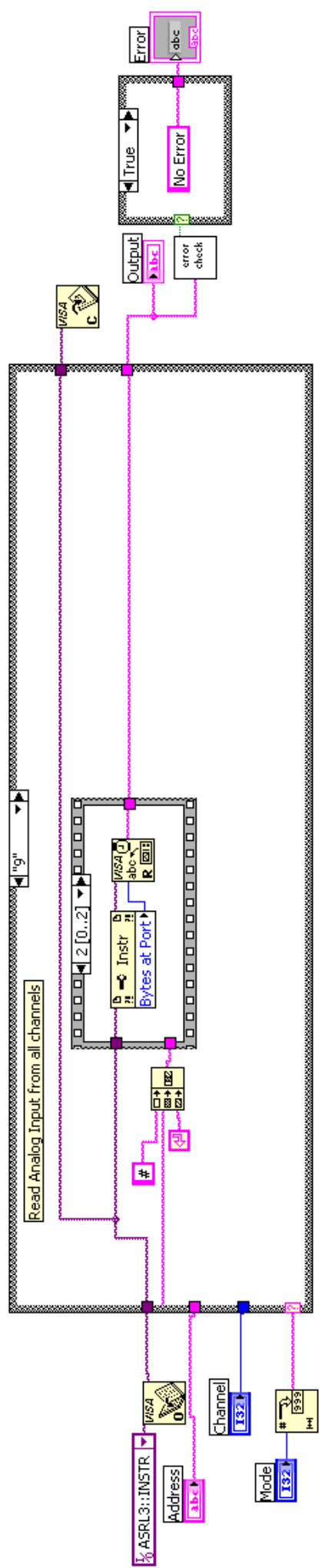

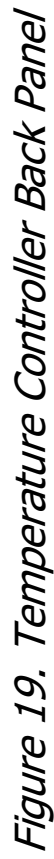




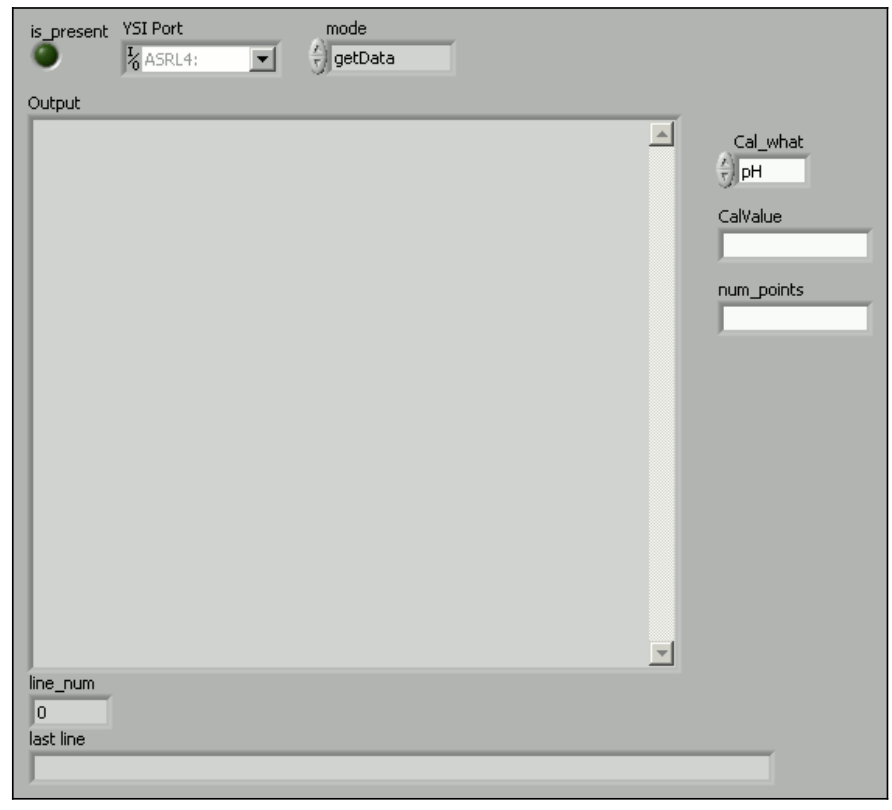

Figure 20. YSI Control Front Panel 


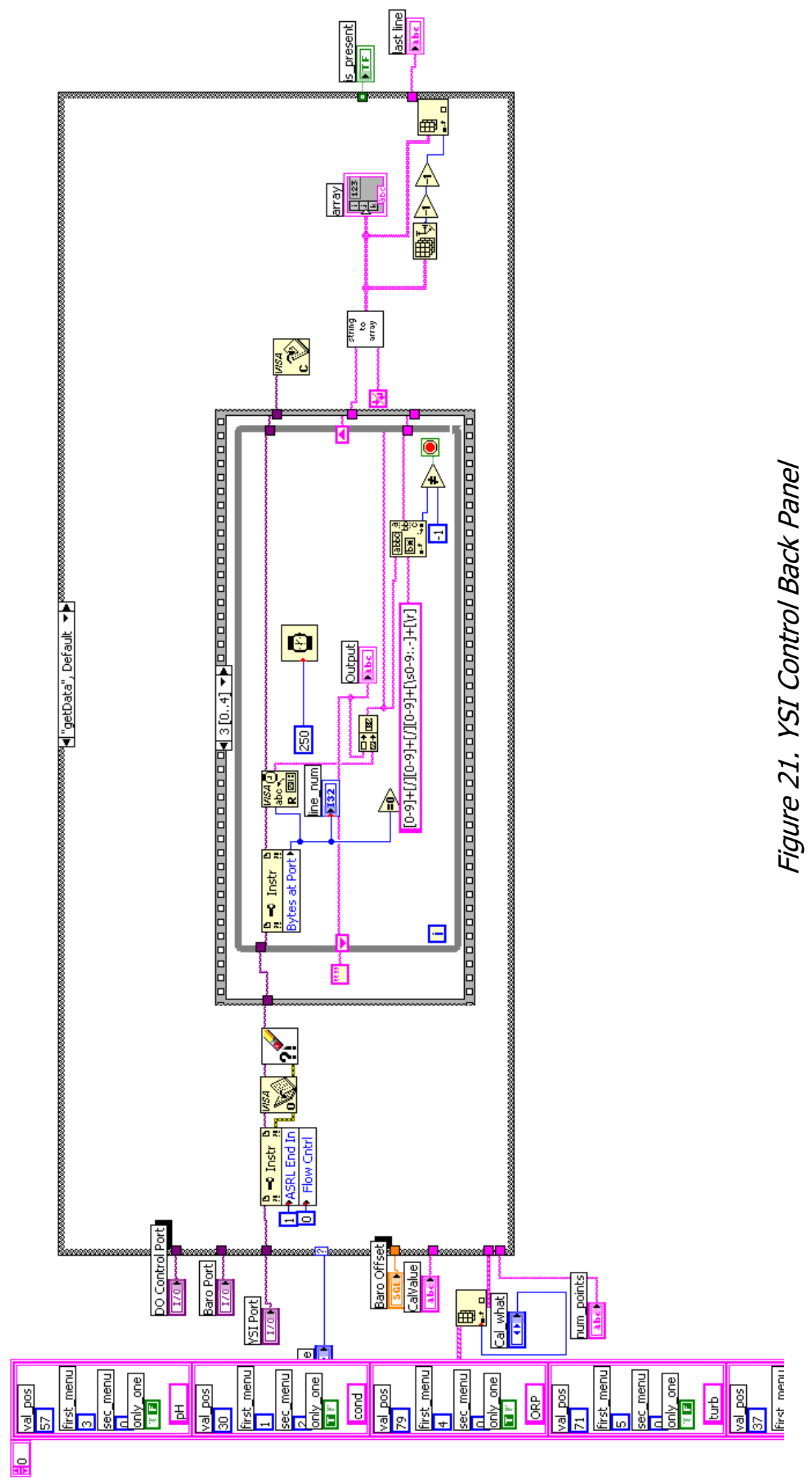


While software packages that allow access to a LabVIEW program's front panel over an internet connection do exist, simple text files were chosen instead to control the system due to concerns about the bandwidth of the phone line to the project area. Text files stored on the computer contain the scheduling information for measurements, the commands sent to the ADAMs modules, and the sensors to be read. Possible commands include:

- archive the data file,

- upload data files to FTP server,

- download script files from FTP server,

- get temperature data,

- calibrate the YSI sensor,

- run a script file to get data or store a sample, and

- reset the computer.

To determine which script file or action to run, the control software looks for a file named mainScript.txt. This script file contains all of the commands run over a period of days. This period is set on the front panel of the control software. Below is one possible mainScript file.

script1.txt;

01: 02: 03: $04:=0.00,6.00,12.00,18.00$

script2.txt;

01: $02: 03: 04:=0.00,8.00,16.00$

upload;

01: $02: 03: 04:=1.00$

download;

01: 02: 03: $04:=1.00$

pH_Cal_2pt.txt;

02: $04:=12.00$ 
This script is meant to run on a period of four days. Script1.txt would contain the instructions to take a chemistry sample. It runs on six hour sampling periods so it takes samples at midnight, $6 \mathrm{am}, 12 \mathrm{pm}$ and $6 \mathrm{pm}$ everyday of the four day period. Script2.txt runs every day as well, but at a different sampling rate - eight hours rather than six. Upload and download run every night at 1am. pH_Cal_2pt.txt runs a two point $\mathrm{pH}$ calibration on days two and four at noon. This method of scheduling tasks allows for different sampling rates for different sampling points and different calibration periods depending upon the sensor.

The data collected from the sensor VIs are stored in ASCII text files. Each line in the data file corresponds to one reading and includes a timestamp, the value collected by the sensor, and an identifying string that lets the database know where the measurement was taken. Below is a portion of one data file:

$$
\begin{aligned}
& \text { 2007-03-07 12:09:00,+010.99,temp,04,02 } \\
& \text { 2007-03-07 12:09:00,+009.91,temp,04,01 } \\
& \text { 2007-03-07 12:09:00,+009.36,temp,04,00 } \\
& \text { 2007-03-07 12:00:00,121.8,chem,1,Turb } \\
& \text { 2007-03-07 12:00:00,161.2,chem,1,ORP } \\
& \text { 2007-03-07 12:00:00,4.78,chem,1,pH } \\
& \text { 2007-03-07 12:00:00,122.6,chem,1,Do }
\end{aligned}
$$

The first part of each line is the time stamp, the next part is the sensor measurement and the rest of each line is the identifying string. The time stamp corresponds to when the measurement began. In this example, the first three lines are temperature measurements from the ADAMs module with address " 4 ". 
The last four lines are chemistry measurements from the first sample point. New data files are created by the control system either according to the size of the current file or according to a command scheduled in the input files. The size of the data files for this project were intentionally limited to about $122 \mathrm{~Kb}$. This was to prevent the FTP server from timing out during upload.

Data files are uploaded to a remote FTP server according to the mainScript.txt file. As data files are uploaded they are renamed on the control system computer to prevent duplication. The control system can also be programmed to check the FTP server for updated control files. When the new control files on the FTP server are downloaded, they are renamed on the FTP server to indicate that they have been downloaded so the control software will not download them a second time.

\subsection{Web}

\subsubsection{Data Access Requirements}

Without the presence of a web site many of the overarching project requirements would have been impossible to fulfill. The most important function fulfilled by the web site is access from any computer connected to the internet to both the data collected previously by the system and to the control software. Lesser requirements include the easy expansion of the original web site to include other locations (not just the Susie Mine), password protected access to the data with multiple permissions levels and basic data analysis and plotting tools.

Many options exist for building a database backed web site for both the programming language and the database software. However, the time and 
money constraints narrowed the search considerably. MySQL was chosen for the database because of it's widespread use and many online recourses. Ruby on Rails, a framework based on Ruby, was used to create the website because of it's ease of implementation and fast development time.

\subsubsection{Ruby on Rails}

Ruby is an open source, object oriented programming language. Since Ruby is open source it was free to use. Although Ruby is a relatively new language, many online sources of information exist [13]. Ruby also has many extension packages, called gems that can be found online and freely downloaded. Among these are interfaces to various plotting and data analysis software, authentication systems and methods to output database records into a comma separated value format.

The most attractive feature of Ruby for this project was a framework called Ruby on Rails [8]. A framework is a set of tools and software used to automate the creation of common functions. One of the main functions of a database-backed web site is the modification of records in a database. Records can be Created, Read, Updated or Deleted (CRUD). Given a table in a database, Ruby on Rails creates the functions and files necessary for these actions. Another advantage of a dynamic webpage created with Ruby on Rails is that it is easily transferable to another computer, even if the other computer has a different operating system. Ruby on Rails design is built around a Model-View-Controller architecture. This is somewhat similar to LabVIEW. The view in Ruby on Rails is analogous to LabVIEW's front panel and the in Ruby on Rails controller is analogous to 
LabVIEW's back panel. The model is the data stored in the database.

\subsubsection{MySQL}

MySQL is a relational database management system, similar to Microsoft Access

[7]. Like Ruby, it is open-source and has many user groups and sources of information available on the internet. It operates on many different platforms and so it is easy to transfer between Linux and Windows boxes. Because of this and its potential to handle huge amounts of data, MySQL seems to be the default database for dynamic web pages. Three types of data needed to be organized in the ACAM system: user data (permissions, user specific information etc.), information about the hardware, and the actual measurements collected by the control system. MySQL was the logical, inexpensive choice.

\subsubsection{Database Structure}

All of the instrument variables, sensor variables, and other information regarding hardware is stored in the database to ensure that it is available to support the analyser. The basic structure of the database is shown in Figure 22. More tables exist in the database than those shown, but the tables shown are the bare minimum needed to store all of the information about the hardware used in the project. The structure of the database is centered on the ability to uniquely identify where a particular measurement came from - the sample point, the sensor that collected the data and the instrument that holds the sensor. These three pieces of information - sample point, sensor and instrument - create two many-to-many relationships in the database. 


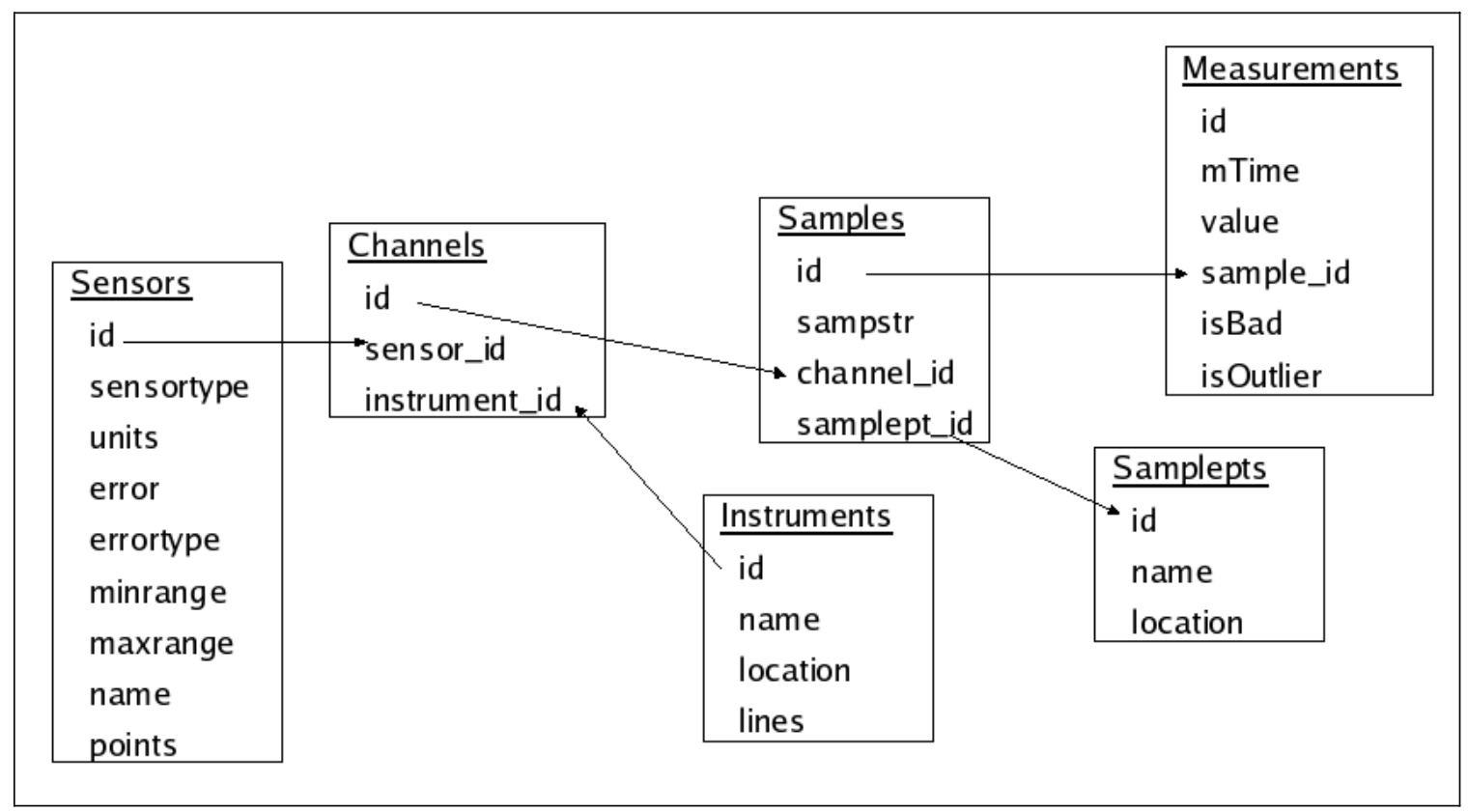

Figure 22. Database Structure

The first many-to-many relationship is the many instruments with each having more than one sensor. The Sensors table (Figure 22) illustrates this relationship and includes all of the sensors used in the project - $\mathrm{pH}$, ORP, Temperature etc along with relevant data about each sensor. This data includes error, accuracy, minimum and maximum range. The Instruments table contains information about the instruments used in the project - the four temperature modules and the chemistry instrument. These two tables are linked by the Channel table. For instance, the YSI chemistry instrument and a 6136 Turbidity probe are linked in the Channels table.

Pumping samples to the chemistry sensor led to the second many-to-many relationship. If thermocouples were the only sensor type used, this second many-to-many relationship would not exist because each thermocouple can only measure the temperature at one point. However, the chemistry instrument has a 
total of six channels that can measure any one of the four sample points, so another table was needed to join the many sample points to the many channels. The sample points are stored in the Samplepts table. This table simply lists the names of the sample points. The Samplepts table and the Channels table are joined by the Samples table. Each record in the Samples table is the unique identifier that allows a single measurement to be traced back to a single instrument, sensor and sample point. The sampstr field in the database is the same string that is at the end of each line in the datafiles created by the control software.

The Measurements table stores the actual data collected by the control system. Each record in the Measurements table contains a timestamp, the value of the measurement, a boolean value showing whether the measurement has been identified as an outlier and an integer value linking the measurement back to a single sample in the Samples table.

\section{User data}

Currently, user data such as email address are accessed only to determine user permissions on the web site. However in the future it will be possible to send out reports to individuals based on entries in the user table.

\subsubsection{Data Handling}

Data handling includes plotting, data parsing in order to upload data files created by the control software to the database, smoothing and methods to deal with outliers, missing data and/or bad data that will occur. Some of these functions, like the plotting, are completed with software outside of the actual web page, while others, like the identification of missing data, are accomplished by code 
directly associated with the web site.

\section{Plotting}

Without some way to view the data, the website loses much of its possible functionality and overall value. The ability to see the plot of the data over time is important especially to get an idea of how a treatment system is operating at a given point and time. The software package chosen to do the plotting is called Gnuplot. It is a command line driven data and function plotting utility for Linux, Windows and many other platforms. Octave, an open source MATLAB clone, uses Gnuplot for its plotting functionality. Gnuplot was chosen because of the large feature set and because a Ruby gem existed to easily allow the website to communicate with Gnuplot. 
When plotting data, the first page a user sees contains a series of checkboxes arranged according to sample location and sensor type. An image of this page is shown in Figure 23.

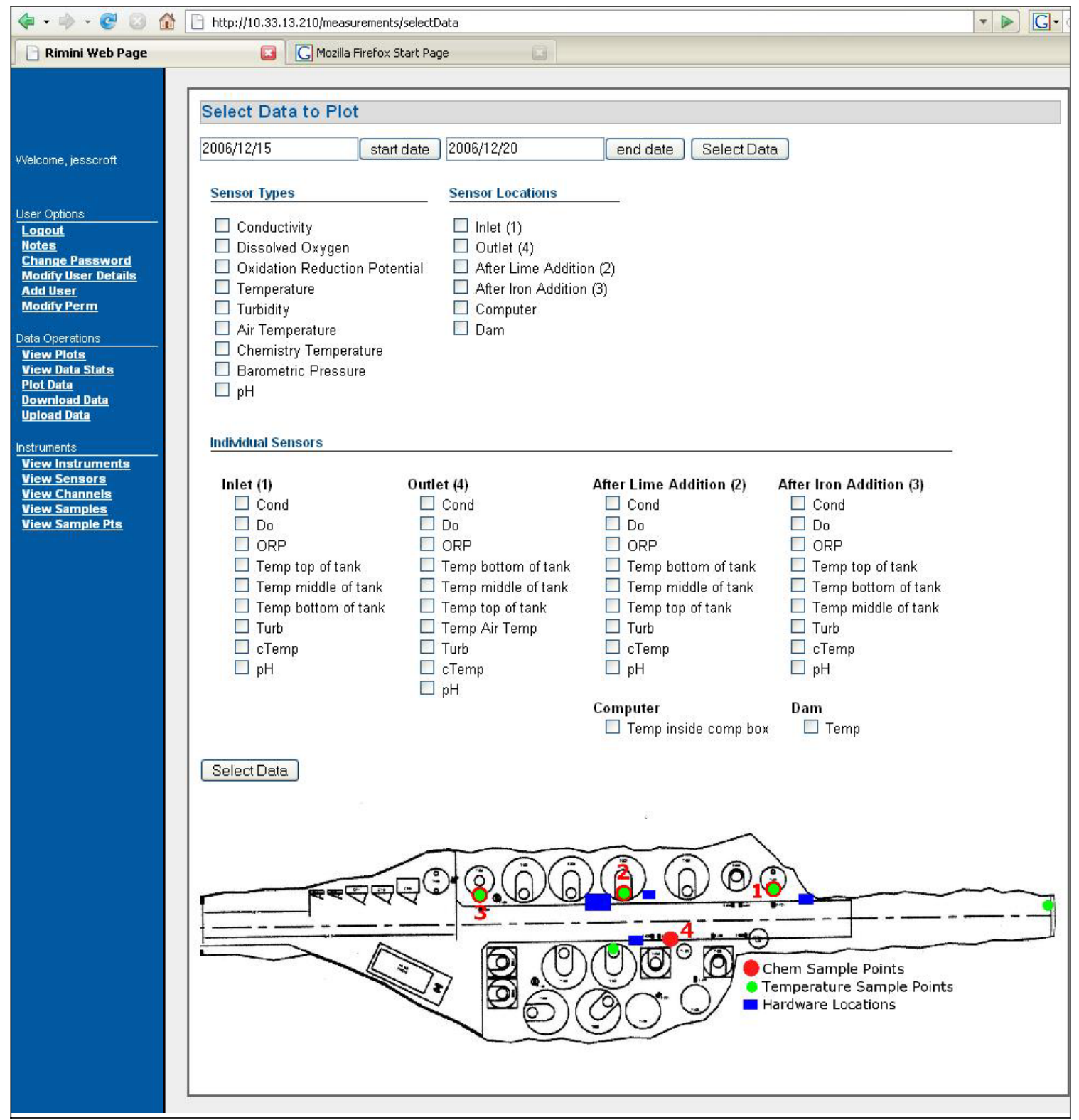

Figure 23. Web page for selecting data to plot. 
After a set of data is selected according to date range, sensor and/or sample point the data set is sent to Gnuplot, which returns a preliminary plot of the data according to sensor, instrument and sample point categories already stored in the database. Data on the plot is organized by sensor. This plot can then be modified using a set of options on the plot page. Available options include plot wide changes such as over all plot size (in pixels), title, axis labels, horizontal and vertical grid lines, location of the key and the range of the x-axis. Two independent $y$-axis, one on either side of the graph, can also be configured for each sensor from this interface with various options for color, point type, line type and labels.

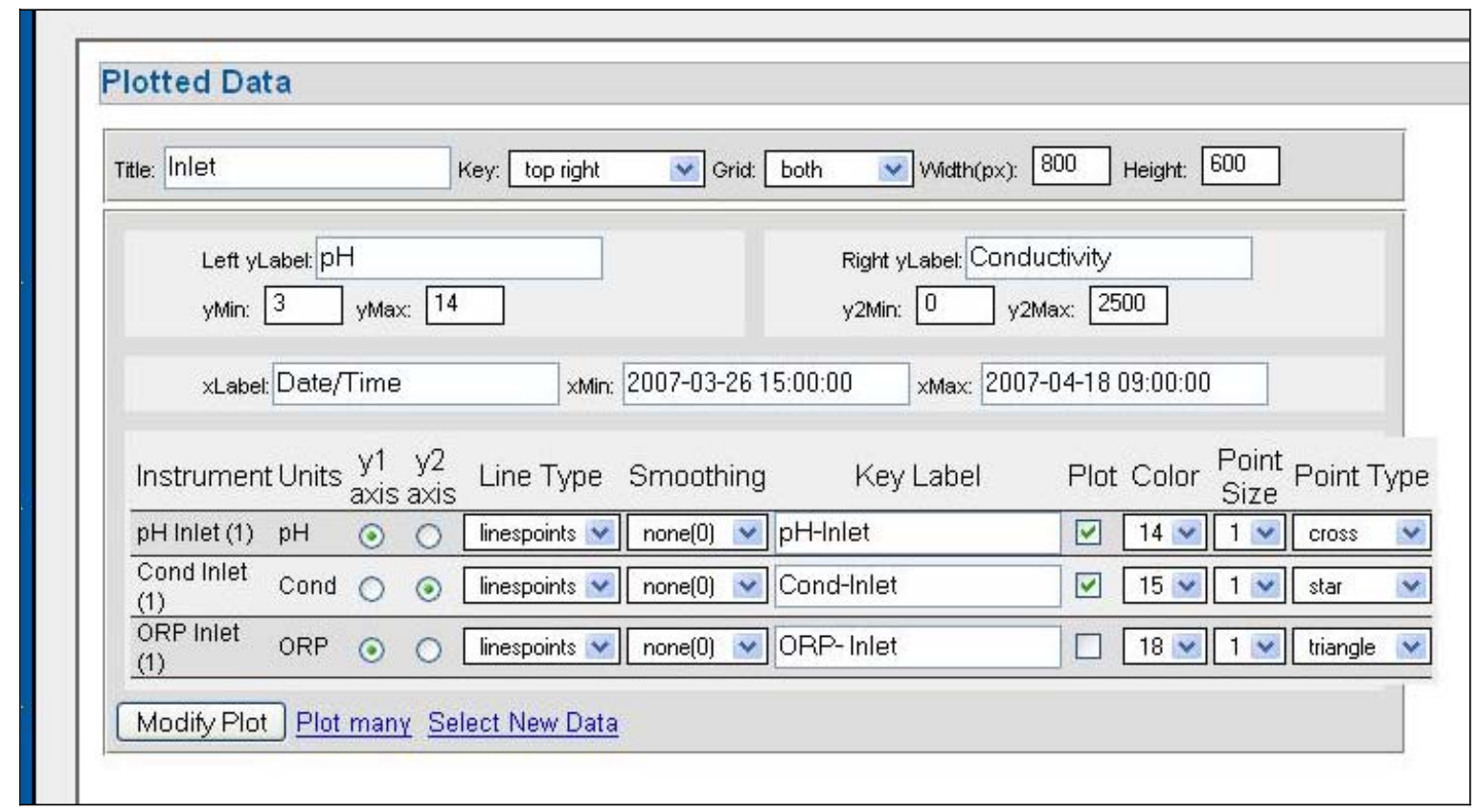

Figure 24. Plotting interface.

By default, all of the selected data are put in one plot, but another type of graph where each sensor has its own set of axis is available with many of the same options. This type of graph makes it possible to view three or more types of data at the same time. For example, the second type of plot could be used to 
compare the $\mathrm{pH}$, conductivity and ORP data from one sample point. This would be difficult if only two scales were available.

Error inherent with each sensor is stored in a field in the Sensor table. Each type of sensor has its own error value. The web page can handle two types of errors: absolute or percentage. For instance, the $\mathrm{pH}$ has an absolute error of \pm 0.2 . The conductivity sensor has an error of $5 \%$ of the value of the measurement. These errors are included as error bars in the plots and can be turned on or off by a user.

The data files created by the control system are uploaded into the database automatically from a remote FTP server or manually using a page on the website to upload a single data file. A Ruby script on the computer hosting the web site can be programmed to check the FTP server at regular intervals or the command to check the FTP server for new data can be initialized from the website. The upload routine involves parsing the data files for invalid records (those where the readings have been corrupted and include characters that are not numbers), checking to make sure the sample string is in the database, matching up the sample string in the data file with a sample, and then entering the records into the measurements table of the database.

Smoothing is an option available in the plot options. The smoothing routine uses a Hann window [5]. Three smoothing levels are pre-selectable in the plot interface -7 point, 13 point and 25 point. Outliers can either be included or excluded from the routine. Currently the smoothing routine does not take into account changes in the sample rate - it only looks for large gaps of missing data. 


\section{Missing data, bad data and outliers}

Bad data, caused by malfunctioning sensors, is not currently detectable by the web site or during upload. However the interactive nature of the project's web page allows the locations of bad data to be flagged. Bad data can be identified in the data stream and then selected either by individual points or by a range of dates. These records are not erased from the database, but are marked by a boolean value in the measurements table. Bad data records can be specified individually or by a range of dates.

Missing data is automatically identified when data is uploaded to the web page. Any large gaps between measurements, as specified by the user in the samples table, are automatically entered into a missing data table. This missing data table is consulted by the plotting software both to determine when to break the plot line and for the smoothing routine. Outliers, like missing data, will be detected by the web site during upload.

The Missing data and Outlier detection routines are not hard coded into the web page programming. They exist independently of the web page as Ruby scripts, This is for two reasons: 1) so they can easily changed if the routines are deemed inadequate and 2) speed. It would be possible to have many different outlier detection routines available or have different routines available for the various types of measurements.

The interface to the control software is the simple upload and download of text files to an FTP server. The control software on the computer at the monitoring site reads the scheduling file to determine when to check the FTP server for new 
script files. This allows for near real-time interaction with the control software without the added complexity of dedicated software on the control system computer to handle the communications. The FTP server can be accessed through the web page or using FTP software.

\section{User Permissions}

Permissions to the various pages on the web site are set in the database. This allows some people to access the administrative functions of the web site and allows others to only access the plotting or data download portions without any ability to modify the sensor or instrument data. For users with no permissions or login, the only page available is a short explanation of the project and contact information to obtain access.

There are three levels of access built into the web page: Administrator, PlotData and GetData. Administrator, the level with the highest level of permissions, has the ability to add new instruments, sensors, sample points and channels to the database. Also under administrator access are the data upload page and the ability to create or delete user accounts. PlotData and GetData permissions levels can change their own user details such as email address as well as view the instrument data stored in the database. The difference between PlotData and GetData is only in the ability to download data in a comma separated values format. 


\section{Analysis of Results at Rimini}

\subsection{Overview}

The monitoring system was installed in the Susie Mine December 13-14, 2006. It ran for approximately one month before MSE-TA turned on their treatment

system January $15^{\text {th }}, 2007$. MSE-TA's treatment system ran until January $26^{\text {th }}$ 2007 when their budget ran out. While MSE-TA's system was operational, water from the four sample points was analyzed. After MSE-TA shut their system down, the monitoring system sampled only the overflow from the dam.

The control software and the communications system presented the most problems. Although there is phone service to the mine, the phone line up to Rimini is a single copper line approximately 10 miles from the distribution point. Since this single line serves all residences in Rimini the signal strength was inadequate to connect to an internet service provider and the FTP server. Due to the lack of communications, errors in the control system were not caught immediately leading to a loss of data. Since then, with modifications made to the control software, reliability has improved.

The data will be analyzed in to parts: while MSE-TA's system was running and after MSE-TA stopped treatment. The data collected during system operation was incomplete due to a control system failure.

\subsection{Performance During Treatment System Operation}

While MSE-TA's system was running, fluid was pulled from the four sample points to take chemistry measurements, and temperature readings were taken at 
12 points in MSE-TA's treatment process. For sample points at the (1) inlet, (2) after the lime addition and (3) after the iron addition, the fluid samples were drawn directly from the holding tanks. See Figure 27 on page 65 . Both the tubing and the thermocouples were attached to PVC pipe which was placed in the three holding tanks (Figure 25). This allowed the thermocouples to be placed at three depths in the tank. To access water for sample point four (outlet), a "T" fitting was placed on an existing pipe.

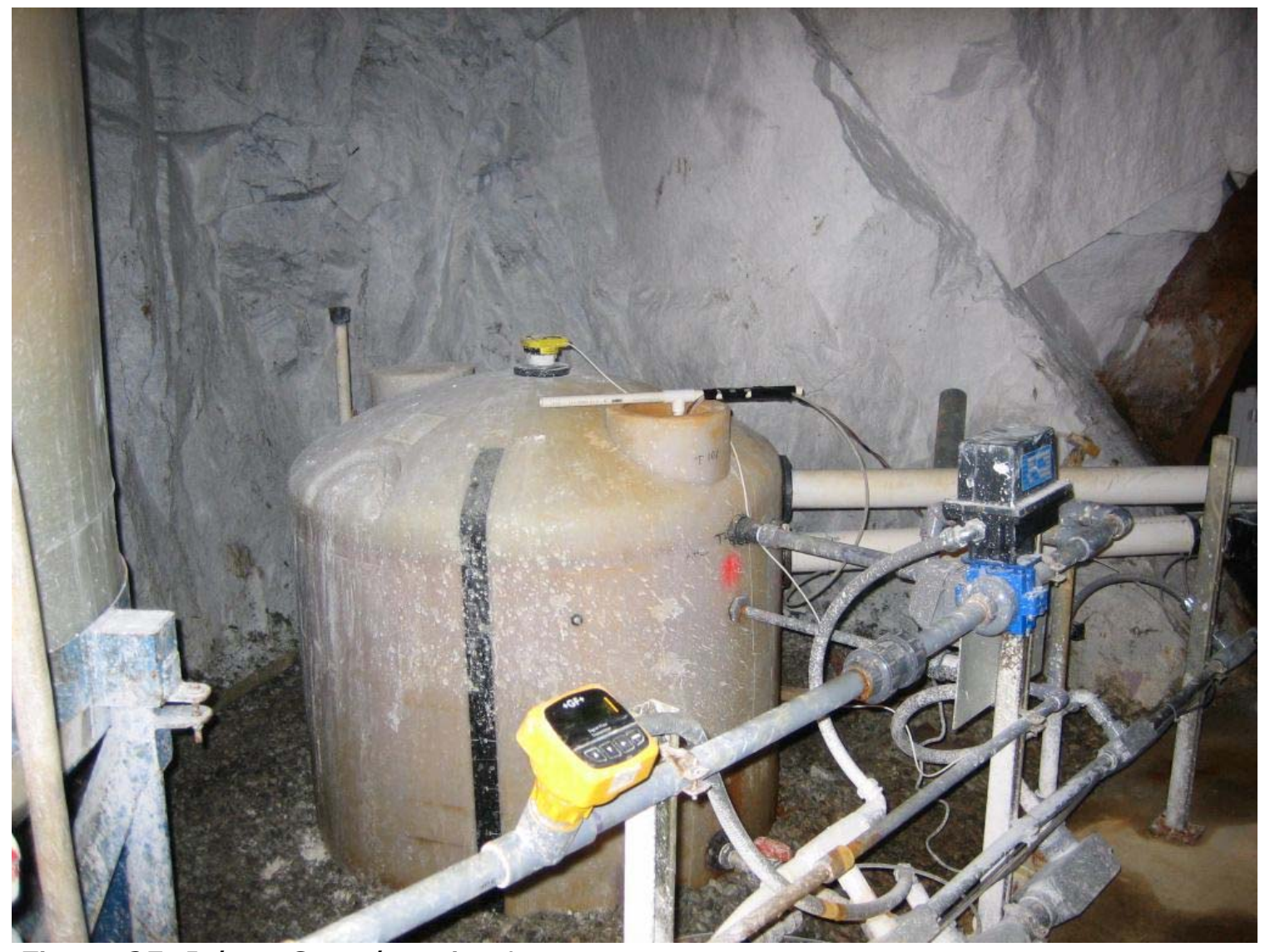

Figure 25. Inlet - Sample point 1.

Three thermocouples, one behind the dam, one inside the computer equipment box, and one for air temperature were also placed in the adit.

After MSE-TA's system was shut down sampling from all four continued until the 
holding tanks were emptied. Overflow from the dam went directly out into Tenmile creek. After the holding tanks were emptied, sample points 2-4 were no longer operational and sample point one (inlet) was moved to the overflow from the dam.

\subsubsection{Sample Rate}

The limiting factor for sample rate is the pump. The pump can move approximately $1 \mathrm{~L}$ of water in 60 seconds (s). If the sample point is $30^{\prime}$ from the chemistry sensor, the tubing between the sample point and the chemistry sensor has a volume of $289 \mathrm{~mL}$. Before the fluid was pumped into the flow cell, the pump was turned on for at least 50 seconds to pump three volumes through the tubing. A normal sample routine for the system goes like this:

- 90 s to flush the line

- 95 s to fill the flow cell with sample water

- 60 s to drain the flow cell

- 95 s to refill the flow cell with sample water

- 30 s to take a reading

- 60 s to drain the flow cell

- $95 \mathrm{~s}$ to flush the flow cell with treated water

- 60 s to drain the flow cell

The approximate time for each sample is 585 seconds or just under 10 minutes. With a more powerful pump the sample time could be cut by a significant amount. The flow cell was flushed with treated water after each sample.

Over time, the amount of water the pump can move has decreased to about $1 / 2 \mathrm{~L}$ in 60s. This is most likely due to iron build up on the inside of the tubing. The timings in the sample routines have been increased to compensate, but 
inspection and cleansing of the sample tubing should be part of a regular maintenance routine.

While MSE-TA's system was operational chemistry measurements were taken every two hours. Because of the time it took to take samples the time difference between the first and last samples was around 30 minutes. Since there was only one point to sample once MSE-TA shut their system off, samples were taken every hour starting at the beginning of February. One chemistry measurement included readings from all six chemistry sensors. Temperature readings were taken from all thermocouples at three minute intervals regardless of the state of MSE-TA's system.

The large volume of water $-3,600$ gallons per stage for just the settling - and the relatively small flow rate - never greater than 4.5 gallons per minute for a minimum fill time of around 13 hours - led me to believe that a chemistry sample every two hours would be a fast enough sample rate to catch most changes in the chemistry of the system. At any one time, the total volume of water in the system was around 10,000 gallons. The temperature data was most likely oversampled at three minutes, but the fast sampling rate was in order to test both the control system and the performance of the website and database.

\subsubsection{Collected Data}

The data collected while MSE-TA's system was operational was incomplete and not very accurate. This was partially due to a control system failure and due to a film that built up on the chemistry sensors. However, the system of pinch valves, tubing and pump worked well. Every two hours samples were taken from the 
four sample points for a total of 625 samples from January $15^{\text {th }}$ to January $22^{\text {nd }}$. Three of the sensors, the turbidity, the temperature and the dissolved oxygen will not be analyzed except to show plots of the data collected by the control software. The turbidity sensor uses light bounced off the black bottom of the flow cell to determine the amount of solid suspended in the sample. However, red clayish silt on the bottom of the flow cell resulting from precipitation from the third and to a lesser degree the second sample points, rendered the turbidity measurements inaccurate. The YSI temperature sensor, although required for conductivity measurements, was not useful since the fluid was pumped at least 15 feet to get the to the flow cell. Build up on the membrane of the dissolved oxygen sensor made the readings completely unreliable.

The parameters that will be analyzed are Conductivity, $\mathrm{pH}$, and Oxidation Reduction Potential (ORP) and temperature data collected from the thermocouples. For reference, a plot of the flow through rate of MSE-TA's system is below in Figure 26. During normal operation the flow rate would have

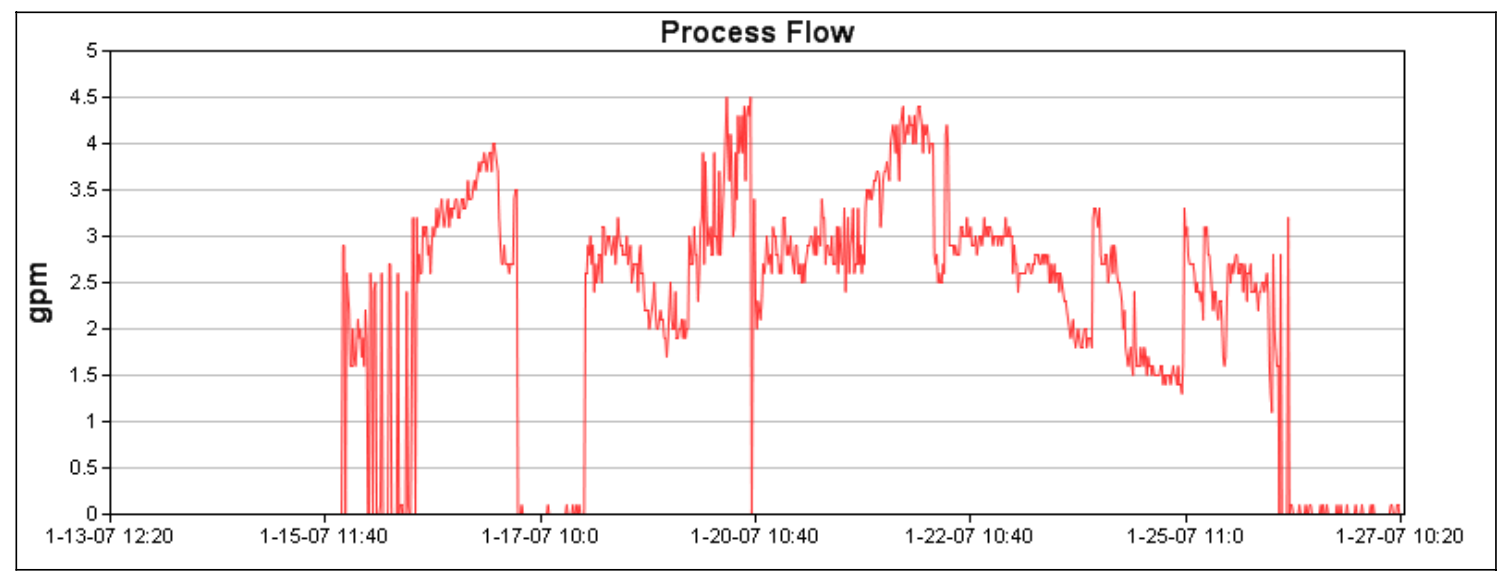

Figure 26. Treatment system flow rate

Figure courtesy of MSE-TA 
been constant, but since MSE had just turned their system on and because they wanted to test the limits of operation, the flow rate is not constant. Figure 5 is duplicated below (as Figure 27) for convenient access. 


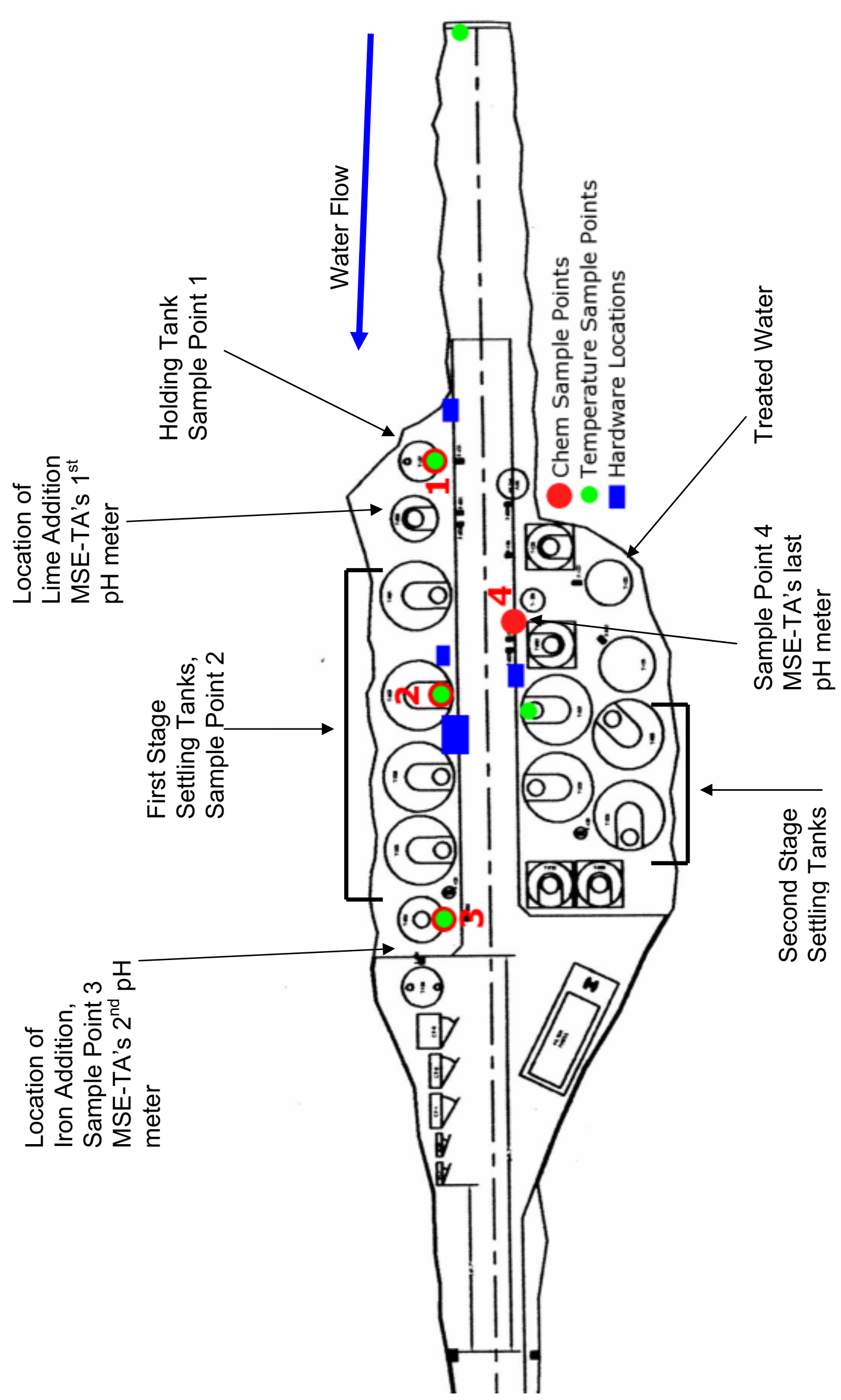

Figure 27. Susie mine adit - hardware and sample point locations. 


\section{Conductivity}

Conductivity is the first parameter to look at since it can show if fluid was present at a particular sample point. Below are plots of the conductivity at all four sample points from January $13^{\text {th }}, 2007$ to January $22^{\text {nd }}, 2007$ (Figure 28). Around 3am on the morning of the $22^{\text {nd }}$, the chemistry sensor stopped responding, and no more chemistry data was collected while MSE-TA's system was operating. 

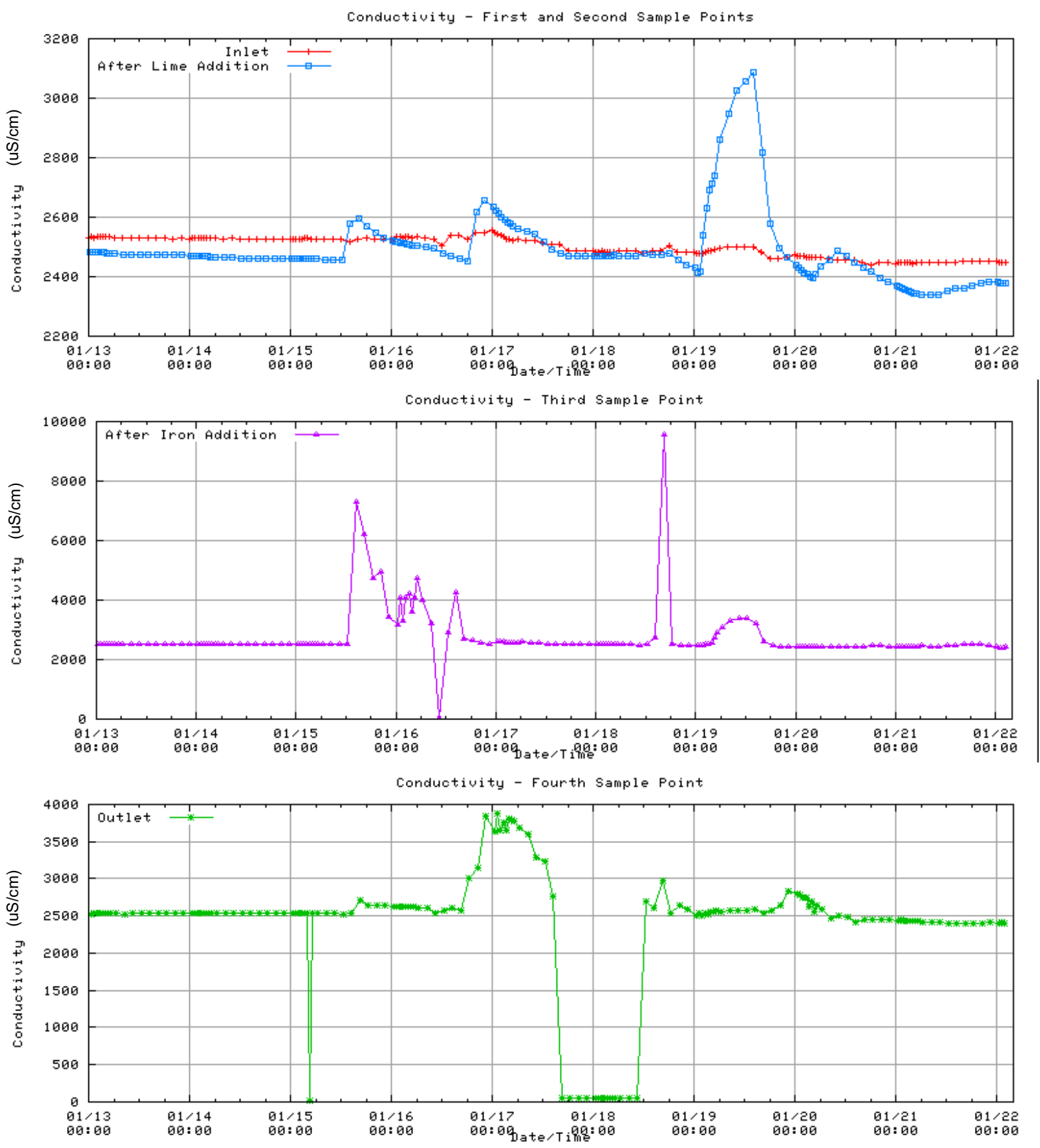

Figure 28. Conductivity at all four sample points

As expected, the conductivity of the inlet was relatively constant. As shown in the first plot, when the lime was added the conductivity increased. The addition of the Iron Hydroxide at the third sample point caused the conductivity to be much higher (notice the scale of the $y$-axis) than at the first and second sample 
points. At one point in the middle plot and for almost a full 24 hours in the last plot, the conductivity drops to zero. This is because no fluid was present at the third and fourth sample points. The large gap in the conductivity of the $4^{\text {th }}$ sample point is also apparent in MSE-TA's flow rate data. At the third point, where the tubing is attached to the PVC pipe, it just means that the water level in the tank was below the sample tubing. At the fourth point it means that no water was in the pipe.

$\mathrm{pH}$

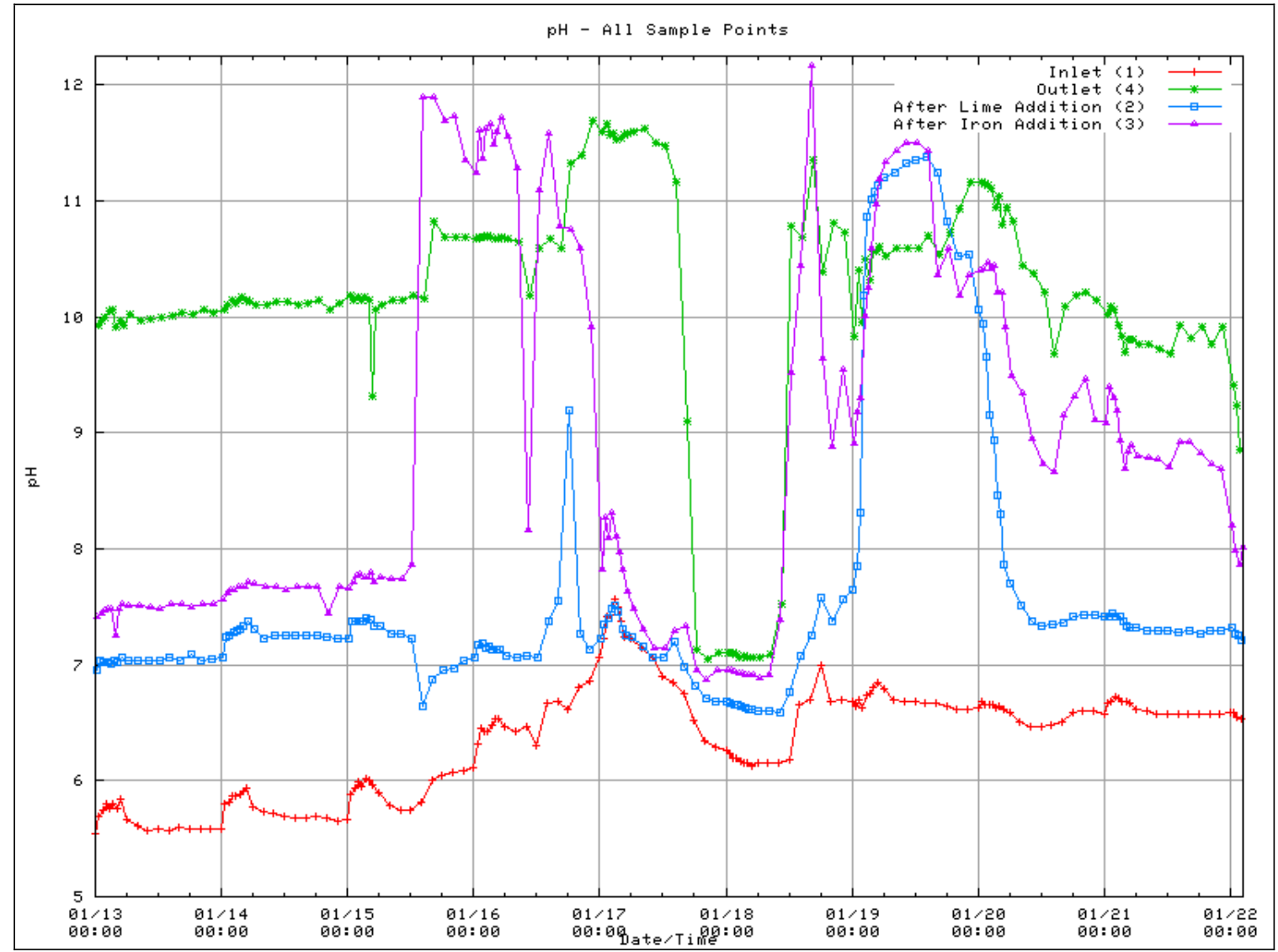

Figure 29. $\mathrm{pH}$ at all four sample points

The $\mathrm{pH}$ was also a parameter of interest because the first step in MSE-TA's treatment process was a $\mathrm{pH}$ adjustment to precipitate contaminants. Notice 
should be given to the conductivity measurements when looking at the other data collected by the chemistry sensor. If the conductivity is close to zero, then the other chemistry parameters taken at the sampling point are most likely invalid as well. For instance, in the middle of the plot of the $\mathrm{pH}$ data, the large dip, especially in the output is due to the fact that no water was in the flow cell when the measurement was taken. This corresponds to a zero flow rate as seen in Figure 26. In this case, the fourth sample point would be affected much faster than the other sampling points because the fourth sample point is sampled from the actual outflow and not from a holding tank like the other three sampling points. Since we were flushing the flow cell with water from the fourth sample point between each sample, and the $\mathrm{pH}$ of the fourth sample point was high, it caused the measurements to be lower and probably closer to their actual values. Some problems with the control system are also apparent in the plot of the $\mathrm{pH}$ in Figure 29. First, the treated water (the water from the outlet) was used to rinse the chemistry sensor off after each measurement. It was assumed that the $\mathrm{pH}$ of the treated water would be closer to 7 . This is most likely the reason why the $\mathrm{pH}$ of the Inlet is not constant and somewhat higher than expected. Second, problems with how the control system read the main script file caused the system to sample almost non-stop for a few hours after midnight every day. This explains the position of the transient upward shift shown in the plot, especially in the data from the Inlet, starting at midnight and lasting until 6am. It is most apparent from $1 / 13 / 2007$ to $1 / 16 / 2007$.

MSE-TA's control system depended upon $\mathrm{pH}$ readings. These readings were 
not taken at the same points as the monitoring system sample points, but are presented in Figures 30, 31 and 32 for comparison. MSE-TA's first pH meter was placed directly after the lime addition, their second $\mathrm{pH}$ meter was placed between the first set of settling tanks and the iron addition, and the third $\mathrm{pH}$ meter measured the treated water. (See Figure 18) When the $\mathrm{pH}$ meters were off, they reported a default value of $\mathrm{pH} 14.25$. Figure 32 is a plot of the data collected by MSE-TA's first pH meter.

MSE-TA's first pH meter has no analogous sample point in the monitoring system. Their $\mathrm{pH}$ meter is directly after the lime addition while the closest monitoring system sample point is in the settling tanks. All totaled the four settling tanks after the lime addition held 3600 gallons of water, so a comparison is impossible to make.

MSE-TA's second $\mathrm{pH}$ meter does have an analogous sample point in the monitoring system. The third sample point was placed in the tank where the iron hydroxide was added and the second $\mathrm{pH}$ meter was on the outflow of that same tank. Many of same features can be seen in both plots (Figure 31 and Figure 29). The large drop in the $\mathrm{pH}$ on January $16^{\text {th }}$ shows up in both plots as well as in the overall decline in $\mathrm{pH}$ in the day following. Overall, however, the $\mathrm{pH}$ recorded by the monitoring system is a whole unit lower than that reported by MSE-TA' $s$ system. This is most likely due to a combination of a one-time calibration error and build-up on the $\mathrm{pH}$ sensor (see Section 3.3.3). If this is the case, the rest of the $\mathrm{pH}$ readings should also be lower overall. 


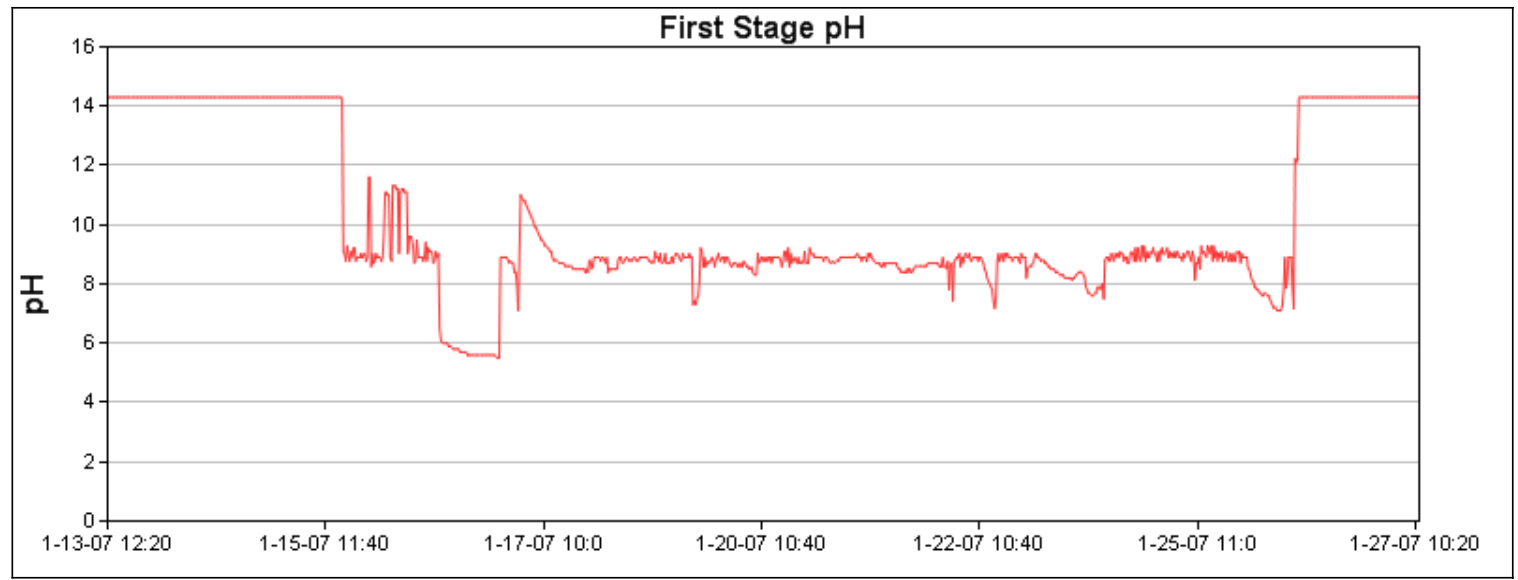

Figure 32. MSE-TA - First Stage $p H$

Figure courtesy of MSE-TA

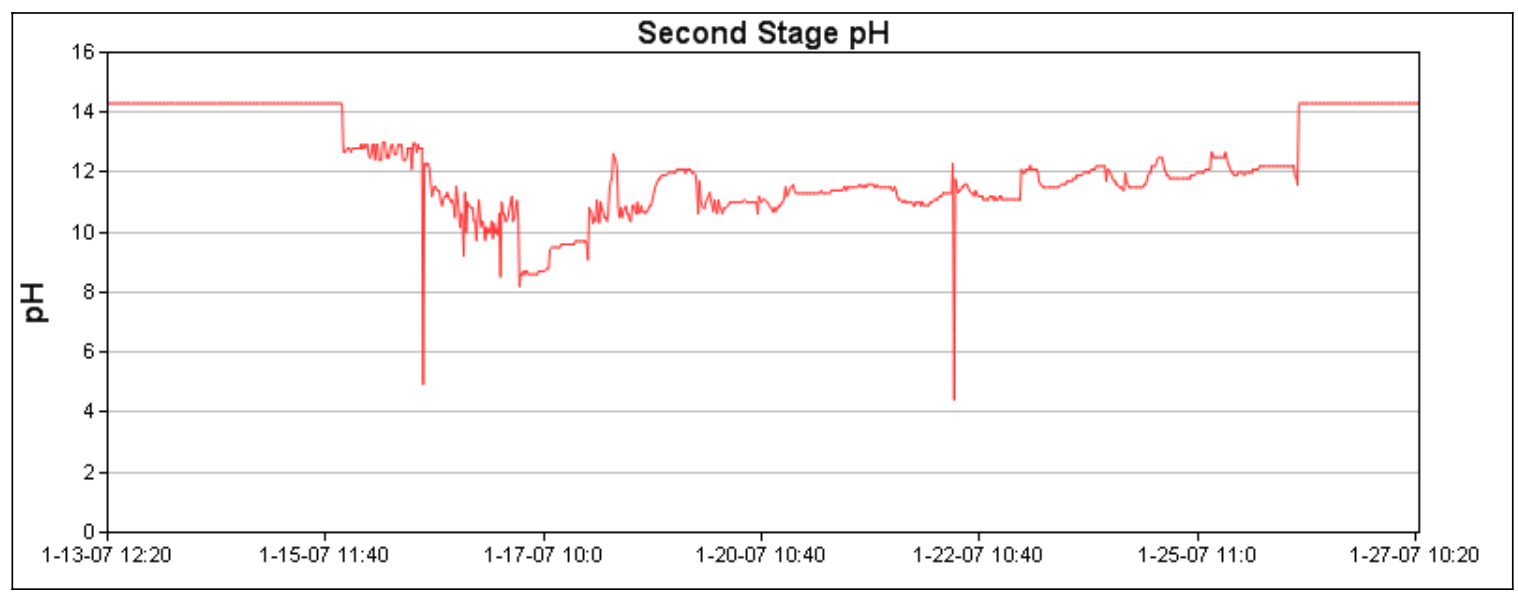

Figure 31. Second Stage $\mathrm{pH}$

Figure courtesy of MSE-TA

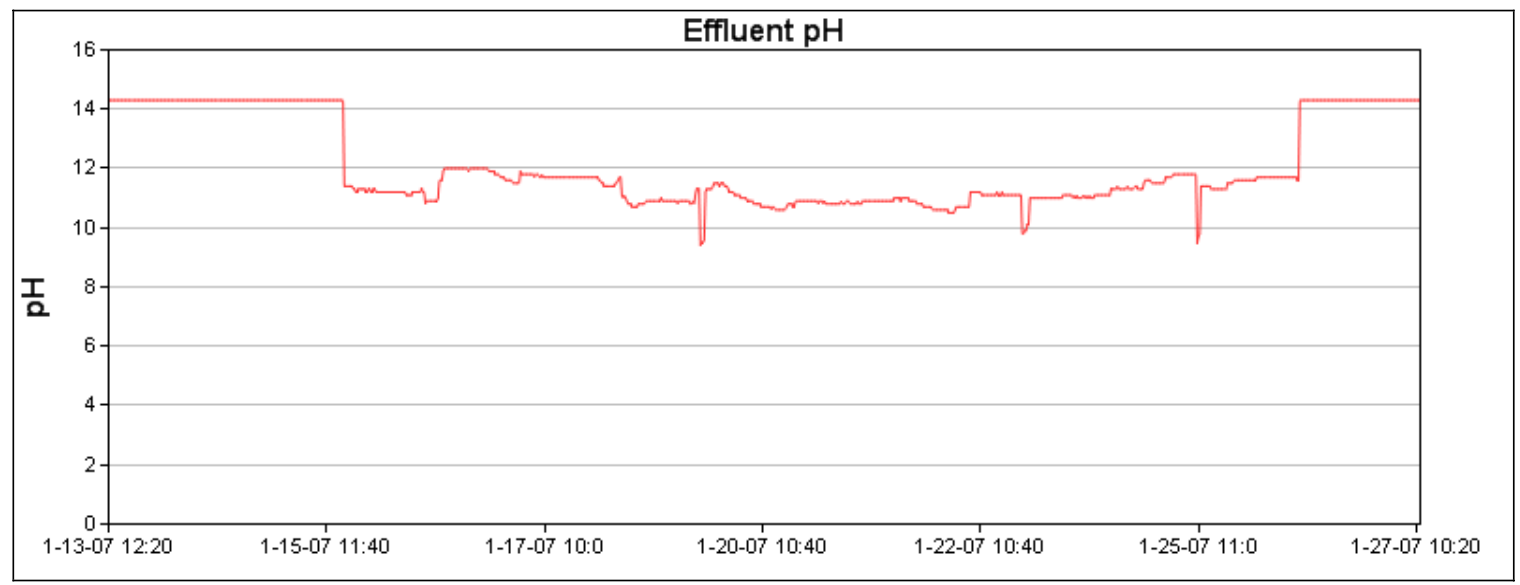

Figure 30. Effluent $p H$

Figure courtesy of MSE-TA 
MSE-TA's effluent $\mathrm{pH}$ meter and the fourth sample point in the monitoring system are also analogous, although the lack of flow on the $17^{\text {th }}$ affected the monitoring system much more than MSE-TA's pH meter (Figure 30). This is because while the monitoring system had to pump a new sample from the sampling point every two hours, MSE-TA's pH meter was always sitting in water. When the flow stopped the $\mathrm{pH}$ meter was still sitting in water, even though there was no water at the monitoring system's sample point. 


\section{ORP}

Oxidation Reduction Potential and $\mathrm{pH}$ are measured by the same sensor on the YSI 6600EDS, so it is not too surprising that the graphs show some of the same features.

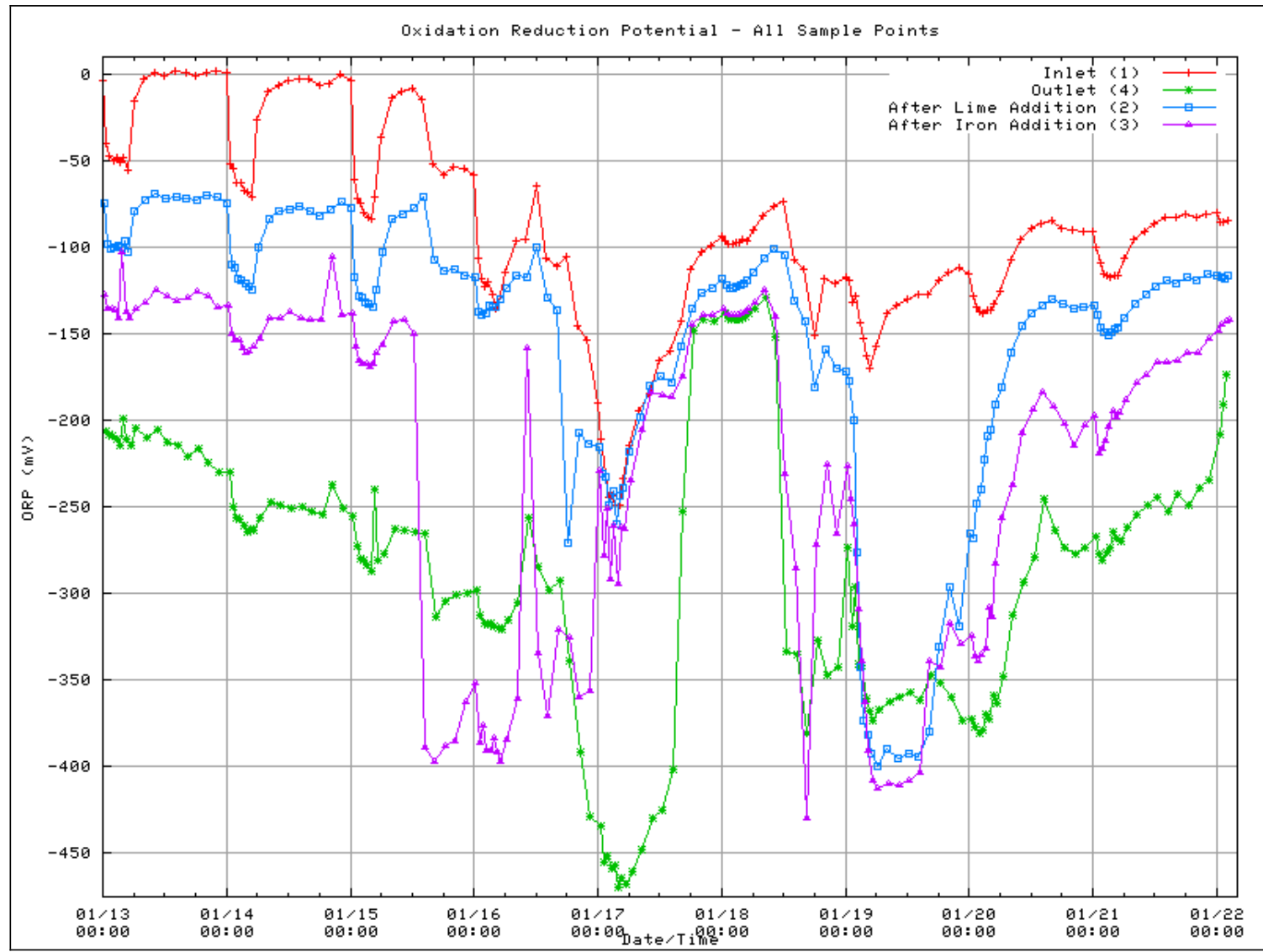

Figure 33. Oxidation Reduction Potential (ORP) at all four sample points

The same discontinuities found in the $\mathrm{pH}$ data from midnight to 6am show up more clearly in the ORP measurements (Figure 33). The few hours during which the treatment system was not operational are also apparent in this plot. A lower ORP indicates that the fluid has less oxidation potential. Since the oxidation of pyrite is the cause of acid mine drainage and the problem the treatment system was designed to remediate, the oxidation potentials seen the above plot make 
sense. Overall, each successive step in the treatment process produces water with a lower oxidation potential.

\section{Temperature}

Temperature data was collected every three minutes for a total of 4,700 points per thermocouple. Each of the four sample points had three thermocouples placed at different depths in the holding tanks, there was one thermocouple placed near the fourth sample point to monitor air temperature, one thermocouple placed behind the dam, and the last thermocouple inside the equipment box holding the computer. Interference from the pinch valves caused the temperature readings to artificially rise when chemistry samples were being taken, and although the amplitude of the interference is not much larger than the accuracy of the thermocouple $( \pm 0.3 \mathrm{C})$, the problem is obvious when looking at the plots. 
The pinch valve interference is especially obvious in the data collected from the top thermocouple in the inlet holding tank (Figure 34), although when looked at closely it is also present in the other two thermocouples. Water from the dam flows through an opening at the top of the dam's wall, through a pipe and then into the top of the inlet holding tank. This is why the top thermocouple is at a consistently lower temperature than the other two.

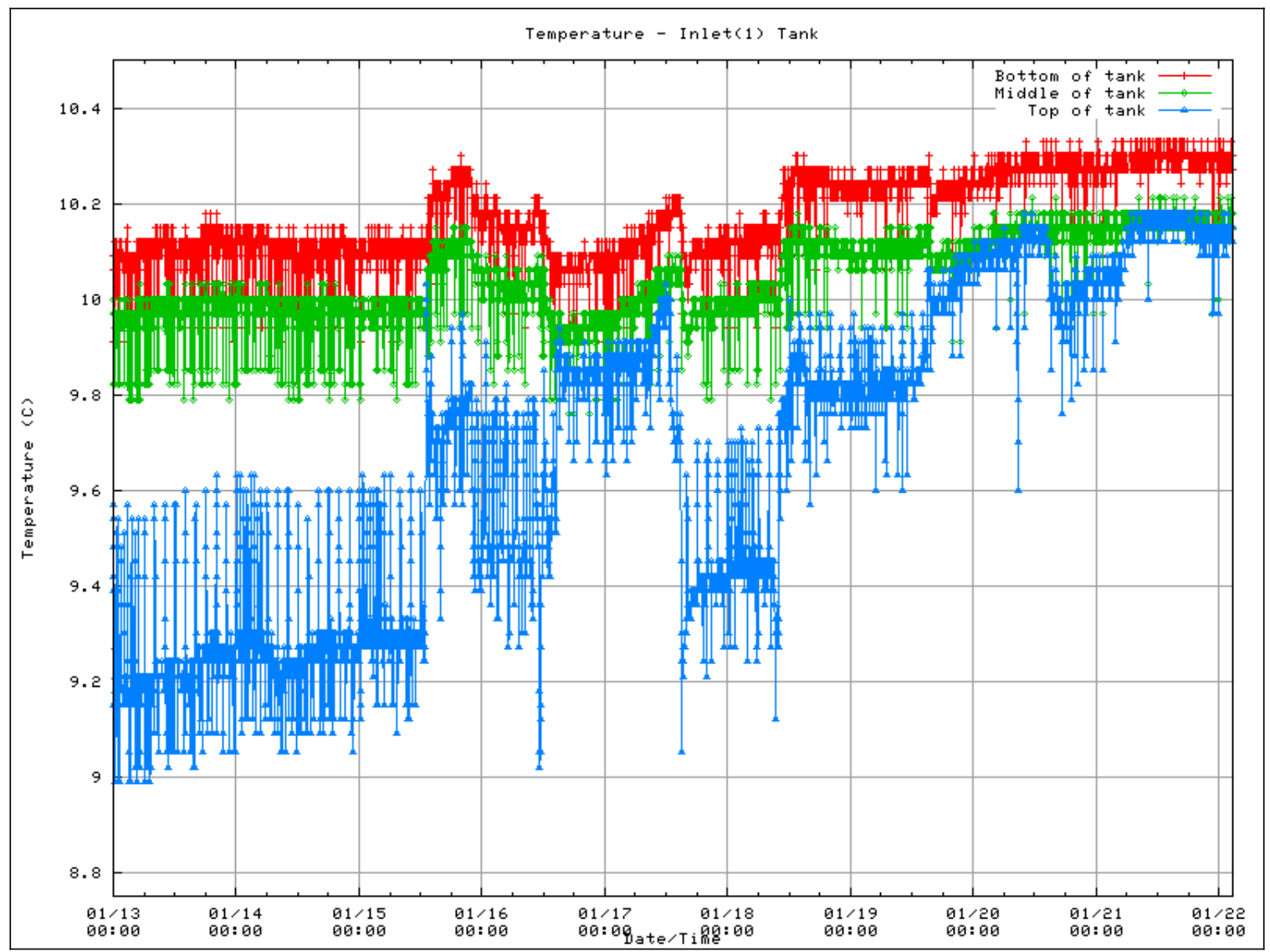

Figure 34. Temperature at Inlet 
The data collected from the thermocouples at the second sample point (after the iron addition) also shows interference from the pinch valves (Figure 35). The overall trends are apparent in the plot, such as the large spike in temperature on the morning of Jan $18^{\text {th }}$ and the rise in temperature when MSE-TA's system was turned on around noon on Jan $15^{\text {th }}$. The interference can be seen in small temperature variations that happen regularly every two hours.

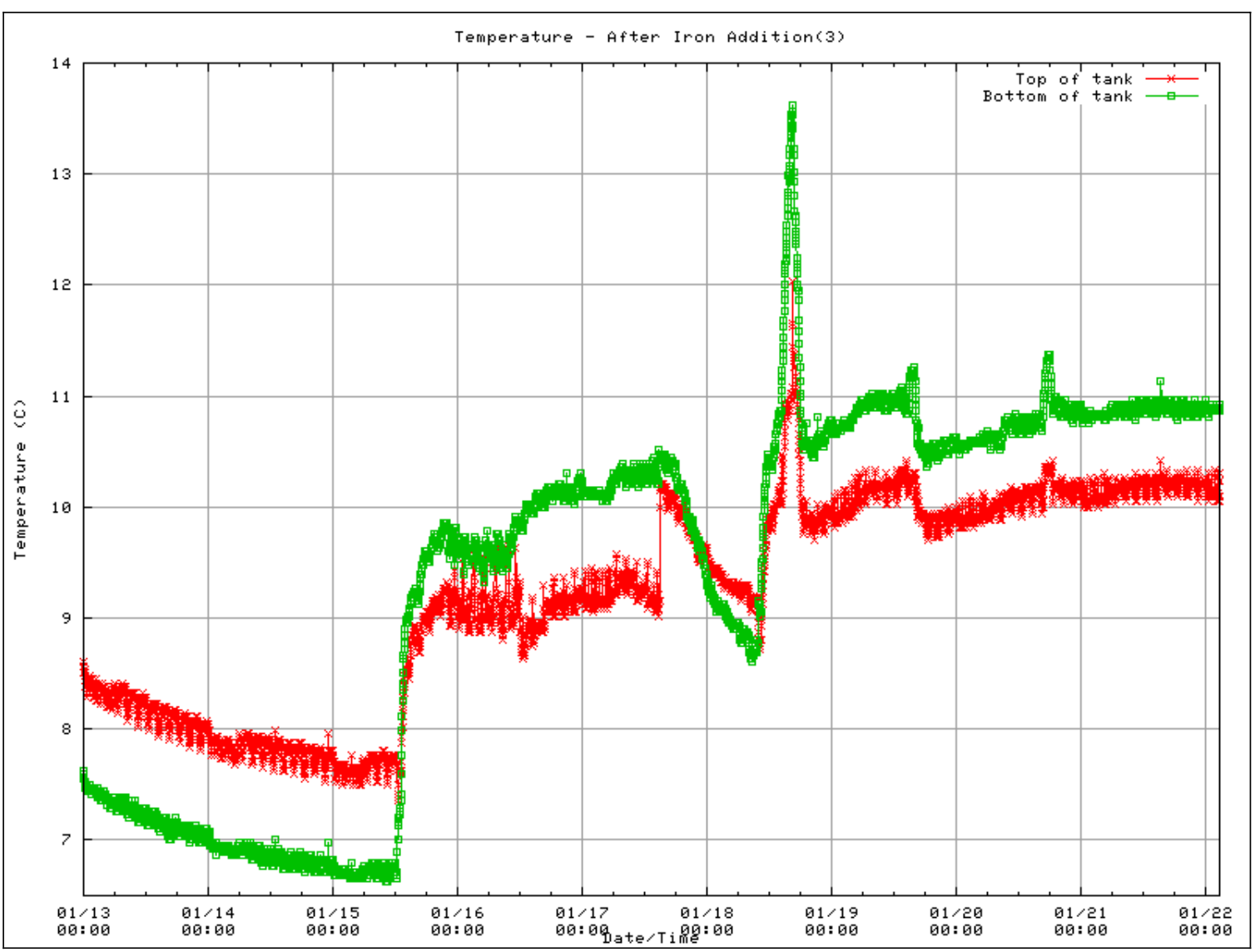

Figure 35. Temperature after iron addition 
A negative large spike in temperature data collected from thermocouples immersed in one of the second stage settling tanks is seen when MSE-TA's system starts operating (Figure 36).

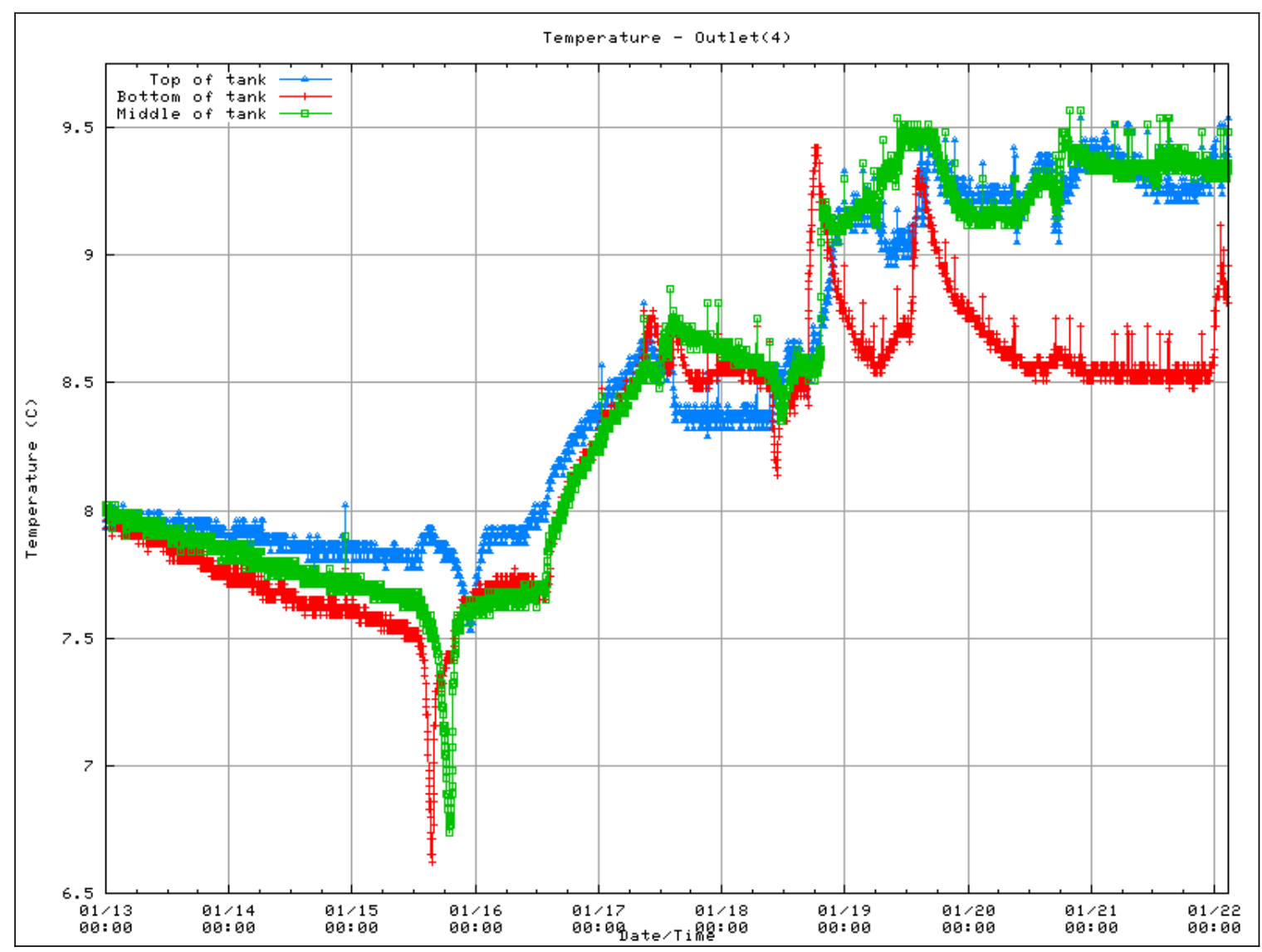

Figure 36. Temperature at outlet 


\subsection{Hardware Analysis}

\section{Tubing Wear}

Tubing wear was a problem that was anticipated in the system. However it did not prove to be as problematic as anticipated. The tubing in the pump was replaced when the system was installed and ran for seven weeks before failing by losing rebound. A plot of the conductivity values around the time the tubing wore out is below. As the tubing failed, the water level in the flow cell was lower after every sampling and eventually the conductivity sensor and, similarly the other chemistry sensors were unable to take an accurate reading. According to the plot (Figure 37), the water level in the flow cell was not high enough to take an accurate conductivity measurement starting around 2:00pm on Feb $21^{\mathrm{st}}$. 


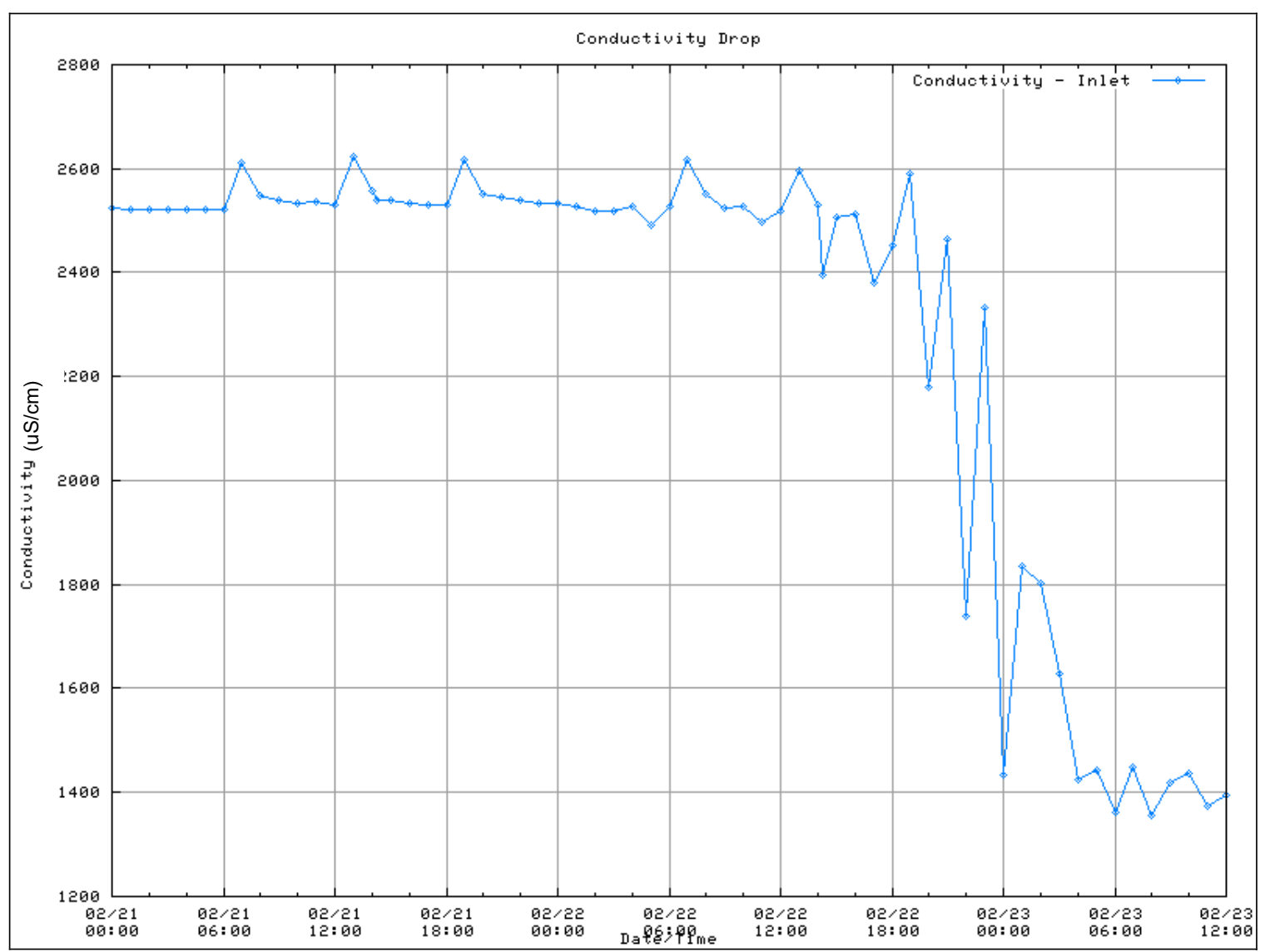

Figure 37. Recorded conductivity at inlet during pump tubing failure

Modifications to the control system can help mitigate this problem by checking the conductivity before taking a measurement and then running the pump until the conductivity reaches a threshold value. This will not prevent the tubing from wearing out, but will work as a temporary fix until someone can travel to the site to replace the tubing. 


\subsubsection{Pinch Valve Interference}

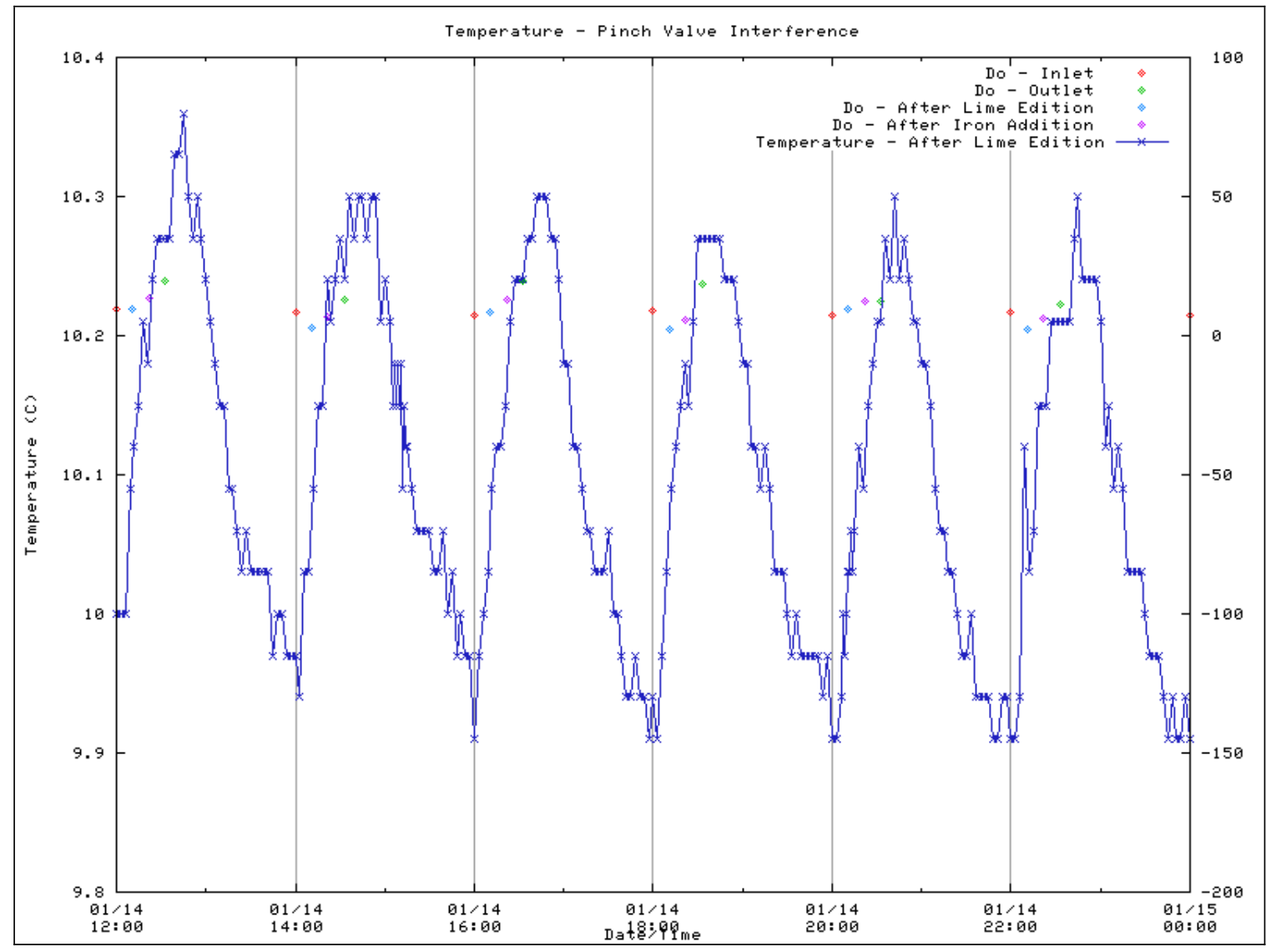

Figure 38. Temperature data showing pinch valve interference

As seen in Figure 38 the temperature data had a sawtooth component with a period of two hours. This is the same period as the chemistry sampling routine occurred. The data were collected from the thermocouple at the bottom of the tank at the second settling point. The dots on the plot serve to indicate when the chemistry samples were taken. As soon as the sampling started (and when the pinch valves and pump turned on), the temperature rises. Although the amplitude is only $0.3 \mathrm{C}$ and the accuracy of the temperature is $\pm 0.3 \mathrm{C}$, the pattern was too repetitive to be caused by random noise. 


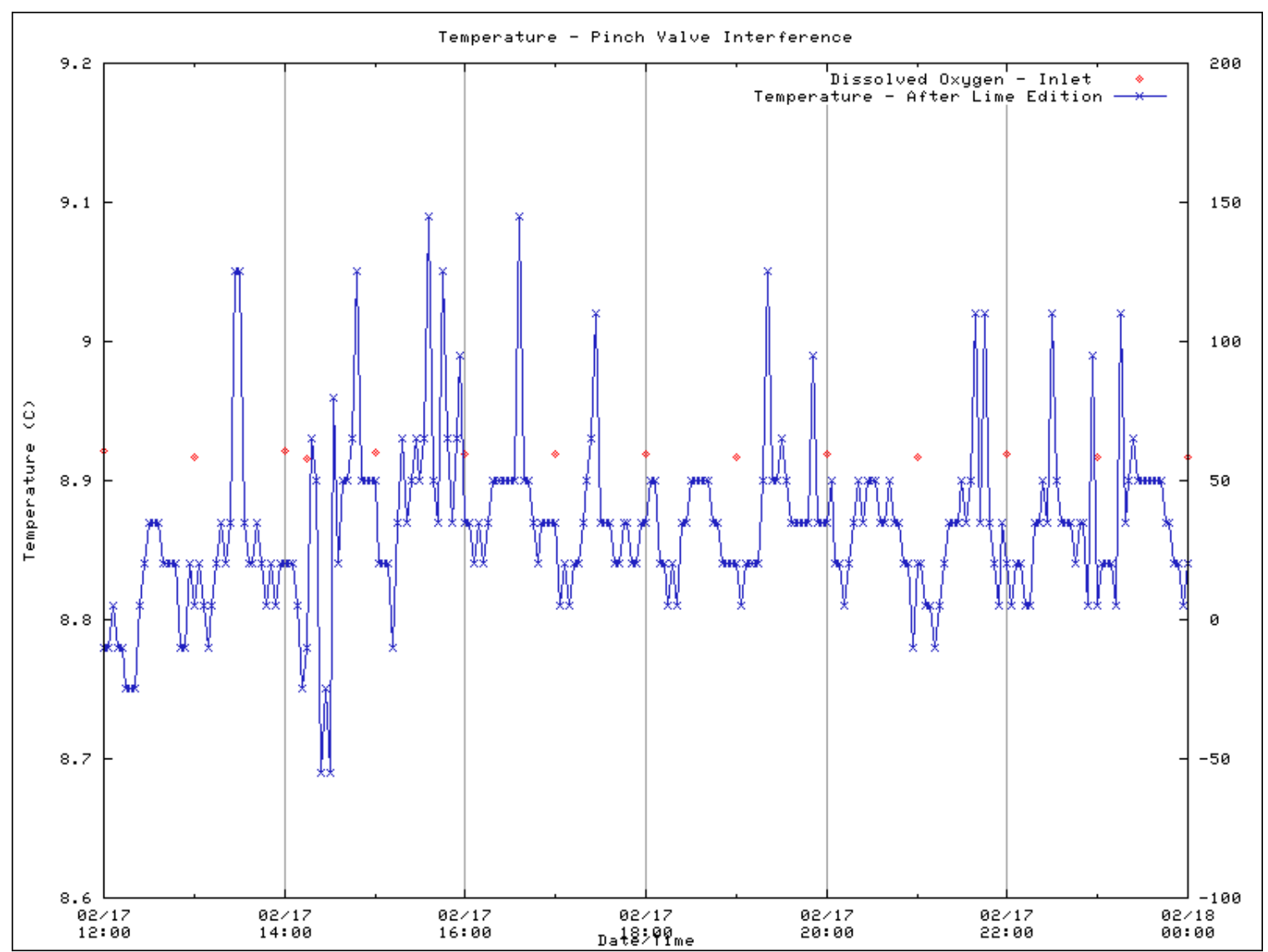

Figure 39. Temperature data after pinch valve interference was fixed

This problem was eventually traced to the pinch valve that allows the flow cell to drain. The 12 pinch valves in the pump box were made by Valcor, but the valve that allows the flow cell to drain was made by a different manufacturer. The ADAMs modules, the relays and the pinch valves were all on channel 1 of the power supply, so when the $13^{\text {th }}$ pinch valve was turned on it caused a voltage drop affecting the temperature readings. Moving the $13^{\text {th }}$ pinch valve to channel 2 of the power supply fixed the problem. A plot of data from the same thermocouple after the problem was fixed is displayed in Figure 39.

\subsubsection{Snubbing on pinch valves}

Every time the pinch valves were turned on or off, EM noise was created. This 
noise was picked up by an oscilloscope on a thermocouple wire $20^{\prime}$ from where the pinch valves are located. Each pinch valve has an inductance, so when a pinch valve is shut off it sends a voltage spike back into the relay. Although a diode was placed across each pinch valve, it didn't mitigate the voltage spike. A resistor in series with the diode would be one way to fix the voltage spike.

\subsubsection{Sensor Build up}

Another problem that was not anticipated, was the level of buildup on the chemistry sensors. Iron in the water formed a hard red film (a mixture of calcium and iron) on the sensors and once MSE-TA's treatment system was initiated, the problem worsened. Mostly this build up came from the second and third sample

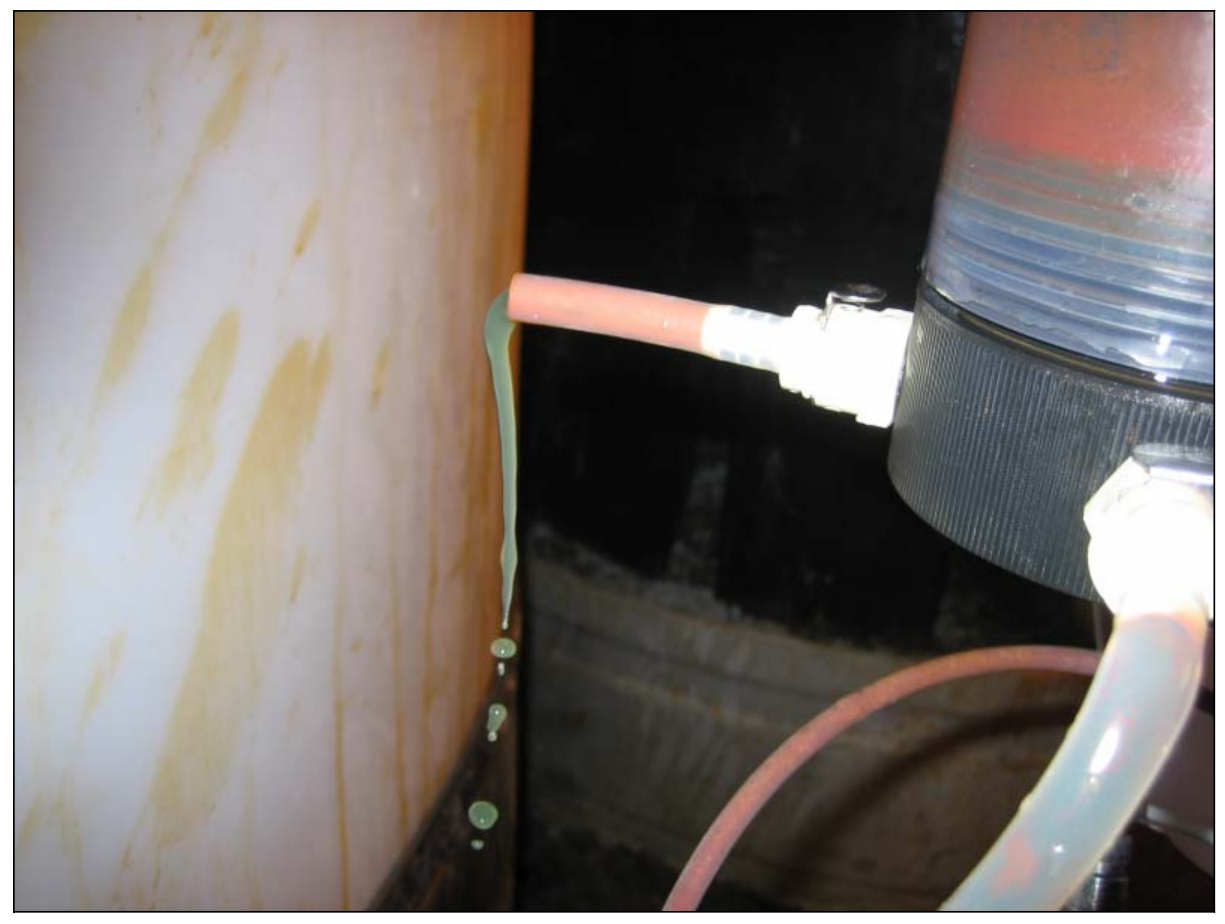

Figure 40. Water from the third step, iron build up on the flow cell points. Figure 40 shows a sample from the third sample point. The water is green with iron ions. When these ions oxidized, a bright red film formed on the sides of the flow cell. In the data this build up is best shown on a plot of the 
dissolved oxygen from when the system was installed December $16^{\text {th }}$ to January $23^{\text {rd }}, 2007$ (Figure 41). Since the dissolved oxygen is measured using a membrane through which oxygen passes it was most susceptible to the build up. Although the system was not taking chemistry readings from Dec 22 to Jan 8 , the sensors were sitting the sample water. The build up prevented oxygen from moving through the membrane and the measured amount of dissolved oxygen went from about $80 \%$ down to $0 \%$.

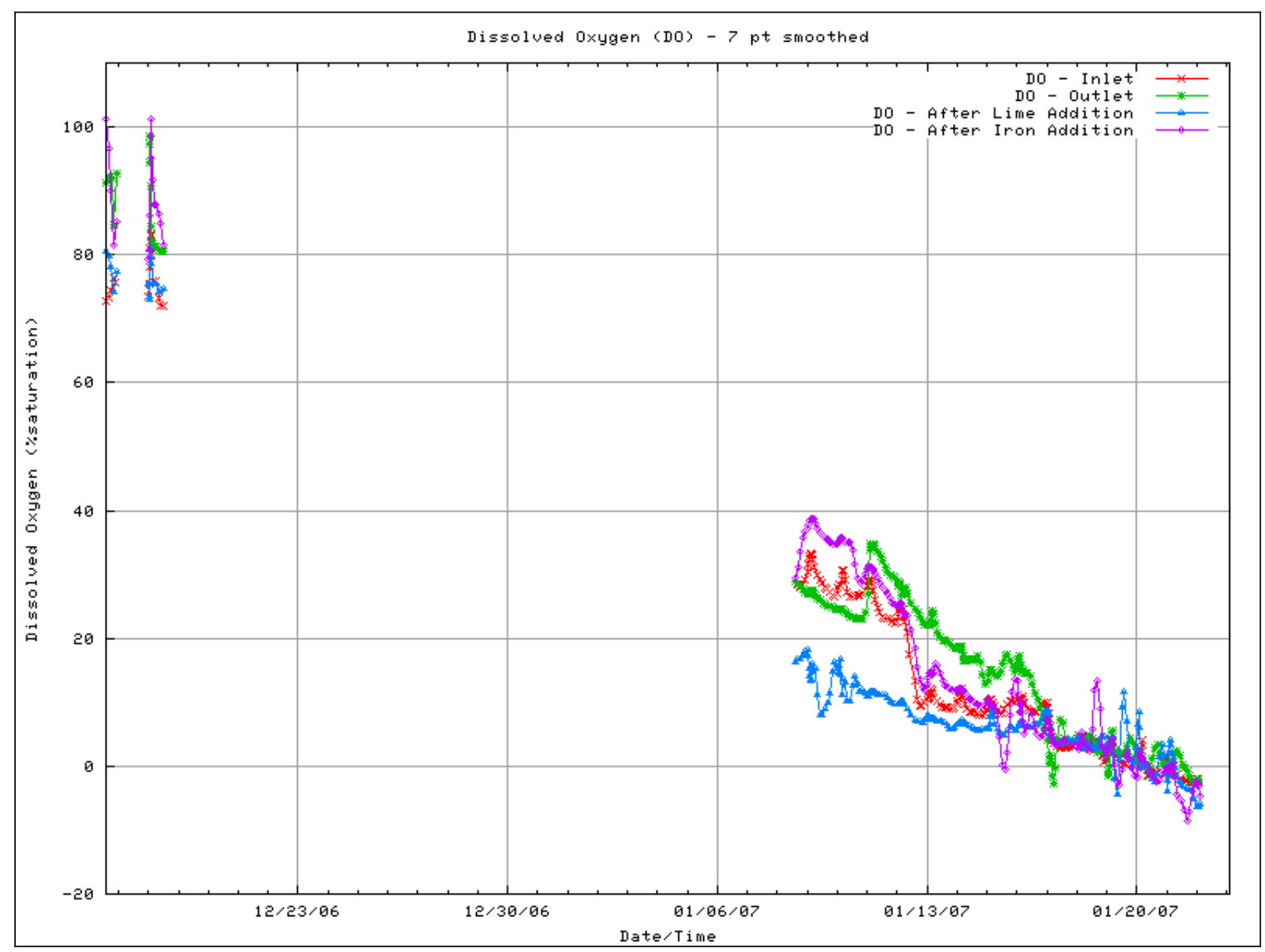

Figure 41. Dissolved Oxygen data showing evidence of sensor buildup

Although the turbidity sensor on the 6600EDS has a brush specifically designed to clean crud off the turbidity sensor and surrounding sensors, it was not designed for use with the flow cell. The overflow tube in the center of the flow 
cell does not allow enough room for the brush.

Two solutions existed. The first was to modify the flow cell so the overflow tube was shortened and plugged, then unscrew the flow cell from the sonde so the flow cell could be suspended below the sonde with the sensors still in the flow cell. This would allow the brush on the turbidity sensor to move freely. However with the possibility of falling rocks in the adit, damage to the chemistry sensor could have resulted.

The second option was to flush the cell out with vinegar after every few samples to dissolved the buildup. The vinegar was stored in one of the sample bottles. Vinegar was pumped into the flow cell, allowed to sit for a few minutes and then pumped back into the sample bottle for re-use. Then the flow cell was filled with water, allowed to sit and emptied. Flushing the flow cell with vinegar caused spikes in the chemistry data, however if the cell is flushed with sample water immediately after the vinegar the spikes are no longer a problem.

\subsection{Control System Performance}

Other than the interference between the pinch valve and the temperature modules, most of the other problems with the ACAM system were directly caused by the chemistry sensor losing communication with the control software - either due to a failure of the control system to use the chemistry sensor's built in menu system, or due to human error. Many of these errors could be avoided by a better user interface and more advanced system of communication with the chemistry sensor. Table 4 is a summary of when the errors occurred, how much data was lost, the cause of the error and the solution. 
Table 4. Control software failures - dates, causes and solutions

\begin{tabular}{|c|c|c|c|c|}
\hline Sensor & $\begin{array}{l}\text { Start } \\
\text { Date }\end{array}$ & End Date & Cause & Solution \\
\hline $\begin{array}{l}\text { Chemistry, } \\
\text { Temperature }\end{array}$ & \multicolumn{2}{|c|}{ 12/18/2006 and12/31/2006 } & $\begin{array}{l}\text { Control System Error - } \\
\text { Day } 14 \text { is actually Day } \\
0\end{array}$ & $\begin{array}{l}\text { Modified control } \\
\text { software }\end{array}$ \\
\hline $\begin{array}{l}\text { Chemistry, } \\
\text { Temperature }\end{array}$ & $12 / 20 / 2006$ & $12 / 21 / 2006$ & $\begin{array}{l}\text { Time reset incorrectly. } \\
\text { User Error. }\end{array}$ & \\
\hline Chemistry, & $12 / 21 / 2006$ & 1/08/2007 & $\begin{array}{l}\text { Chem sensor } \\
\text { accidentally } \\
\text { unplugged. } \\
\text { User Error }\end{array}$ & $\begin{array}{l}\text { Screw the serial cord } \\
\text { of the chem sensor } \\
\text { into the computer. }\end{array}$ \\
\hline $\begin{array}{l}\text { Chemistry, } \\
\text { Temperature }\end{array}$ & $1 / 21 / 2007$ & $2 / 03 / 07$ & $\begin{array}{l}\text { Chem Sensor Not } \\
\text { Responding }\end{array}$ & $\begin{array}{l}\text { Modified Control } \\
\text { Software }\end{array}$ \\
\hline $\begin{array}{l}\text { Chemistry } \\
\text { (bad data) }\end{array}$ & $2 / 03 / 07$ & $2 / 17 / 07$ & Control System Error & $\begin{array}{l}\text { Modified Control } \\
\text { Software. }\end{array}$ \\
\hline
\end{tabular}

Improvements to the control software were made on-site at the beginning of February 2007, and further improvements were made at the end of March 2007 when the chemistry sensor was brought back to the laboratory in Butte, Montana for a week. These improvements included the addition of functionality to the control software for resetting the computer, the detection of multiple scheduled samples in the queue (indicating communication problems with the chemistry sensor), the ability of the control software to reset the connection to the chemistry sensor.

\subsection{Web Site Performance}

As with any website, there is always room for improvement, but overall the website worked well. The major problem, and most noticeable problem, is the time required to plot large amounts of data. One possible solution is to cache the data that is most often plotted. However, given the large amounts of data 
that must be handled, this is not an optimal solution. The temperature readings were taken every three minutes, so for just one sample point for one week there are 3,360 data points. If all of the temperature channels are plotted for just one week a total of 43,000 records have to be pulled out of the database and then fed line by line into Gnuplot. It may be better to automate the creation of the most useful plots every week and display them on the web page.

\subsection{Performance After the Treatment System Shut Down}

After MSE's treatment system was shut down, all of the tanks except the dam overflow tank were emptied and the PVC pipe to which the thermocouples and sample tubing was removed from the tanks. Due to drainage problems over flow from the dam ran directly into the creek rather than going into the holding tank first. The monitoring system continued to collect chemistry data from the first sample point, but rather than sampling from the overflow tank fluid was pulled from the pool of water behind the black curtain. Although all of the thermocouples previously inside the tanks were recording adit air temperature, the data was collected and stored in the database in order to see how well the database and web site could handle large amounts of data. After MSE's treatment system was shut down all of the temperature data was collected every three minutes and chemistry data from the first sample point was collected every hour. 


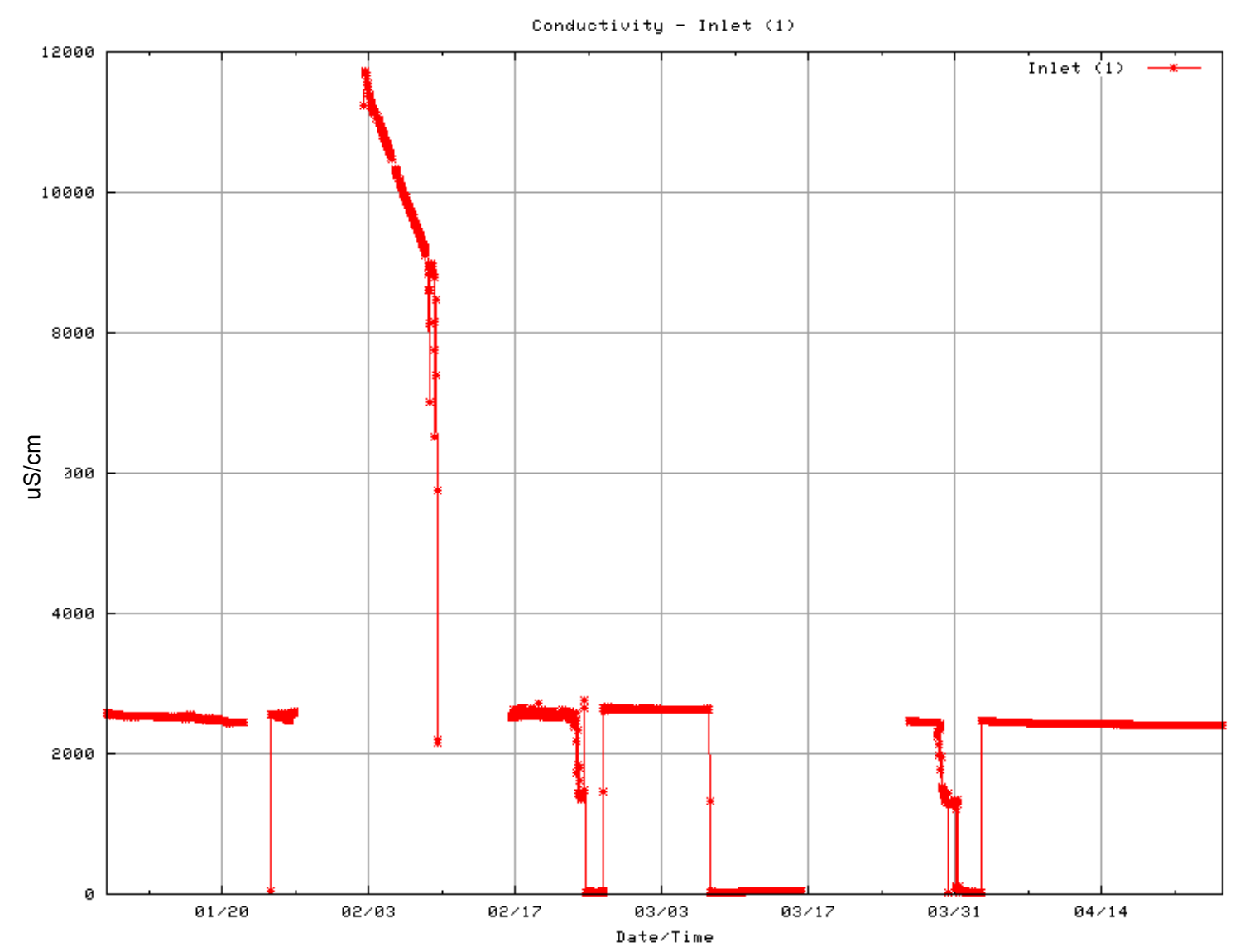

Figure 42. Conductivity at first sample point from January 2007 through April 2007

As can be seen in a plot of the conductivity data collected from mid-January through April of 2007 (Figure 42), there were a some periods of time where the system failed. Two types of failure can be seen. Control system failure happened where no data points exist. Failure due to calibration or lack of fluid at the sample occurred where the conductivity is zero or significantly higher than normal. The first failure happened while MSE's system was operational and was due to a communication failure with the YSI chemistry instrument. The second error in the data collection was due to a bad calibration. The last gaps in data were due to either the intake pipe being clogged up with silt or the failure of the pump tubing. The last gap of missing data occurred in mid-March when the 
chemistry sensor was brought back to Butte to work on the communications. (All of these failures are also noted in Table 4.) A week later when the drainage problems in the adit had been fixed by MSE, the intake for the first sample point was put back into the overflow holding tank. The system ran smoothly for the next four weeks.

The plots for $\mathrm{pH}$ and ORP from February through April 2007 are below in Figure 43 and Figure 44. When the monitoring system was restarted (and re-calibrated) in mid-February, vinegar was pumped from one of the sample bottles into the flow cell every six hours to help remove build-up on the sensors. Although the vinegar did help prevent sensor fouling, it also interfered with actual measurements as can be seen in the first third of both the $\mathrm{pH}$ and ORP plots. This interference was later fixed by more through rinsing of the sensors by pumping water through the flow cell after the vinegar. 


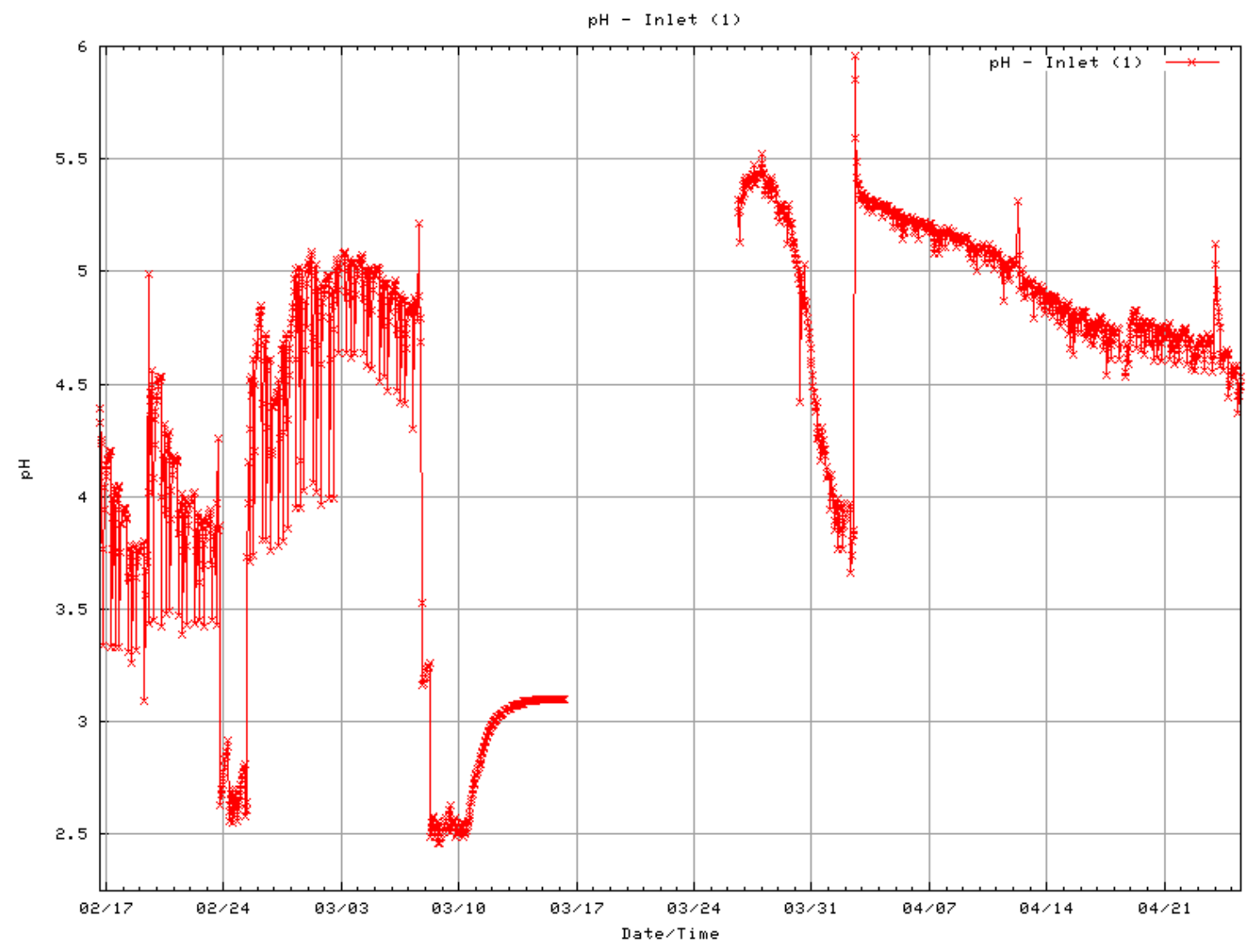

Figure 43. pH at the first sample point - February through April 2007 


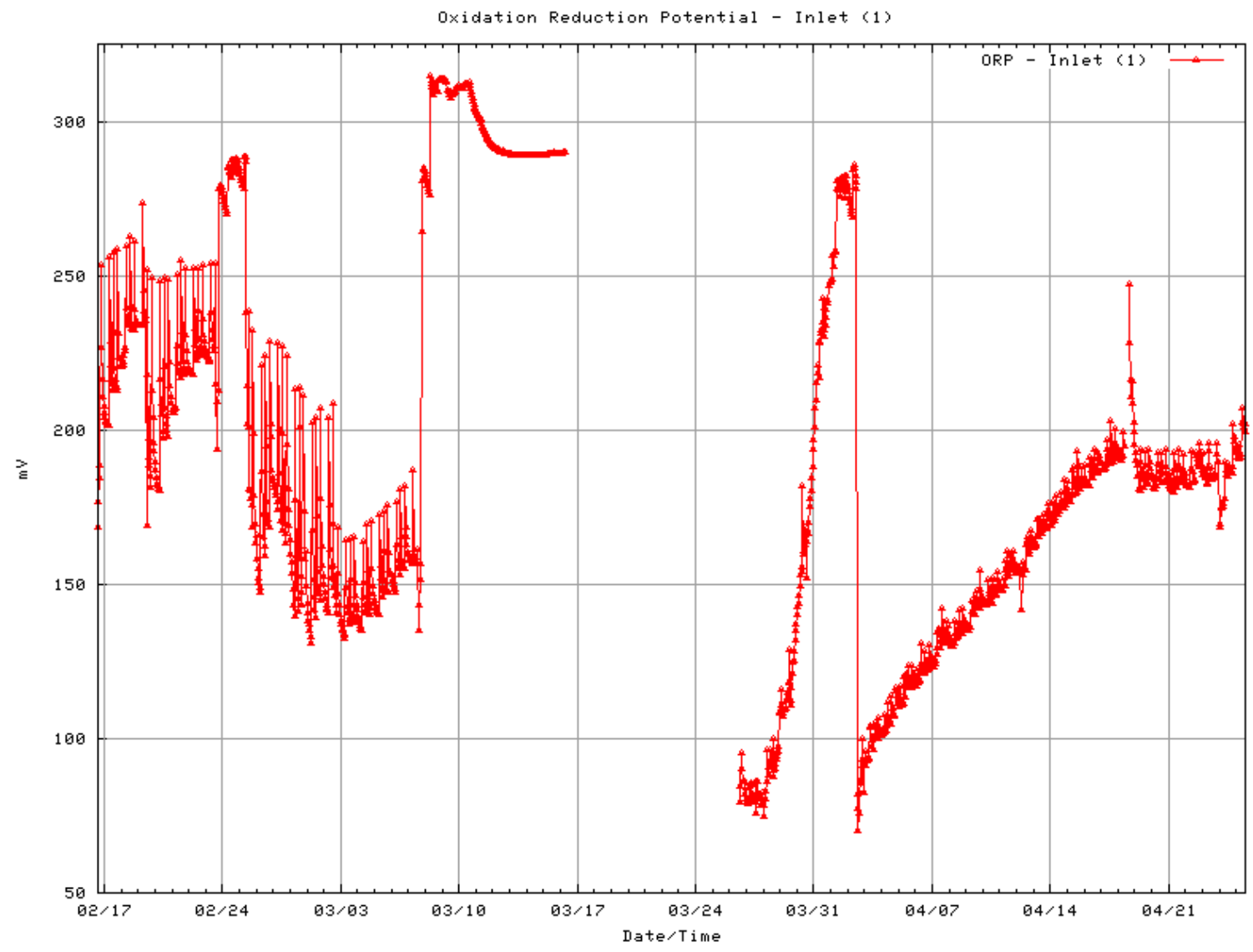

Figure 44. ORP at the first sample point - February through April 2007 


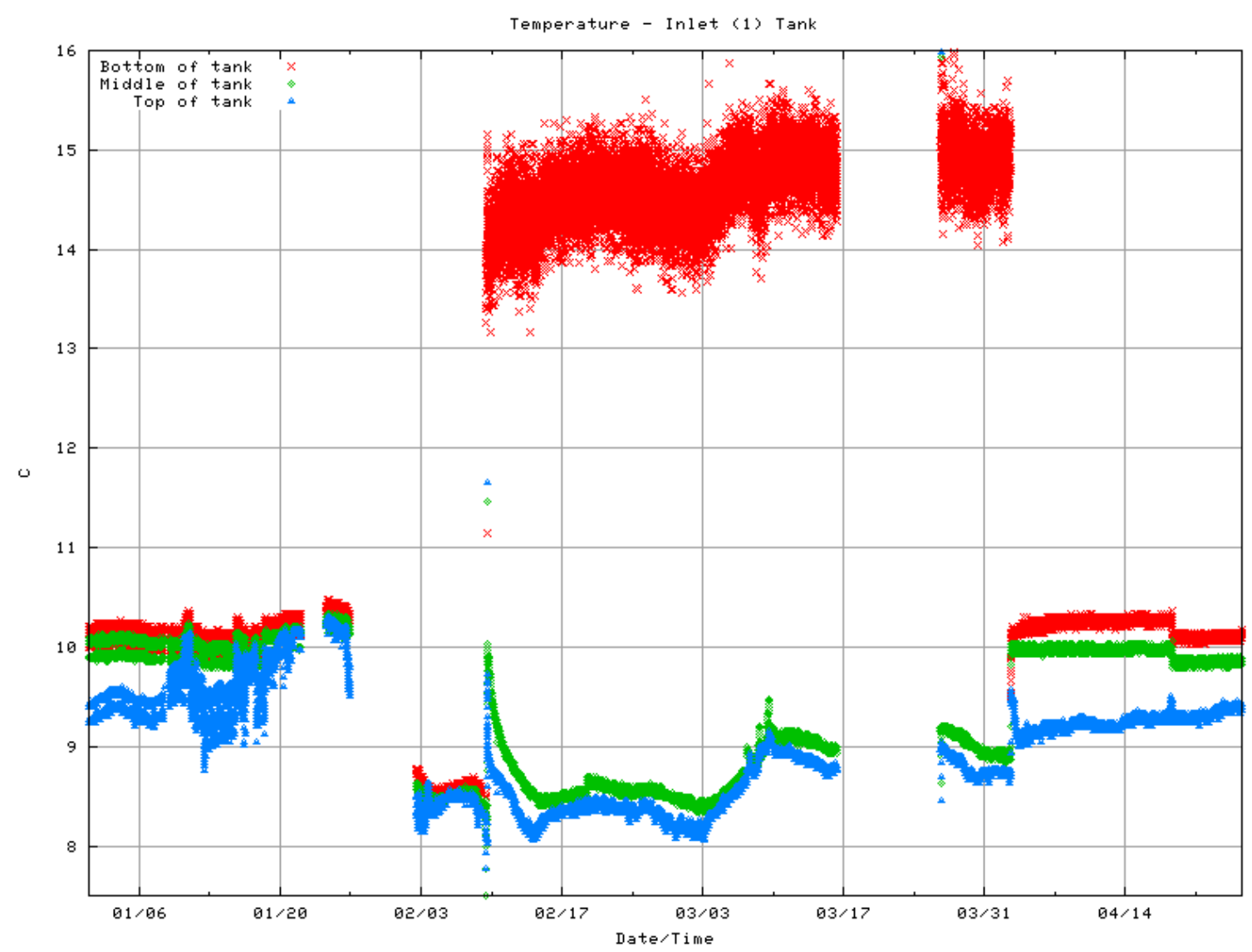

Figure 45. Temperature data from first sample point.

The temperature data in Figure 45 and Figure 46 show the data collected by the thermocouples in the holding tank and the temperature of the water behind the dam over the same time period as Figure 42. Overall the thermocouple data was more reliable than the chemistry data. Only three times did the system stop collecting temperature data. For two months, the thermocouple behind the dam and the thermocouple at the bottom of the holding tank were disconnected from the ADAMs module. They were both reconnected in the beginning of April. 


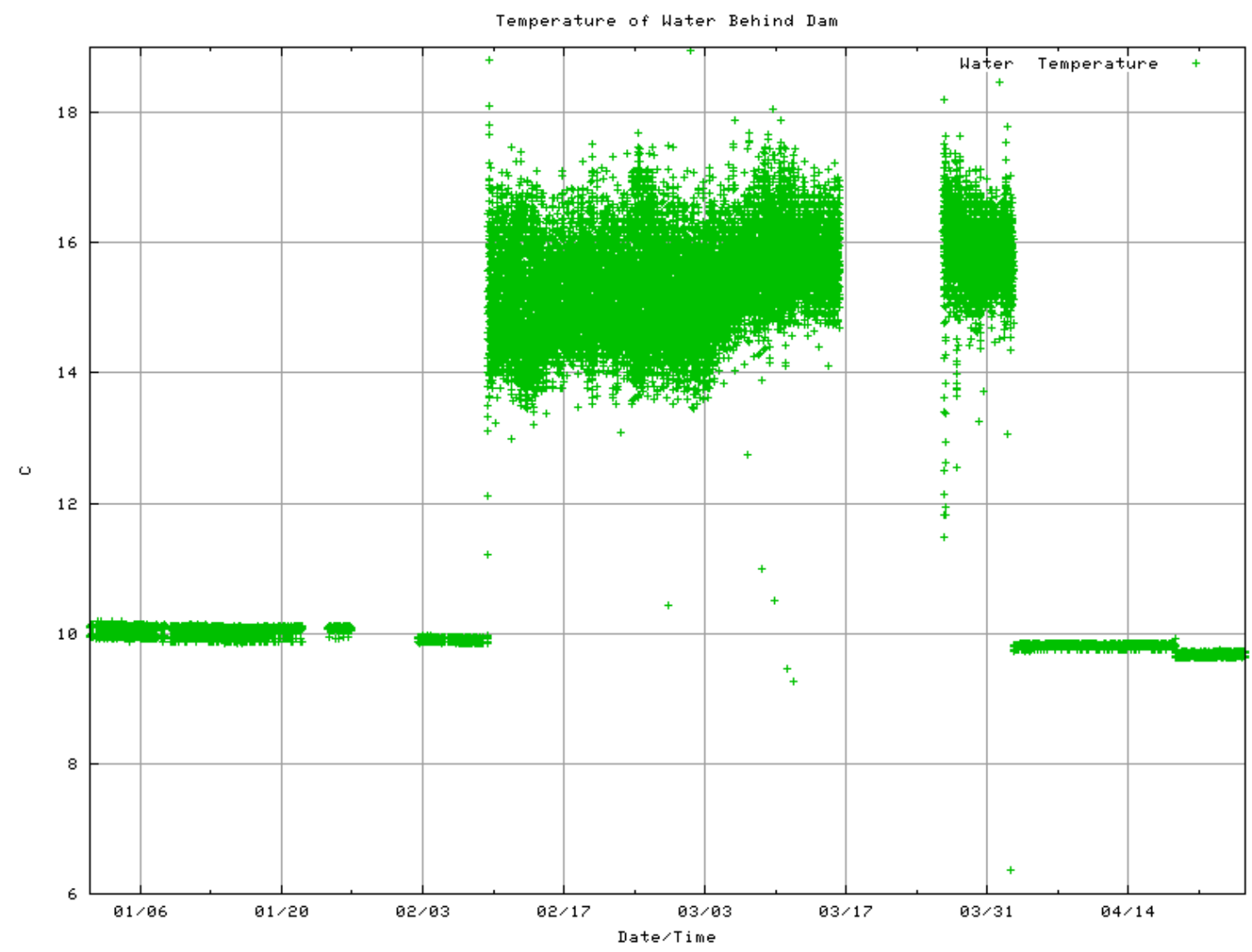

Figure 46. Temperature of water behind the dam.

\subsection{Calibration Data}

Although the system had the capability of self-calibration, calibration of the YSI chemistry sensor was done during trips up to Rimini. The $\mathrm{pH}$ sensor and the conductivity sensor were calibrated most often. Calibration data up until the middle of February is somewhat suspect due to the build up on the sensors. Of all of the sensors the turbidity sensor needed to be calibrated least. The last calibration was the middle of March. Towards the end of April, the $\mathrm{pH}$ of the water was taken with a different calibrated $\mathrm{pH}$ sensor at the mine site. The $\mathrm{pH}$ reported by the monitoring system was 4.58 and the $\mathrm{pH}$ reported by the 
additional $\mathrm{pH}$ meter was 4.69. Although this was just one point, it does help confirm that the last calibration of the $\mathrm{pH}$ probe was accurate. Figures 48 through 53 show plots of the calibration constant for the YSI sensors from December 2006 through March 2007.

The conductivity, dissolved oxygen and turbidity probes each had one calibration constant that was used to gain the signal. Since oxidation-reduction potential is measured in milli-volts the only calibration constant is an offset. The pH probe used a linear equation to convert the voltage across the proton selective glass membrane into $\mathrm{pH}$ so it had both an offset constant and a gain constant. The temperature probe did not require calibration.

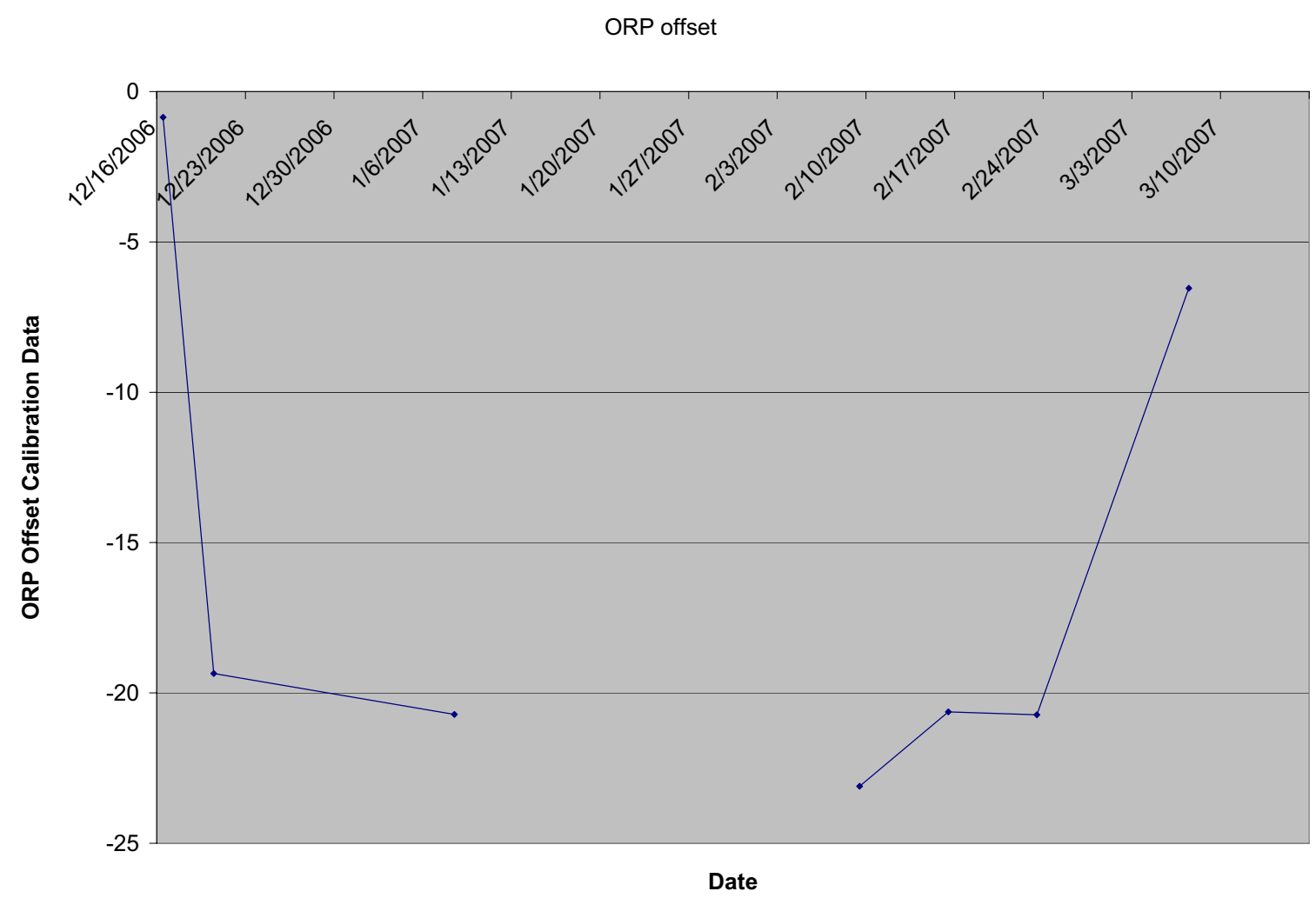

Figure 47. ORP Offset Calibration Constants - December 2006 through March 2007

Zobell solution and table of temperature offsets was used for calibration. 


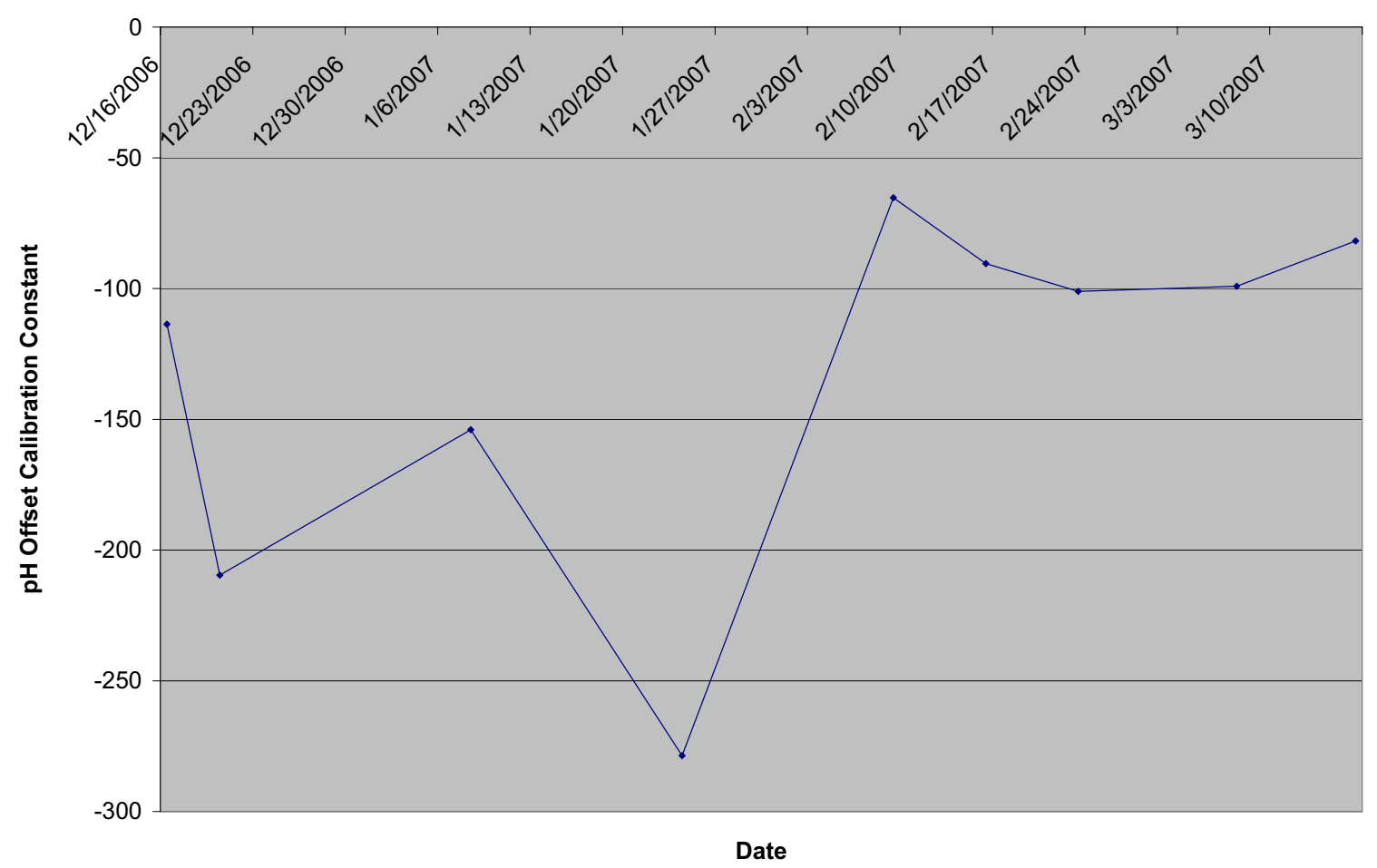

Figure 48. pH Offset Calibration Constants - December 2006 through March 2007 $\mathrm{pH}$ buffers of 4,7 and 10 were used for three point calibration. For two point calibration only 4 and 7 were used.

pH Gain

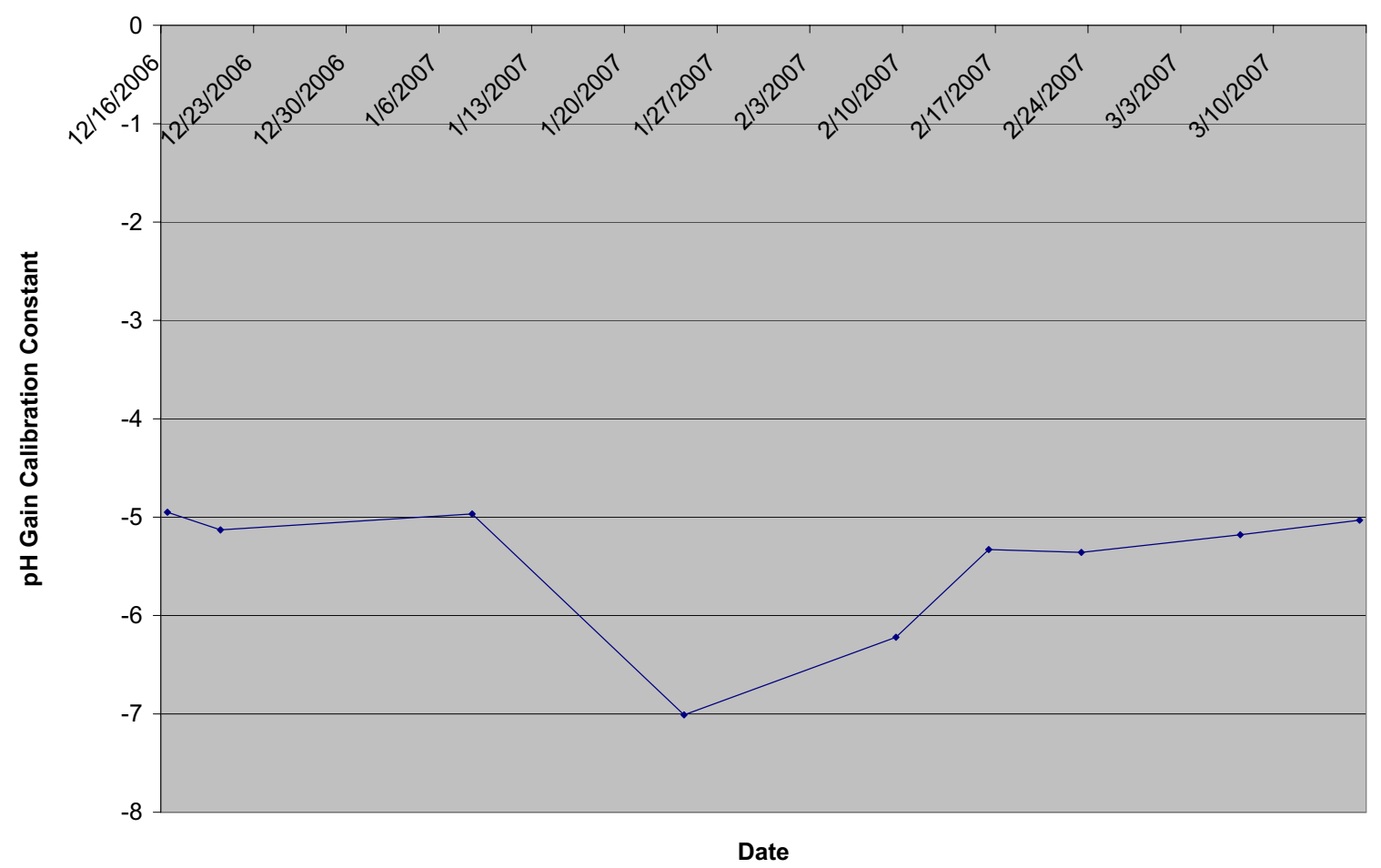

Figure 49. . pH Gain Calbration Constants - December 2006 through March 2007 


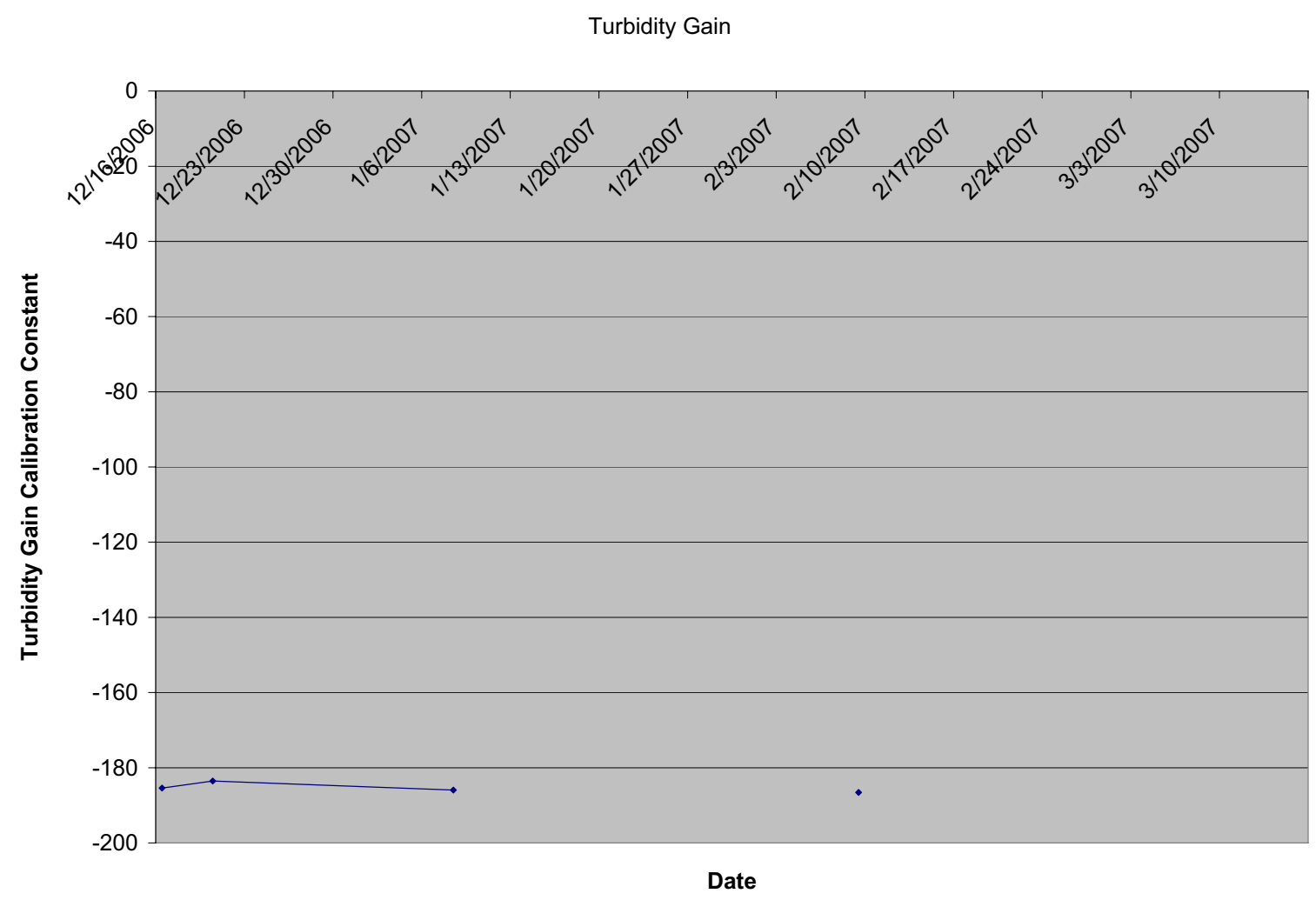

Figure 50. Turbidity Gain Calibration Constants - December 2006 through March 2007

A 100NTU standard was used to calibrate the turbidity gain constant. The sensor appeared to hold its calibration better than the others. However, due to silt on the bottom of the flow cell the data was not reliable. 
Dissolved Oxygen Gain

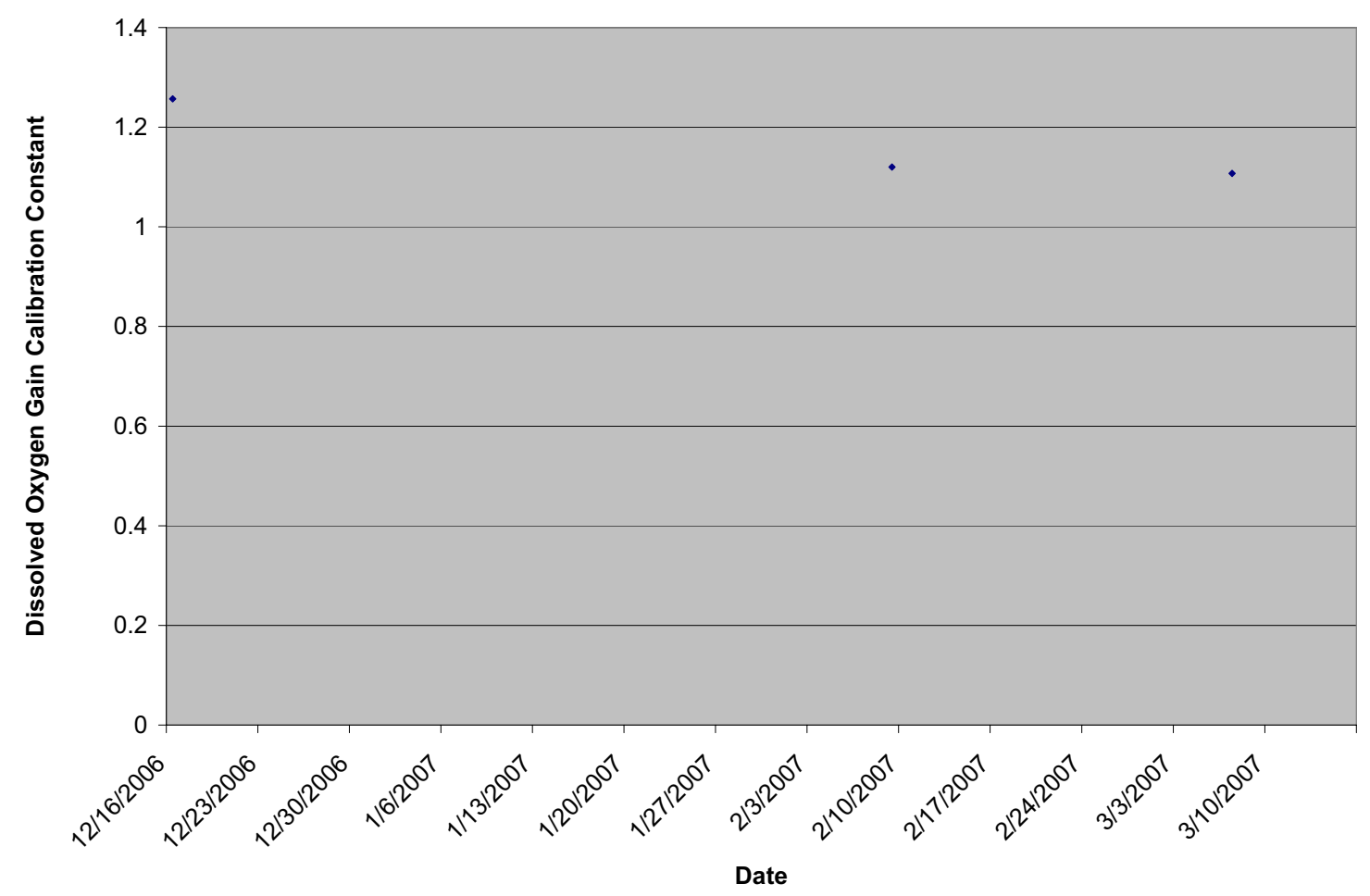

Figure 51. Dissolved Oxygen Gain Calibration Constants - December 2006 through March 2007

Dissolved Oxygen was calibrated using barometric pressure readings and about $3 \mathrm{~cm}$ of water in the bottom of the flow cell.

As can be in seen in a plot of the conductivity data and the conductivity calibration constants (Figure 52), the ACAM system was calibrated on a regular basis. However, more care could have been taken with calibration and at least one more calibration should have been made in mid-April 2007. In all of the calibrations made after MSE-TA's treatment system shut down data collection was interrupted either by the failure of the pump tubing or due to the sample tubing becoming plugged by silt.

However, some helpful information can still be gleaned from the calibration data. Firstly, fouling of is much more detrimental to the quality the data then drift. When MSE-TA's treatment system was operational and build-up formed on the 


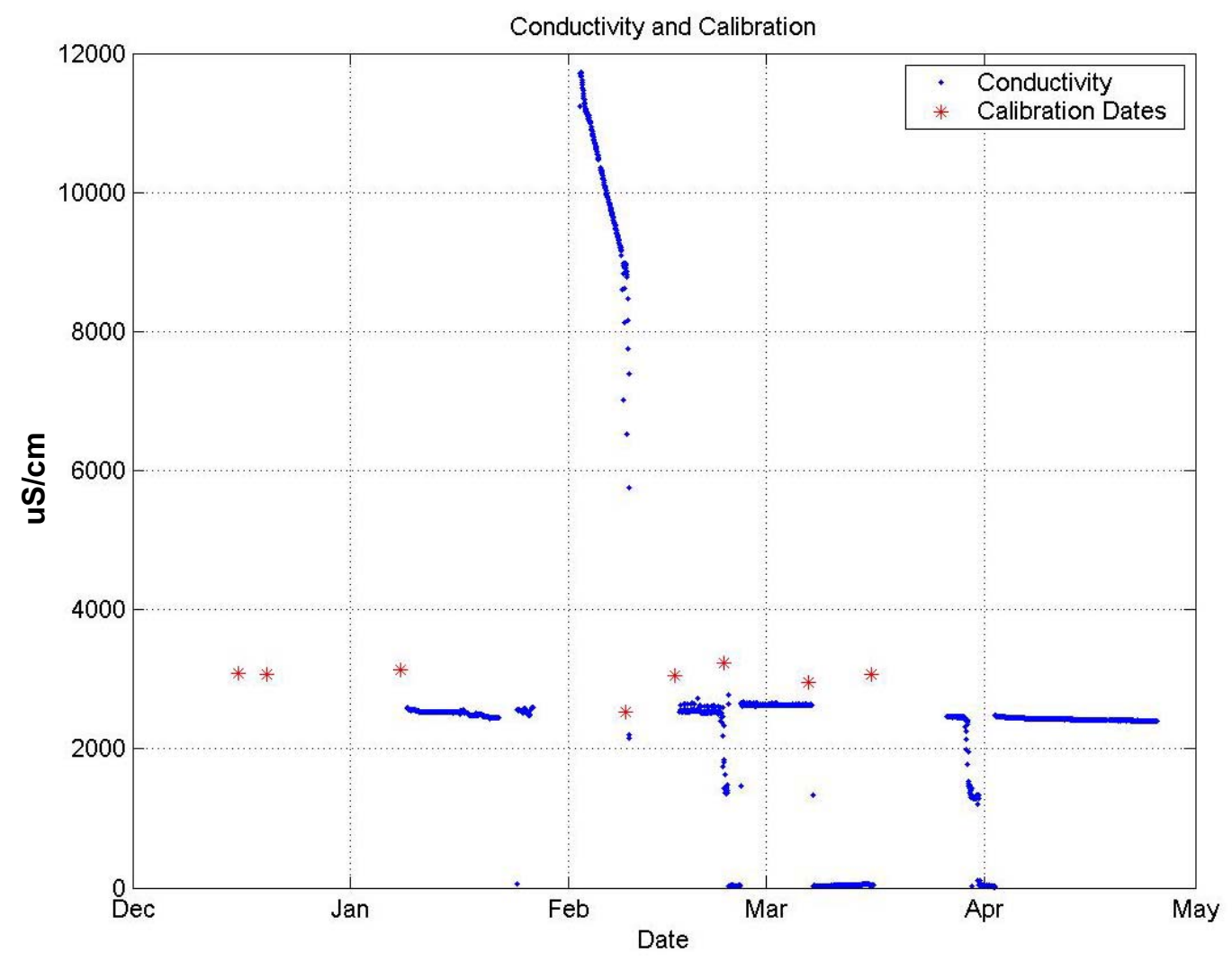

Figure 52. Calibration with respect to conductivity data. (Calibration constants not to scale)

sensors, the $\mathrm{pH}$ sensor in particular had calibration constants that greatly differed between calibrations. At the very least, this means that the data before each calibration is less reliable than the data collected immediately after a calibration. So the less the calibration constants vary between one calibration and the next the better the data is likely to be. Indeed, once MSE-TA's system was turned off the calibration constants for the $\mathrm{pH}$ sensor changed less from one calibration to the next. Like the $\mathrm{pH}$ sensor, the ORP sensor changed less from one calibration to the next after MSE-TA's treatment shut down. The large jump from an offset of $-20 \mathrm{mV}$ to $-6 \mathrm{mV}$ between the last two calibration constants resulted from a misreading of the temperature compensation chart.

The turbidity sensor seemed was the most impervious to sensor drift, although 
with this setup automated calibration would not be possible due to silt on the bottom of the flow cell. Both the flow cell and the turbidity sensor were cleaned before each calibration. The maximum difference between any two turbidity calibration constants was $1.5 \%$.

\section{Conclusion and Further Work}

As stated in the introduction, requirements for the ACAM system included remote access to the control system, two way communications, self-calibration of the instruments, low on-site maintenance, low installation and construction costs and a method of accessing newly collected data without traveling to the site. Many of these requirements were met. The system is capable of automated operation for both sampling and calibration. The web site is accessible for anyone with a username and password from anywhere with an internet connection and three levels of access allow a few people complete access to modify and add instrument information while other people can only view data. Once the system was installed, the only hardware costs were the replacement of the pump tubing and the cost of standards used to calibrate the chemistry sensors. The system collected 300,000 useable data points. The hardware and software costs totaled $\$ 27,000$ and $\$ 30,000$ was spent on labor. The total cost per sample was 19 cents. While the data collected by the ACAM system does not have the level of confidence associated with measurements taken in a lab environment, it can be used to provide an idea of system behavior over time for a very reasonable cost. The last remaining roadblock to meeting the requirement of remote access to the control system, lack of consistent communications between the web site server 
and the control software, would take the least amount of work, but probably the most money to solve at the Susie Mine, although the cost might be significantly less at other sites. One option not available at the Susie Mine was cellular communications. In the event that a cellular signal is not available some kind of radio signal to a cell phone could be established.

Other minor problems that stemmed from a lack of knowledge about chemistry are easily solved or have been solved. For instance, a sample bottle of distilled water can stored at future treatment sites to routinely rinse the sensors between samples. Vinegar will be used periodically to clean the sensors.

Most of the modifications needed to improve to the control system are minor, including general bug fixing and ease of use issues. The most important element to be added is the ability of the control system to sense when the flow cell is full by monitoring the conductivity sensor. Another important change that should occur in a future version of the system is to move the control software onto an embedded system. This would cost less than a full desktop computer and perhaps allow the system to be run disconnected from the power grid either using wind or solar power.

Like the control system many of the changes to the web site need to encompass ease of use issues but also include expanded functionality. One of the problems with any website is that they can always be improved. Changes and additions to the website for the ACAM system include the identification of outliers, a built in way to construct control software scheduling files, weekly or bi-weekly reports sent out to users containing recently collected data, and the expansion of the site 
to include other monitoring locations.

One of the things that we wanted to find out is how often the sensors need to be calibrated. The build-up on the sensors made most of the calibrations between January 2007 and mid-February 2007 unreliable. The quality improved when the sensors were cleaned and vinegar was pumped through they flow cell on a regular basis. If fouling is a major problem at other sites and pumping vinegar or some other solvent through the flow cell to clean the sensors is ineffective, then travel to the site in order to manually clean the sensors will need to become more frequent. However, if conditions are close to what they were in the Susie mine after MSE-TA's treatment system shut down, calibrations for the conductivity sensor, the $\mathrm{pH}$ and the ORP sensors should probably occur at least every two weeks and more frequently if a higher accuracy is needed. Limiting travel to the site to every month or two months, in this case, is feasible. One important point is that while monitoring the Susie Mine, the sensors never had time to dry out due to high humidity and frequent sampling.

Lessons learned in this project like using vinegar to clean the sensors or having distilled water on hand will be applied to the next incarnation of this system. Other, less obvious lessons, will be applied as well. Having an extra chemistry sensor to work with in Butte would have allowed for a much quicker response to some of the control system problems. Troubleshooting the interfering pinch valve would have been easier had the control box holding the relays been better organized. Checking the last data point that was collected before the system was turned off for recalibration or cleaning and then checking the first data point 
collected after the system was turned on would have helped mitigate some of the gaps in the data. In order to view the status or manually control the system a keyboard, mouse and monitor needed to be plugged into the computer. The addition of a small LCD screen and a few input buttons would have made the system much more accessible.

During summer 2007, the system will be moved to another monitoring project for further testing and modifications. 


\section{Bibliography}

[1] Banks, David, et al. "Mine-water chemistry: the good, the bad and the ugly." Environmental Geology. 32.3 (1997): 157-174.

[2] Bates, Edward, et al. "SITE Technology Capsule - Active and Semi-Passive Lime Treatment of Acid Mine Drainage." United States Environmental Protection Agency. 2003 <http://www.epa.gov/nrmrl/pubs/540r05015/540r05015a.pdf>

[3] Burcham, T.N, et al. "Distributed data acquisition system for runoff monitoring and automated water sampler control." . 14. (1998): 591-597.

[4] Burgh, Scott R, and James May. "Automated ground water sampling and analysis of Tricholorethene." . 25.1 (2005): 113-122.

[5] Cappellini, Vito. Digital filters and their applications. New York: Academic Press, 1978. pg 69

[6] Dean, John G, et al. "Removing heavy metals from waste water." Environmental Science \& Technology. 6.6 (1972): 518-522.

[7] Dubois, Paul. MySQL. Indianapolis, IN: Sam's Publishing, 2003.

[8] Hansson, David Heinemeier. 18 Jan. 2007. Ruby on Rails 2007-04-01. <http://www.rubyonrails.org>

[9] Nishioka, Kenji, et al. "Online automated water quality monitoring." Tectonophysics. 3. (1979): 1779-1799.

[10] Pardee, J. T. and F. C. Schrader. Metalliferous Deposits of the Greater Helena Mining Region Montana. : United States Government Printing Office, 1933.

[11] Robb, Gordon A, and James D. F. Robinson. "Acid Drainage in Mines." The Geographical Journal. 161.1 (1995): 47-54.

[12] Soltero, Manny, Jing Zhang and Chris Cockrill. "422 and 485 Standards Overview and System Configurations." Texas Instruments. 2002 <http://focus.ti.com.cn/cn/lit/an/slla070c/slla070c.pdf>

[13] Thomas, Dave, Chad Fowler and Andy Hunt. Programming Ruby. Raleigh, North Carolina: The Pragmatic Programmers, LLC., 2005.

[14] Tschmelak, Jens, et al. "Automated Water Analyser Computer Supported 
System (AWACSS) Part i:." Biosensors and Bioelectronics. 20.8 (2005): 1499-1508.

[15] YSI Incorporated. YSI Environmental Operations Manual. Yellow Springs, $\mathrm{OH}$ : YSI Incorporated, 2005.

[16] United States Environmental Protection Agency. 27 Feb. 2006. Environmental Concerts with Mining - EPA Region 8 2007-04-01. <http://www.epa.gov/region08/land_wate/mining/envcon.html> 